\title{
AVALIAÇÃO DO SINAL ELETROMIOGRÁFICO COMO PARÂMETRO PARA DETERMINAÇÃO DO LIMIAR DE FADIGA MUSCULAR.
}

\author{
FÁBIO MÍCOLIS DE AZEVEDO
}

\begin{abstract}
Tese apresentada à Escola de Educação Física e Esporte da Universidade de São Paulo, como requisito parcial para a obtenção do grau de Doutor em Educação Física.
\end{abstract}

ORIENTADOR: PROF. DR. ALBERTO CARLOS AMADIO CO-ORIENTADOR: PROF. DR. NERI ALVES 
Azevedo, Fábio Mícolis

Avaliação do sinal eletromiográfico como parâmetro para determinação do limiar de fadiga muscular / Fábio Mícolis de Azevedo. -- São Paulo: [s.n.], 2007. iv, 125p.

Tese (Doutorado) - Escola de Educação Física e Esporte da Universidade de São Paulo.

Orientador: Prof. Dr. Alberto Carlos Amadio

Co-orientador: Prof. Dr. Neri Alves

1. Eletromiografia 2. Fadiga muscular 3. Quadriceps femoral 4. Limiar de Fadiga Eletromiográfico 5. Biomecânica 


\section{SUMÁRIO}

\section{Página}

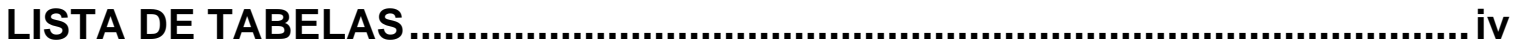

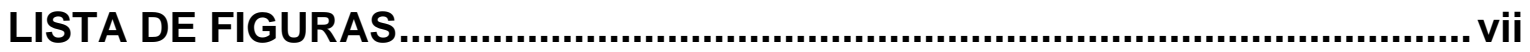

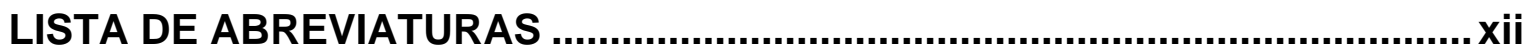

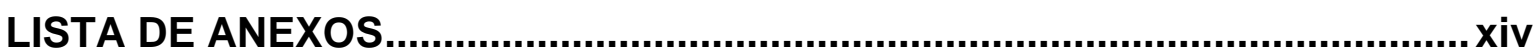

RESUMO

ABSTRACT

1. INTRODUÇÃO

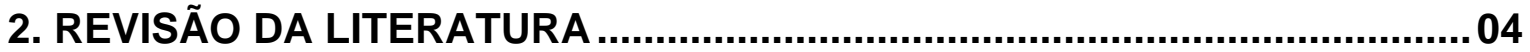

2.1. Considerações sobre a eletromiografia de superfície........................ 04

2.2. Considerações sobre indicadores da fadiga muscular localizada obtidos através da análise espectral do sinal eletromiográfico

2.3. Bases do Processamento do sinal eletromiográfico para determinação do Limiar de Fadiga Eletromiográfico ........................ 10

2.4. Considerações adicionais sobre a determinação do Limiar de Fadiga Eletromiográfico................................................................ 12

2.4.1. Introdução aos métodos de indução à fadiga ......................... 12

2.4.2. Processamento do sinal eletromiográfico...............................17

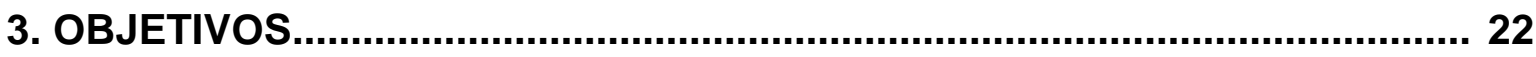

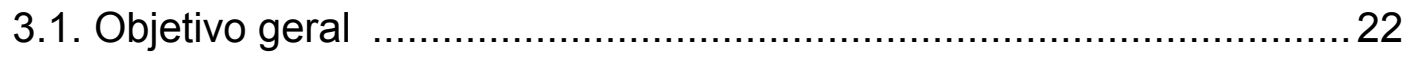

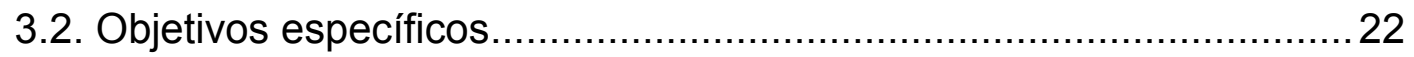

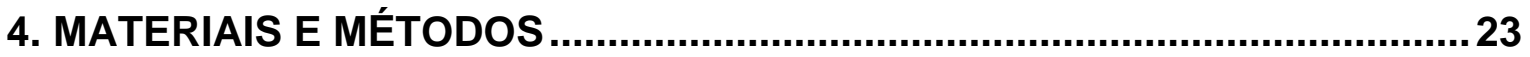

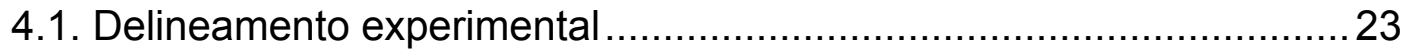

4.2. Descrição dos protocolos experimentais .......................................... 24

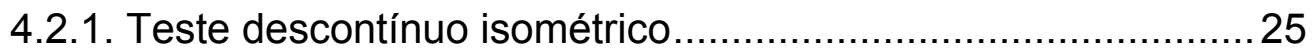

4.2.2. Teste descontínuo isotônico com peso fixo ............................. 27

4.2.3. Teste descontínuo isotônico no cicloergômetro ....................... 28

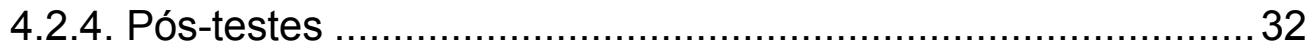


4.3. Grupo Amostral 33

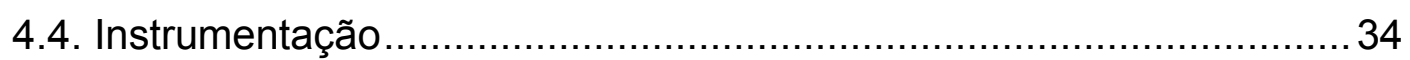

4.4.1. Eletromiografo e eletrodos ....................................... 34

4.4.2 Fixação dos eletrodos ................................................. 35

4.4.3. Eletrogoniômetro e célula de carga .................................... 36

4.4.4. Transdutor para análise metabólica ................................... 37

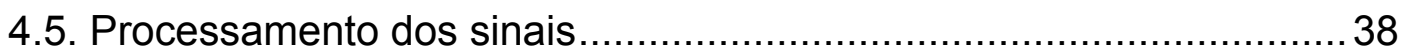

4.5.1. Processamento dos sinais eletromiográficos para determinação do Limiar de Fadiga Eletromiográfico ............. 38

4.5.2. Processamento dos sinais eletromiográficos no Pós-

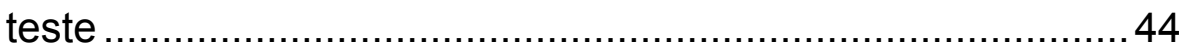

4.6. Análises complementares do sinal EMG .................................... 45

4.6.1. Análise do comportamento da Freqüência Mediana inicial e final durante os testes de fadiga .

4.6.2. Análise descritiva dos parâmetros das regressões dos testes de fadiga.

4.6.3. Análise multivariada das bandas de freqüência através do método das componentes principais...........................4 47

4.7 Tratamento estatístico dos dados ............................................. 50

4.7.1. Tratamento estatístico paramétrico e não paramétrico ...........50

4.7.2. Tratamento estatístico multivariado através de componentes principais ........................................... 50

4.8. Delimitações e controle do erro experimental .............................51

4.8.1. Delimitações e os procedimentos de coleta de dados.............51

4.8.2. Delimitações e os procedimentos dos testes máximos ...........52

4.8.3. Delimitações relacionadas aos instrumentos de medidas .......53

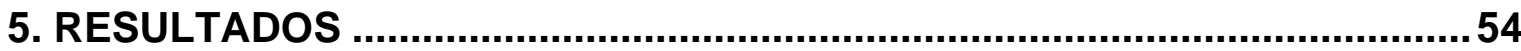

5.1. Caracterização dos sujeitos da amostra................................... 54

5.2. Parâmetros temporais relacionados aos testes de fadiga .................54

5.3. Resultados do teste descontínuo isométrico ................................58

5.3.1. Coeficiente de inclinação e limiar de fadiga eletromiográfico 
5.3.2. Resultados da análise do comportamento da freqüência mediana inicial e final durante os testes de fadiga

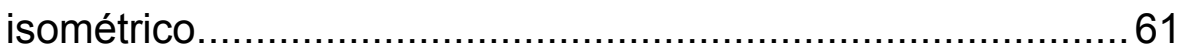

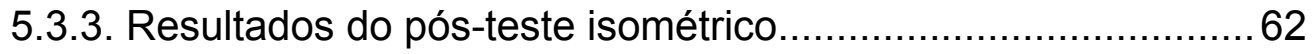

5.4. Resultados do teste descontínuo isotônico com peso fixo ..................66

5.4.1. Coeficiente de inclinação e limiar de fadiga eletromiográfico 66

5.4.2. Resultados da análise do comportamento da freqüência mediana inicial e final durante os testes de fadiga

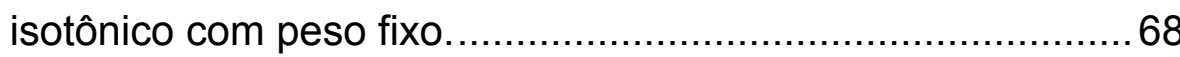

5.4.3. Resultados do pós-teste isotônico com peso fixo..................... 70

5.5. Resultados do teste descontínuo no ergômetro ................................ 73

5.5.1. Coeficiente de inclinação e limiar de fadiga eletromiográfico

5.5.2. Resultados da análise do comportamento da freqüência mediana inicial e final durante os testes de fadiga no

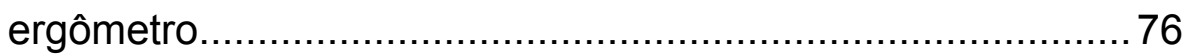

5.5.3. Resultados do pós-teste no ergômetro................................... 78

5.6. Resultados da análise das bandas de freqüência através do método das componentes principais.................................... 80

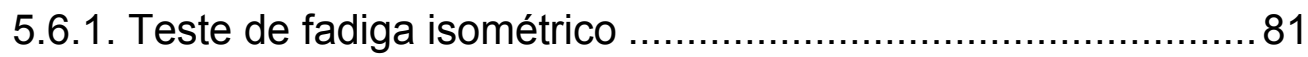

5.6.2. Teste de fadiga isotônico com peso fixo.................................. 83

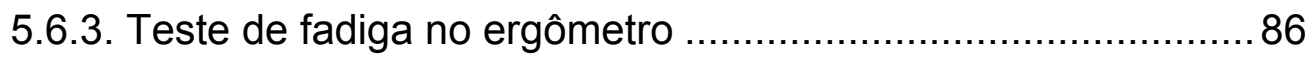

6. DISCUSSÃO

6.1. Considerações sobre o delineamento experimental.......................... 88

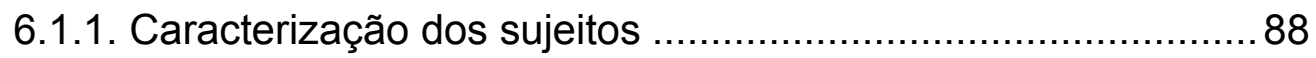

6.1.2. Velocidade angular dos movimentos no teste de fadiga

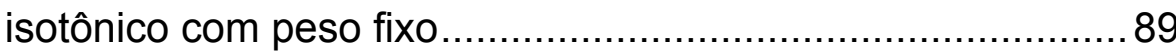

6.2. O tempo total de exercício como indicador global do processo

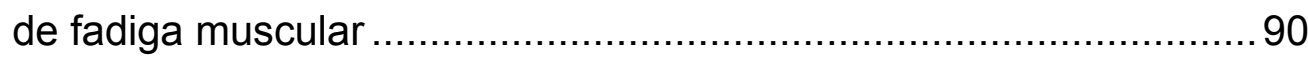

6.3. Comportamento da Fmed durante o exercício, monitorado através do coeficiente de inclinação. 
6.3.1. Considerações sobre o coeficiente de inclinação como indicador do processo de fadiga muscular ..................................... 92

6.3.2. Considerações sobre a qualidade dos ajustes ....................... 95

6.4. Considerações sobre o limiar de fadiga eletromiográfico (LFE)

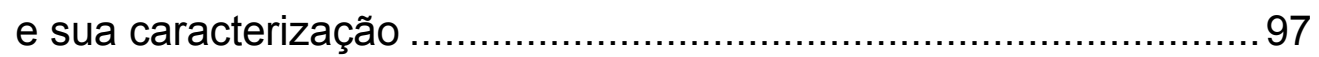

6.5. Considerações sobre as análises complementares. ......................... 100

6.5.1. Freqüências medianas obtidas durante o início e o momento de exaustão nos testes de fadiga ...................................... 100

6.5.2. Considerações sobre a análise isolada das bandas de freqüência através do método de componentes principais ............... 102

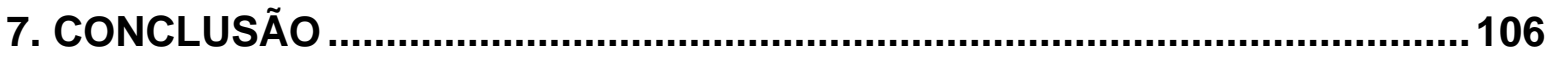

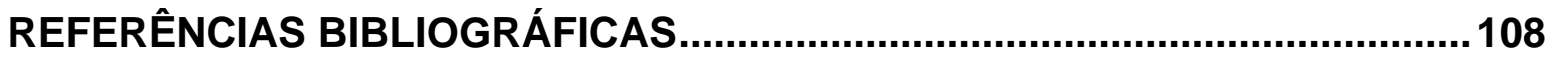


Acredito que este é o fim de um ciclo. A partir deste ponto não sei o que me aguarda ou quais serão os desafios que me serão apresentados. Para mim não existe sentido em dedicar um punhado de idéias e esforço a aquelas pessoas que tanto amo. Prefiro dedicar o melhor de minha pessoa, sempre com a esperança de corresponder as expectativas daqueles que me apóiam. Obrigado!

Fábio Mícolis de Azevedo 


\section{AGRADECIMENTOS}

Ao meu pai Roberto, minha mãe Regina, meu avô Humberto pelas condições e apoio que foram determinantes para que eu pudesse chegar até este momento de minha vida.

A minha esposa Raquel pelo apoio e amor, pela dedicação, pelo carinho e principalmente por nunca ter desistido de mim. Amo-te por tudo isso e te admiro por ser a mulher forte, verdadeira e honesta que sempre esta ao meu lado. Obrigado por tudo!

A Fundação de Amparo a Pesquisa do Estado de São Paulo que forneceu apoio financeiro para execução desta pesquisa através do processo número 04/01061-4. Também agradeço sua acessória científica que, ao longo do processo, sempre apontou aspectos de grande relevância para o aperfeiçoamento deste estudo.

Aos companheiros do Laboratório de Biomecânica da EEFE - USP. Mesmo que por um curto período de tempo tive a oportunidade de conviver, neste laboratório, com pessoas competentes, dedicadas e com extremo bom humor. Saibam que guardo um grande apreço por todos vocês.

A minha sogra e meu sogro, Neuza e Giuseppe Napolitano, que me acolheram em sua casa possibilitando minha estada, na cidade de São Paulo, durante o período de cumprimento dos créditos. Com absoluta certeza sem esta ajuda este trabalho provavelmente não existiria. Saibam que os considero como um segundo pai e uma segunda mãe.

Aos funcionários da secretaria da Pós-graduação, sempre muito competentes e gentis na solução de nossos problemas. Em especial as secretárias Ilza e Célia. 
A direção da empresa Lynx Tecnologia eletrônica, em especial ao Sr. Jaime Ono pelo empréstimo do equipamento utilizado neste trabalho. Agradeço sua paciência, idéias e conversas que foram fundamentais para o enriquecimento deste estudo.

Ao Prof. Dr. Rúben de Faria Negrão Filho, coordenador do Laboratório de Fisioterapia Aplicada ao Movimento Humano da FCT - UNESP de Presidente Prudente. Mestre que me acompanha desde a graduação e ao qual sou grato por compartilhar nossos trabalhos, idéias, ações e principalmente sua amizade.

Ao Prof. Dr. Alberto Carlos Amadio que direta ou indiretamente sempre contribuiu, incondicionalmente, para minha formação acadêmica. Em nossas conversas sempre encontrei um homem sábio, humilde, honesto e extremamente competente. Não tenho palavras para agradecer toda a ajuda e apoio que recebi. Apenas digo que sou extremamente grato pela oportunidade que tive em trabalhar com o senhor.

Ao Prof Dr. Neri Alves, orientador, amigo e mentor. Depois de quase nove anos, percebo que se não fosse pela sua paciência em ensinar um aluno da fisioterapia a fazer uma tal de IC, com toda certeza, hoje não estaria completando este ciclo. 
LISTA DE TABELAS

Página

TABELA 01- Contribuição da produção aeróbica / anaeróbica de ATP durante o exercício máximo como função da duração do evento, adaptado de POWERS e HOWLEY (2000). 16

TABELA 02- Valores do $\mathrm{VO}_{2}$ máximo e pontuação do questionário IPAQ para o grupo de sujeitos selecionados para este estudo.

TABELA 03- Valores médios $( \pm S D)$ dos coeficientes de inclinação da freqüência mediana em função do tempo de exercício, para as porções do VL, VM e RF durante o teste de fadiga isométrico a $15 \%, 30 \%, 45 \%$ e $60 \%$ correspondente a carga máxima $(n=15)$. 59

TABELA 04- Parâmetros relacionados a qualidade dos ajustes lineares das Fmed em função do tempo de exercício, durante os testes de fadiga na modalidade de exercício isométrico.

TABELA 05- Valores médios ( $\pm S D$ ), normalizados, da Fmed no início do exercício para as porções do VL, VM e RF durante o teste de fadiga isométrico a $15 \%, 30 \%, 45 \%$ e $60 \%$ correspondente a carga máxima $(n=15) . .62$

TABELA 06- Valores médios $( \pm S D$ ), normalizados, da Fmed no final do exercício (exaustão) para as porções do VL, VM e RF durante o teste de fadiga isométrico a $15 \%, 30 \%, 45 \%$ e $60 \%$ correspondente a carga máxima ( $\mathrm{n}$ $=15)$. .63

TABELA 07- Valores médios $( \pm S D)$, da Fmed normalizada para as porções do VL, VM e RF nos momentos de início do exercício, fadiga e exaustão no pós-teste $(n=15)$. 65

TABELA 08- Valores médios ( $\pm S D$ ), dos tempos, em segundos, para as porções do VL, VM e RF nos momentos de fadiga e exaustão durante o pós-teste e o tempo total de exercício na carga $15 \%$ do teste de fadiga isométrico $(n=15)$ 65

TABELA 09- Valores médios $( \pm S D)$ dos coeficientes de inclinação entre a freqüência mediana em função do tempo de exercício, para as porções do VL, VM e RF durante o teste de fadiga isotônico com peso fixo a $15 \%, 30 \%, 45 \%$ e $60 \%$ correspondente a carga máxima $(n=15) . .67$ 
TABELA 10- Parâmetros relacionados a qualidade dos ajustes lineares das Fmed em função do tempo de exercício, durante os testes de fadiga na modalidade de exercício isotônico com peso fixo. 68

TABELA 11 Valores médios ( $\pm S D$ ), normalizados ${ }^{1}$, da Fmed no início do exercício para as porções do VL, VM e RF durante o teste de fadiga isotônico com peso fixo a $15 \%, 30 \%, 45 \%$ e $60 \%$ correspondente a carga máxima $(n=15)$. 69

TABELA 12 Valores médios $( \pm S D)$, normalizados ${ }^{1}$, da Fmed no final do exercício (exaustão) para as porções do VL, VM e RF durante o teste de fadiga isotônico com peso fixo a 15\%,30\%, 45\% e 60\% correspondente a carga máxima $(n=15)$. 70

TABELA 13 Valores médios ( $\pm S D$ ), da Fmed normalizada ${ }^{2}$ para as porções do VL, VM e RF nos momentos de início do exercício, fadiga e exaustão no pós-teste $(n=15)$. 71

TABELA 14 Valores médios ( $\pm S D$ ), dos tempos, em segundos, para as porções do VL, VM e RF nos momentos de fadiga e exaustão durante o pós-teste e o tempo total de exercício na carga $15 \%$ do teste de fadiga isotônico com peso fixo $(n=15)$. .73

TABELA 15- Valores médios $( \pm S D)$ dos coeficientes de inclinação entre a freqüência mediana em função do tempo de exercício, para as porções do VL, VM e RF durante o teste de fadiga no ergômetro a $70 \%, 80 \%$, $90 \%$ e $100 \%$ correspondente ao $\mathrm{VO}_{2}$ máximo $(n=15)$ .75

TABELA 16 Parâmetros relacionados a qualidade dos ajustes lineares das Fmed em função do tempo de exercício, durante os testes de fadiga na modalidade de exercício no ergômetro. 76

TABELA 17 Valores médios ( \pm SD), normalizados ${ }^{1}$, da Fmed no início do exercício para as porções do VL, VM e RF durante o teste de fadiga no ergômetro a $70 \%, 80 \%, 90 \%$ e $100 \%$ correspondente ao $\mathrm{VO}_{2}$ máximo $(n=15)$. .77

TABELA 18 Valores médios ( $\pm S D$ ), normalizados ${ }^{1}$, da Fmed no final do exercício (exaustão) para as porções do VL, VM e RF durante o teste de fadiga no ergômetro a $70 \%, 80 \%, 90 \%$ e $100 \%$ correspondente ao $\mathrm{VO}_{2}$ máximo $(n=15)$. .78

TABELA 19 Valores médios ( \pm SD), da Fmed normalizada ${ }^{2}$ para as porções do VL, VM e RF nos momentos de início do exercício, fadiga e exaustão no pós-teste $(n=15)$. .79 
TABELA 20 Valores médios $( \pm S D$ ), dos tempos, em segundos, para as porções do VL, VM e RF nos momentos de fadiga e exaustão durante o pós-teste e o tempo total de exercício na carga $70 \%$ do teste de fadiga no ergômetro $(n=15)$. 


\section{LISTA DE FIGURAS}

Página

FIGURA 01- Diagrama representativo das aplicações da eletromiografia em biomecânica, adaptado de Amadio (1996).

FIGURA 02- Representação esquemática da geração do potencial de ação da unidade motora, adaptado de DeLUCA (1979). 6

FIGURA 03- Exemplos de espectros de freqüência obtidos através da aplicação da Transformada Rápida de Fourier (FFT) em sinais EMG provenientes de contrações isotônicas, adaptado de AZEVEDO (2003). 9

FIGURA 04- Gráfico "A" apresenta o comportamento temporal - RMS (linha branca tracejada) - do sinal EMG em função do tempo de execução de um exercício isométrico até a exaustão. O gráfico "B" apresenta o comportamento da função de distribuição espectral (SDF) calculada através do mesmo sinal, observa-se a compressão do espectro para as bandas de freqüência mais baixa.

FIGURA 05- Fluxograma representando o delineamento experimental deste estudo. 23

FIGURA 06- Aparelho de ginástica, para extensão de perna, utilizado nos protocolos de exercício isométrico e isotônico com peso fixo.

FIGURA 07- Força média (SD) exercida pela perna com contração isométrica máxima do músculo quadríceps, em função do ângulo de extensão $(n=10)$, Reproduzido de OTA (2006). 26

FIGURA 08- Exemplo de sinais de força obtidos durante um teste de contração isométrica voluntária maxima (CVIM). Considerou-se para análise o período central de dois segundos. 27

FIGURA 09- Sujeito posicionado no cicloergômetro, preparado para realizar um teste máximo no cicloergômetro. 30

FIGURA 10- Acima, exemplo de monitoração no $\mathrm{VO}_{2}$ de um sujeito durante um teste máximo. Abaixo, representação dos estágios de incremento de carga durante o teste. 
FIGURA 11- A esquerda, condicionador de sinais utilizado para integração dos sinais de EMG e instrumentação, modelo EMG 1000 da marca Lynx. A direita, eletrodos descartáveis e pré-amplificador. 35

FIGURA 12- Acima e a esquerda, esquema representativo da posição dos eletrodos sobre o músculo Reto Femoral (RF), Vasto Lateral (VL) e Vasto Medial (VM), adaptado de Cifrek (2000). À direita, procedimento para detecção de um ponto motor através de eletroestimulação. Abaixo, posicionamento dos eletrodos nas porções musculares indicadas. .... 36

FIGURA 13- À esquerda (A), eletrogoniômetro acoplado a mesa extensora para monitoração da posição angular do joelho durante o movimento de flexão e extensão da perna durante o exercício isotônico. À direita (B), célula de carga utilizada para monitorar a força aplicada pelo sujeito durante o teste máximo e de fadiga isométrico. 37

FIGURA 14- (A) Transdutor para análise metabólica modelo VO2000 da marca MedGraphics $®$; (B) circuito para coleta das amostrar de ar expirado; (C) "pneumotac"; (D) coletor de saliva; (E) bocal. 38

FIGURA 15- O gráfico "A" apresenta um sinal bruto proveniente de uma contração isométrica e o gráfico " $\mathrm{B}$ " apresenta um sinal bruto proveniente de uma contração isotônica. 40

FIGURA 16- Exemplo da seleção das séries temporais em um sinal proveniente de um teste de fadiga isométrico. 41

FIGURA 17- Exemplo de processamento do sinal EMG proveniente do teste no ergômetro. Observa-se de cima para baixo: a) sinal bruto; b) sinal retificado; c) componente de baixa frequencia e as referencias para seleção das séries temporais.

FIGURA 18- Exemplo de processamento para obtenção dos coeficientes de inclinação dos ajustes realizados nas Fmed em função do tempo. Músculo VL, teste isométrico. 43

FIGURA 19- Exemplo de determinação do Limiar de Fadiga Eletromiográfico para a porção do VL em um teste descontínuo isométrico. O valor do limiar é dado em porcentagem da carga máxima. 44

FIGURA 20- Gráfico exemplificando a determinação do momento de fadiga em um pós-teste. No gráfico considera-se o início da fadiga o momento onde o valor do coeficiente de inclinação, dado pela tangente de $\theta$, apresenta valor significativo diferente de zero $(p<0.05)$. 
FIGURA 21- Exemplo da variação nas bandas de freqüência entre o início e o fim de um teste de fadiga $(n=15)$. Nota-se na figura que as variações são mais evidentes a partir da faixa de $220-240 \mathrm{~Hz}$. 48

FIGURA 22- Acima, (A) exemplo do espectro de potencia de uma série temporal selecionado de um sinal EMG proveniente de um teste de fadiga isométrico, para a porção do VL. Abaixo a esquerda (B), sua respectiva Função de Distribuição Espectral. À direita (C), distribuição espectral com intensidade normalizada obtida através da derivação da SDF. .. 49

FIGURA 23- Valores médios e desvio padrão do tempo de exercício no teste isométrico e isotônico com peso fixo a 15\%, 30\%, 45\% e $60 \%$ correpondente a carga máxima $(n=15)$. " Diferença significativa em relação a carga $30 \%, 45 \%$ e $60 \%$. ${ }^{b}$ Diferença significativa em relação a carga $45 \%$ e $60 \%$. " Diferença significativa em relação ao teste isotônico. 56

FIGURA 24- Valores médios e desvio padrão do tempo de exercício do teste no ergômetro a $70 \%, 80 \%, 90 \%$ e $100 \%$ correpondente ao $\mathrm{VO}_{2}$ máximo $(n=15) .{ }^{a}$ Diferença significativa em relação a carga $90 \%$ e 100\%..... 57

FIGURA 25- Distribuição das velocidades calculadas entre $30^{\circ}$ e $80^{\circ}$ da extensão de perna, para $15 \%, 30 \% 45 \%$ e $60 \%$ referentes a carga máxima no teste isotônico.

FIGURA 26- Coeficientes de inclinação obtidos nas três porções do músculo quadríceps 58

FIGURA 27- Limiares de fadiga muscular localizada obtidos durante o teste de fadiga isométrico. 61

FIGURA 28- Gráficos representativos da distribuição das amostras durante os três momentos selecionados no pós-teste isométrico, para as três porções musculares: RF, VM e VL 64

FIGURA 29- Coeficientes de inclinação obtidos durante o teste isotônico com peso fixo, nas três porções do músculo quadríceps 67

FIGURA 30- Limiares de fadiga muscular localizada obtidos durante o teste de fadiga isotônico com peso fixo. 69

FIGURA 31- Gráficos representativos da distribuição dos valores da Fmed durante os três momentos selecionados, no pós-teste isotônico, para as três porções musculares: RF, VM e VL.

FIGURA 32- Coeficientes de inclinação obtidos nas três porções do músculo quadríceps 
FIGURA 33- Limiares de fadiga muscular localizada obtidos durante o teste de fadiga isométrico..................................................................... 77

FIGURA 34- "Component scores" das bandas isoladas. Quanto maior a distância entre os pares de bandas (seta) maior a contribuição desta componente para a variação total do espectro na faixa analisada de $0-400 \mathrm{~Hz}$, para o teste isométrico. Os índices i e f correspondem as bandas selecionadas no início e no final do exercício, respectivamente. 82

FIGURA 35- "Component scores" dos sujeitos nas duas situações de exercício $(n=15)$ utilizando-se as bandas que representam $2 \%$ da variação total do espectro, para o teste de fadiga isométrico.

FIGURA 36- "Component scores" dos sujeitos nas duas situações de exercício $(n=15)$ utilizando-se as bandas que representam $98 \%$ da variação total do espectro, para o teste de fadiga isométrico. A linha pontilhada (LS) separa as duas situações. 83

FIGURA 37- "Component scores" das bandas isoladas. Quanto maior a distância entre os pares de bandas (seta) maior a contribuição desta componente para a variação total do espectro na faixa analisada $0-400 \mathrm{~Hz}$, para 0 teste de fadiga isotônico. 84

FIGURA 38- "Component scores" dos sujeitos nas duas situações de exercício ( $n=15$ ) utilizando-se $70 \%$ das bandas que representam $2 \%$ da variação total do espectro, para o teste de fadiga isotônico. 85

FIGURA 39- "Component scores" dos sujeitos nas duas situações de exercício $(n=15)$ utilizando-se $30 \%$ das bandas que representam $98 \%$ da variação total do espectro, para o teste de fadiga isométrico. A linha pontilhada representa o limite de separação (LS) entre as duas situações, para o teste de fadiga isotônico 85

FIGURA 40- "Component scores" das bandas isoladas. Quanto maior a distância entre os pares de bandas (seta) maior a contribuição desta componente para a variação total do espectro na faixa analisada $0-400 \mathrm{~Hz}$, para 0 teste de fadiga no ergômetro. 86

FIGURA 41- "Component scores" dos sujeitos nas duas situações de exercício $(n=15)$ utilizando-se as bandas que representam $98 \%$ da variação total do espectro, para o teste de fadiga isométrico 
FIGURA 42- Gráfico exemplificando um ajuste "mestre" (linha) e sua banda de confiança (linha pontilhada) para um conjunto de sujeitos. Este ajuste é descrito pela equação onde: $\mathrm{Fmed}_{\mathrm{n}}$ representa $\mathrm{o}$ valor da Fmed normalizada; "a" representa o intercepto da reta; $\operatorname{tg}(\theta)$ representa o coeficiente linear da reta; $t_{n}$ representa o tempo normalizado de exercício. 101

FIGURA 43- Exemplo da caracterização de uma condição de exaustão, baseado na análise de bandas isoladas através da PCA, para um grupo de 15 sujeitos. Observa-se que a área cinza delimita a condição de exaustão. 


\section{LISTA DE ABREVIATURAS}

Ag - Prata

$\mathrm{AgCl}$ - Cloreto de Prata

ANOVA - Analise de variância

ATP - Adenosina Tri-fosfato

ATP-CP - Fosfocreatina

bpm - Batidas por minuto

$\mathrm{Cl}$ - Coeficiente de Inclinação

CMI - Contração Máxima Isotônica

CMRR - Modo de Rejeição Comum

CV - Coeficiente de Variação

CVIM - Contração Isométrica Voluntária Máxima

EMG - Sinal eletromiográfico

FFT - Transformada Rápida de Fourier

FM - Freqüência Média

Fmed - Freqüência Mediana

IEMG - Integral do sinal eletromiográfico

IPAQ - International of Physical Activity Questionarie

LFE - Limiar de Fadiga Eletromiográfico

LS - Limite de Separação

MET - Equivalente Metabólico ao VO2 Basal.

NS - Não Significante

PCA - Componente Principal

$\mathrm{pH}$ - Potencial Hidrogeniônico

PSD - Densidade Espectral de Potência

RF - Reto Femoral

RMS - Root Mean Square 


\author{
rpm - Rotação Por Minuto \\ SD - Desvio Padrão \\ SDF - Função de Distribuição Espectral \\ SENIAM - Surface EMG for a Non-invasive Assesment of Muscle \\ TDF - Transformada Discreta de Fourier \\ VCO2 - Excreção de gás carbônico \\ VL - Vasto Lateral \\ VM - Vasto medial \\ $\mathrm{VO}_{2}$ - Consumo de Oxigênio
}




\section{LISTA DE ANEXOS}

Página

ANEXO I- $\quad$ Principais linhas do programa para realização das etapas descritas no item 4.5.1 - Determinação do LFE

ANEXO II-

Principais linhas do programa para realização das etapas descritas no item 4.5.2 - Processamento no pós-teste.

ANEXO III- $\quad$ Principais linhas do programa para realização das etapas descritas no item 4.6.2 - Análise descritiva dos parâmetros das regressões dos testes de fadiga 121

ANEXO IV- $\quad$ Principais linhas do programa para realização das etapas descritas no item 4.6.3 - Análise isolada das bandas de freqüência e PCA ......................................................... 122

ANEXO V- $\quad$ Questionário IPAQ ................................................... 125 


\title{
RESUMO
}

\section{AVALIAÇÃO DO SINAL ELETROMIOGRÁFICO COMO PARÂMETRO PARA DETERMINAÇÃO DO LIMIAR DE FADIGA MUSCULAR.}

\author{
Autor: FÁBIO MíCOLIS DE AZEVEDO \\ Orientador: Prof. Dr. ALBERTO CARLOS AMADIO
}

\begin{abstract}
Embora a analise no domínio da freqüência do sinal Eletromiográfico (EMG) seja empregada na caracterização do processo de fadiga muscular localizada sua aplicação, especificamente a da Freqüência Mediana (Fmed), é pouco explorada para a determinação do Limiar de Fadiga Eletromiográfico (LFE). Neste estudo foram realizadas análises baseadas em procedimentos experimentais executados em três diferentes modalidades de exercício: i) isométrico; ii) isotônico com peso fixo; iii) isotônico no cicloergômetro; onde foi monitorado o comportamento da Fmed do sinal EMG em três porções do músculo quadríceps femoral: vasto lateral, vasto medial e reto femoral. Os resultados demonstraram ser possível determinar o LFE através da monitoração da Fmed, em qualquer modalidade de exercício para todas as três porções musculares avaliadas. Entretanto, para o exercício isométrico e isotônico com peso fixo a qualidade dos ajustes, utilizados para o calculo do LFE, apresentou melhores índices estatísticos em comparação com os resultados obtidos no cicloergômetro. Pode ser considerado um reflexo deste comportamento a menor variação nos valores do LFE observada nas duas primeiras modalidades de exercício. Por conseqüência, nestas modalidades, uma melhor caracterização do LFE, relacionada sua definição teórica, foi observada. A análise complementar das bandas de freqüência isoladas demonstrou a possibilidade de melhoramentos relacionados ao processo metodológico de tratamento do sinal EMG para determinação do LFE. Entende-se que a determinação do LFE é uma temática controversa, porém ao mesmo tempo apresenta um grande potencial de exploração científica caracterizando, neste contexto, a contribuição deste estudo para a área.
\end{abstract}

Palavras-chave: biomecânica, eletromiografia, fadiga muscular, músculo quadríceps, limiar de fadiga eletromiográfico. 


\begin{abstract}
EVALUATION OF THE ELECTROMYOGRAPHIC SIGNAL AS PARAMETER FOR

DETERMINATION OF MUSCLE FATIGUE THRESHOLD.
\end{abstract}

Author: FÁBIO MÍCOLIS DE AZEVEDO

Adviser: Prof. Dr. ALBERTO CARLOS AMADIO

Tthough the analysis in the frequency domain of the Electromyographic Signal (EMG) was used in the characterization of the localized muscular fatigue process their application, specifically the Median Frequency (MF), is rarely explored for the determination of Electromyographic Fatigue Threshold (EMG $\mathrm{FT}_{\mathrm{FT}}$ ). In this study analysis based in experimental procedures were executed in three different modalities of exercise: i) isometric; ii) dynamic with fixed load; iii) dynamic in the cycle ergometer; where was monitored the behavior of the EMG signal through the MF in three portions of the quadriceps muscle: vastus lateralis, vastus medialis and rectus femoris. The results demonstrated that the determination of $\mathrm{EMG}_{\mathrm{FT}}$ through the monitorization of MF was possible, in any modality of exercises for all the three muscular portions evaluated. However for the isometric and dynamic exercise with fixed load the quality of the adjustments, used for estimate the $\mathrm{EMG}_{\mathrm{FT}}$, presented better statistical index in comparison with the results obtained in the cycle ergometer. May be considered a reflex of this behavior the smallest variation in the values of $\mathrm{EMG}_{\mathrm{FT}}$ observed in the first two modalities of exercise. For consequence, in these modalities, a better characterization of $\mathrm{EMG}_{\mathrm{FT}}$ was observed when related with your theoretical definition. The complemental analysis of the isolated bands of frequency demonstrated the possibility of improvement related in the methodological process of EMG signal processing for determination of $\mathrm{EMG}_{\mathrm{FT}}$. The understanding around the determination of $\mathrm{EMG}_{\mathrm{FT}}$ demonstrated a controversial theme, however at the same time it presents a great potential of scientific exploration characterizing, in this context, the contribution of present study for this area.

Keywords: biomechanics, electromiography, muscle fatigue, quadriceps muscle, electromyographic fatigue threshold. 


\section{INTRODUÇÃO.}

O fenômeno da fadiga muscular pode ser definido e interpretado de várias maneiras. A literatura científica que aborda o assunto está repleta de definições, dependendo da abordagem temática do estudo. Não é o objetivo neste capítulo apontar a melhor definição, ou a mais adequada para descrever este fenômeno. Busca-se aqui apresentar a fadiga muscular como um fenômeno caracterizado por uma relação de causa e efeito, contextualizando sua importância como um fator chave no desenvolvimento de métodos, capazes de produzir indicadores utilizados no exame da capacidade de resistência de um sujeito.

Entende-se que o efeito observado na fadiga muscular estabelece o foco de suas definições clássicas, que estão relacionadas com o declínio no desempenho mecânico do músculo durante a execução de um exercício. Este comportamento pode ser facilmente monitorado e/ou quantificado através de métodos já desenvolvidos e bastante discutidos. Neste ponto cabe lembrar que o efeito do processo de fadiga muscular é a principal evidência que fundamenta o interesse em se estudar este fenômeno. Isso porque o desempenho mecânico do músculo está relacionado diretamente com rendimento e com a saúde.

Entretanto as causas da fadiga muscular constituem um campo temático que apesar de ser bastante estudado, ainda apresenta controvérsia em relação a alguns pontos. Neste campo observam-se, principalmente, estudos que tem como objetivo a análise de indicadores metabólicos relacionados aos processos de obtenção de energia no nível celular. Mais recentemente, a contribuição de outras ciências permitiu uma integração de conceitos, ferramentas e métodos objetivando um entendimento mais amplo deste fenômeno.

Nesta área constata-se uma contribuição sistemática da biomecânica permitindo, através da eletromiografia, a operação de análises dos padrões dos impulsos neuromusculares durante o exercício. Sabe-se que alterações nestes padrões que estão relacionadas a fatores sistemicos que causam a fadiga muscular. Esta relação fundamenta a monitoração e/ou a identificação do processo de fadiga muscular através de parâmetros extraídos do sinal eletromiográfico (EMG). Na literatura científica este foco de aplicação apesar de ser menos explorado, não é 
recente. Pelo contrário, os primeiros estudos utilizando o sinal EMG objetivando a monitoração do processo de fadiga muscular datam da década de 70.

Estudos nesta temática propõem a monitoração do estado de fadiga muscular através de protocolos de exercício, que utilizam contrações isométricas ou isotônicas (dinâmicas), nas quais a fadiga muscular é caracterizada por um índice que permite indicar o aumento da amplitude ou a diminuição da freqüência do sinal EMG. Paralelamente, através da correlação deste índice com as cargas de exercício, propõe-se também um método para a identificação do Limiar de Fadiga Eletromiográfico (LFE), que pode ser entendido como um indicador da capacidade de resistência de um músculo específico. A busca pela validação deste método representa um grande desafio para a comunidade científica. Neste sentido, verificase que os estudos direcionados para este fim são escassos e também controversos, principalmente no que se referem: i) ao tipo de exercício e os parâmetros utilizados para indução do estado de fadiga muscular; ii) ao processamento do sinal EMG.

Com relação ao processamento do sinal EMG, os estudos clássicos analisam sua amplitude através de parâmetros como o RMS e a integração de períodos prédeterminados da série temporal. Constata-se na literatura que o uso de outros parâmetros, como os obtidos no domínio da freqüência do sinal, são amplamente utilizados de forma a estabelecer índices de fadiga muscular. Porém não se verifica literatura, nas bases consultadas, em relação a aplicação de parâmetros como a Freqüência Mediana e/ou Média, do sinal EMG, no processo de determinação do LFE.

Em um primeiro momento pode-se citar uma lista de fatores que suportam a escolha da amplitude do sinal EMG como parâmetro central para a determinação do LFE. Entretanto, ressalta-se que esta não é uma condição sine qua non para o cálculo do LFE. Tal fato fundamenta novas abordagens do método para cálculo do LFE, permitindo que o processamento no sinal EMG possa ser trabalhado sob diversas perspectivas. Por exemplo, utilizando-se parâmetros no domínio da freqüência do sinal EMG.

Não se pretende com esta breve reflexão justificar o desenvolvimento de novos métodos para a determinação do LFE, e nem de inovações que tenham o poder de definir critérios para que este procedimento exerça na prática o seu 
potencial de aplicação. Entretanto acredita-se que a determinação do LFE a partir do uso de parâmetros no domínio da freqüência do sinal EMG, permita a abertura de uma nova frente de discussão a respeito da temática central que estabelece o uso do sinal EMG como parâmetro para determinação do LFE. Dentro deste contexto, o presente estudo tem a pretensão de agregar informações ao conhecimento já estabelecido, contribuindo com o objetivo final da área temática caracterizada pela validação do LFE e do método empregado para sua determinação. 


\section{REVISÃO DA LITERATURA.}

\subsection{Considerações sobre a Eletromiografia de Superfície.}

Eletromiografia é o termo genérico que expressa o método de registro da atividade elétrica de um músculo quando realiza contração. Este método apresenta inúmeras aplicações, notadamente na clínica médica para diagnóstico de doenças neuromusculares; na reabilitação, na reeducação da ação muscular (biofeedback eletromiográfico); na anatomia, com o intuito de revelar a ação muscular em determinados movimentos; e na biomecânica na sentido de servir como ferramenta indicadora de alguns fenômenos (AMADIO, 1996).

$\mathrm{Na}$ biomecânica, a utilização da eletromiografia tem como propósitos fundamentais (figura 1): (a) servir como indicador de estresse muscular; (b) ser um identificador de padrões de movimentos e (c) identificar parâmetros de controle do sistema nervoso (MOHAMED et al., 2002; ONISHI et al., 1999; MORITANI e HERBERT, 1978; BROWN e STEIN, 1974; LIPPOLD, 1952).

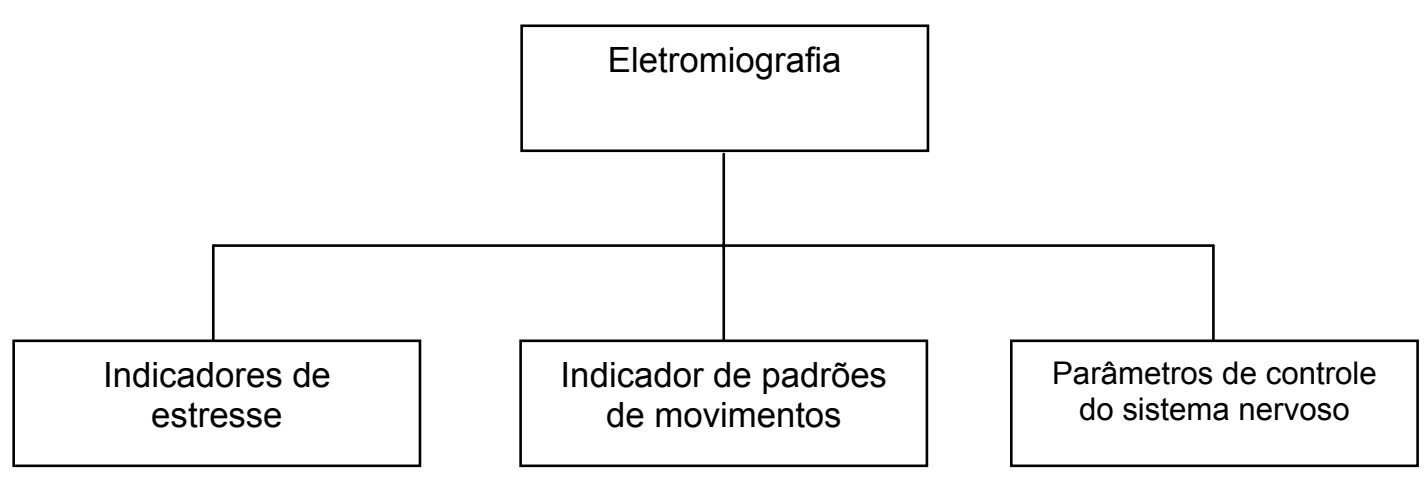

FIGURA 01 - Diagrama representativo das aplicações da eletromiografia em biomecânica, adaptado de Amadio (1996).

É importante dizer que o sinal de EMG reflete os acontecimentos fisiológicos do músculo que são extremamente individualizados, portanto músculo dependente (PEREIRA e AZEVEDO, 2002; ALMEIDA, 1997). 
Sob condições normais, um potencial de ação que se propaga por um motoneurônio ativa todos os seus ramos; por sua vez, estes ativam todas as fibras musculares de uma unidade motora (KRNJEVIC e MILEDI, 1958; PATON e WAUD, 1967). Quando a membrana pós-sináptica de uma fibra muscular for despolarizada, a despolarização propaga em ambas as direções ao longo da fibra. A despolarização de membrana, representada por um movimento de íons, gera uma diferença de potencial entre a face interna e externa da membrana da célula muscular. Um eletrodo localizado nesta região irá detectar esta diferença de potencial, cuja variação no tempo é conhecida como um potencial de ação da fibra muscular. Então cada fibra muscular contribui para formação do sinal captado na região do eletrodo, através de seu potencial de ação Uma representação esquemática desta situação é apresentada na figura 2. No diagrama, $\boldsymbol{n}$ representa o número total de fibras musculares de uma unidade motora que está suficientemente perto do eletrodo para os potenciais de ação serem registrados por ele. Para simplificar, são esquematizadas apenas as fibras musculares de uma unidade motora (DeLUCA, 1997).

As despolarizações da fibra muscular de uma unidade motora se sobrepõem no tempo, o sinal resultante presente no local da captação constitui uma superposição espaço-temporal das contribuições dos potenciais de ação individuais. Para manter o músculo contraído, o sistema nervoso envia uma seqüência destes potenciais, para que as unidades motoras sejam repetitivamente ativadas, resultando em um trem de pulsos. O sinal EMG é resultante do somatório destes trens, dado que são várias as unidades motoras envolvidas para manutenção e ativação da contração muscular. 


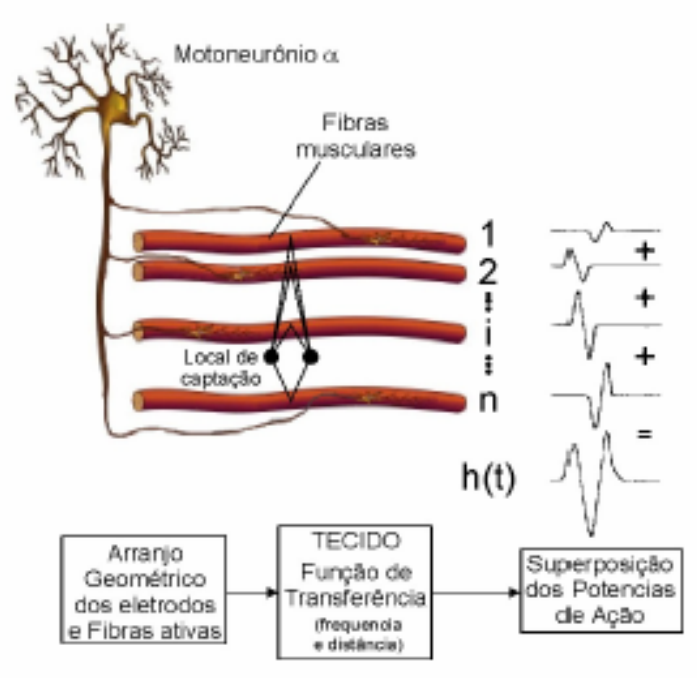

FIGURA 02- Representação esquemática da geração do potencial de ação da unidade motora, adaptado de DeLUCA (1997).

Eletrodos invasivos (de fio ou agulha) são capazes de detectar o potencial de ação de uma única unidade motora e fornecem maiores amplitudes e espectro de potência mais amplo alcançando freqüências de até 10kHz (WEBSTER, 1998), no entanto estes eletrodos apresentam vários inconvenientes, como a necessidade de cuidadosa esterilização, o perigo da quebra dos fios dentro do músculo e, sobretudo o desconforto do indivíduo. Para evitar estes inconvenientes são utilizados, com maior freqüência, eletrodos não invasivos (de superfície). Com estes eletrodos o sinal de EMG captado apresenta freqüências de até cerca de $500 \mathrm{~Hz}$ e amplitudes variando entre $5 \mu \mathrm{V}$ e $50 \mu \mathrm{V}$ dependendo do músculo analisado e da própria configuração do eletrodo utilizado (ALMEIDA, 1997).

Existe uma grande discussão no que diz respeito ao tipo de eletrodos e os procedimentos para o seu posicionamento no músculo. Pois, é fato comprovado que as diferenças na configuração física e química dos eletrodos bem como no seu posicionamento sobre o músculo, alteram o comportamento do sinal EMG registrado. É de interesse da comunidade científica, que trabalha com EMG de superfície, que padrões para estes quesitos sejam propostos a fim de proporcionar a comparação mais fidedigna entre estudos semelhantes. Neste sentido, o projeto SENIAM (Surface EMG for a Non-invasive Assesment of Muscle) tem apresentado recomendações de 
configuração e posicionamento dos eletrodos, com base em um levantamento de artigos publicados entre 1991 e 1996 num total de 114 artigos (HERMENS, et al. 2000; MERLETTI, 2000).

Com relação à configuração física do eletrodo é recomendado a utilização de eletrodos ativos. Estes são confeccionados com um amplificador diferencial muito próximo dos eletrodos de captação e tem por finalidade minimizar o ruído do sinal, incorporado na interface de transmissão, que é composto por baixas amplitudes. Com relação a configuração química é recomendado o uso de eletrodos de $\mathrm{Ag} / \mathrm{AgCl}$ (GEDES, 1972; HERMENS, et al. 2000). Sobre os procedimentos para o posicionamento dos eletrodos, é recomendado que estes não sejam acoplados sobre os pontos motores ou nos limites músculo-tendíneos e que as superfícies de captação sejam separadas por no máximo 40mm. Dessa forma, sugere-se posicionar o eletrodo próximo ao ponto motor na região do ventre muscular, evitando também a proximidade a outros músculos ativos (HERMENS, et al. 2000).

Após a captação do sinal de EMG este precisa ser tratado a fim de se interpretar as alterações fisiológicas decorrentes das contrações. Existem dois tipos básicos de análises a que os sinais de EMG podem ser submetidos: i) análise no domino do tempo do sinal; ii) análise no domínio da freqüência do sinal.

A análise do sinal de EMG no domínio do tempo, permite principalmente a visualização do padrão de ativação muscular durante uma contração, podendo servir como referência para comparações entre diferentes tipos de contrações, exercícios e cargas. Este método permite ainda que relações entre força e atividade elétrica muscular possam ser observadas, apesar de ser uma vertente ainda controversa na literatura especializada (MOHAMED et al., 2002; ONISHI et al., 1999). 


\subsection{Considerações sobre indicadores da fadiga muscular localizada obtidos através da análise espectral do sinal eletromiográfico.}

O fenômeno da fadiga tem sido amplamente definido pela progressiva e contínua atividade voluntária que leva a uma alteração da amplitude e duração dos potenciais de ação (BIGLAND-RITCHIE et al., 1981). Esta alteração deve-se aos processos de recrutamento por soma das unidades motoras. Destacam-se então, duas variáveis do sinal EMG que podem afetar o seu espectro de freqüência: i) o comportamento de disparo das unidades motoras; ii) a forma do potencial de ação das unidades motoras.

Sobre a análise espectral do sinal EMG De Luca e Basmajian (1985), concluem que a diminuição das taxas de disparo das unidades motoras contribuirá para que ocorram mudanças na densidade do espectro de potência do sinal, caracterizando a alteração no estado fisiológico muscular. Em situações de fadiga se observa um simultâneo aumento nos componentes de baixa freqüência e uma diminuição nos componentes de alta freqüência, este último acontece de forma mais discreta. Dessa forma, é importante que o sinal EMG apresentado inicialmente, em uma série temporal, seja analisado no domínio da freqüência (LOWERY et al., 2002; LINDSTRÖN et al., 1970). Esta análise geralmente envolve a aplicação do algoritmo da Transformada Discreta de Fourier (TDF) para a obtenção do espectro de freqüência do sina EMG. A figura 3 mostra a título de ilustração o sinal no domínio do tempo e após o processamento pela Transformada de Fourier.

Devido a esta constatação de que fadiga altera determinadas faixas de freqüência, existe a possibilidade da identificação do limiar de fadiga eletromiográfico (LFE) através da observação de indicadores relacionados ao espectro de freqüência do sinal EMG (ESPOSITO et al., 1998; SADOYAMA e MIYANO, 1981). O indicador mais amplamente utilizado e que apresenta um maior respaldo científico, na sua aplicação, é a freqüência mediana do espectro de freqüência do sinal EMG (HARY et al., 1982). A freqüência mediana tem sido considerado como a mais sensível às alterações na densidade espectral do sinal, 
relacionadas aos processos bioquímicos e fisiológicos que acontecem dentro dos músculos durante as contrações sustentadas.

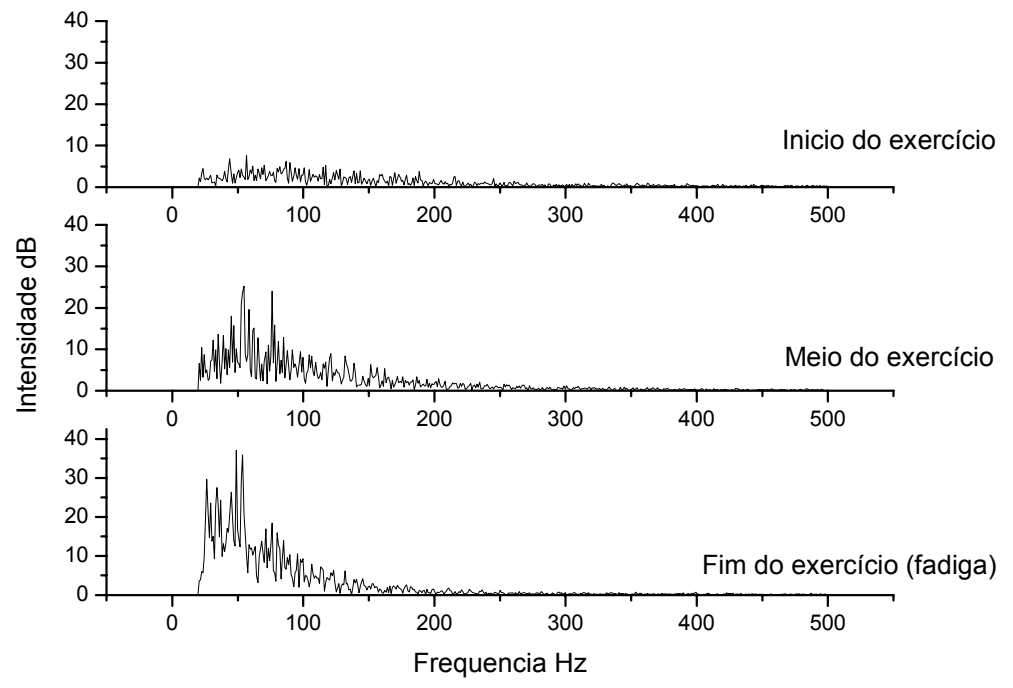

FIGURA 03 - Exemplos de espectros de freqüência obtidos através da aplicação da Transformada Rápida de Fourier (FFT) em sinais EMG provenientes de contrações isotônicas, adaptado de AZEVEDO (2003).

As modificações no espectro de freqüência do sinal EMG durante a fadiga têm uma relação direta com os processos bioquímicos inerentes ao evento da contração muscular. Destaca-se como maior responsável por estas alterações o aumento da concentração de ácido lático no meio intersticial, ocasionado pela sustentação da contração muscular. A freqüência mediana do sinal EMG é afetada pelas mudanças do $\mathrm{pH}$ no meio intersticial do músculo, que dependem da quantidade de lactato que é produzido e removido, assim como outros fatores músculo-dependentes ainda pouco explorados. Esta relação entre EMG e Lactato foi estudado por Moritani et al. (1984), durante contrações isométricas intermitentes dos músculos da preensão da mão, em contrações repetidas a $20 \%$ da contração voluntária máxima. Com base nos seus resultados o autor sugere que os estados metabólicos dos músculos ativos podem ter um papel importante na regulação do recrutamento das unidades motoras durante o exercício. Tais conclusões são reforçadas por Tesch et al. (1983) que verificou uma 
relação inversa entre a freqüência mediana do sinal EMG e a concentração de lactato em exercícios do músculo vasto lateral, medial e reto femoral. Entretanto há estudos de outros autores abordando correlações entre as modificações no espectro da freqüência do sinal EMG e outros indicadores metabólicos de fadiga como, por exemplo, o consumo de oxigênio $\mathrm{VO}_{2}$ durante o exercício (BENOIT et al., 2003; JAMMES et al., 1998).

\subsection{Bases do processamento do sinal eletromiográfico para a determinação do Limiar de Fadiga Eletromiográfico.}

A fadiga muscular é definida como o declínio do desempenho muscular durante o exercício. O conceito de fadiga é aplicado para monitorar ou medir a deterioração do desempenho muscular. A deterioração do desempenho mecânico é, usualmente, o fator que os especialistas observam para identificar um "ponto de fadiga" no qual o músculo não é mais capaz de sustentar um nível de força desejado (MERLETTI et al., 1991). Este fenômeno tem sido analisado nestas últimas décadas, mas sua etiologia ainda não foi totalmente elucidada. Entretanto sabe-se que um dos fatores centrais para a sua causa esta diretamente ligado aos padrões de impulsos neuromusculares que ocorrem durante as contrações (EDWARDS, et al., 1997).

Fundamentada dentro de um contexto científico que aborda tanto o domínio da biomecânica quanto o da fisiologia, a determinação do Limiar de Fadiga Eletromiografico (LFE) tem sido uma importante ferramenta utilizada no estudo do fenômeno da fadiga muscular e conseqüentemente do movimento humano. Para tal, são utilizadas algumas metodologias que têm como base, inicialmente, as propostas de DeVries et al. (1982) e MORITANI et al. (1993).

Tais métodos apresentam duas fases distintas, porém fortemente interligadas, que compreendem o protocolo de exercício a que o sujeito será submetido e os procedimentos matemáticos empregados no processamento do sinal EMG coletado. Os cuidados que permeiam os métodos empregados na determinação do LFE dizem 
respeito a adequada combinação entre a aplicação do protocolo de exercício e a escolha adequada das técnicas de processamento do sinal EMG. Se isto não for observado pode-se obter resultados que não são representativos do processo de fadiga muscular. Entende-se, dessa forma, que a validação do processo de determinação do LFE é um passo importante para proposição de métodos que tenham potencial de aplicação prática (BILODEAU et al., 2003; LINNAMO et al., 2000a; CIFREK et al., 2000).

$\mathrm{Na}$ literatura sobre o assunto, algumas questões que envolvem a validação dos procedimentos para a determinação do LFE já estão estabelecidas. Desta maneira, quanto à análise experimental, os protocolos de exercícios empregados como meio de levar o sujeito a fadiga muscular podem ser isotônicos ou isométricos, aplicados de forma contínua ou descontínua, sendo que na forma contínua, as cargas devem ser incrementadas em um período não inferior a um minuto (CIFREK et al., 2000; MERLETTI e LO CONTE, 1997).

Referente a fase de processamento, a análise do sinal EMG no campo da fadiga muscular envolve a observação, conjunta ou não, do comportamento temporal da Raiz Quadrada da Média (RMS) da Freqüência Média (FM) e da Freqüência Mediana (FMed) do sinal EMG. Estas são as variáveis comumente usadas para descrever o comportamento da amplitude e das componentes de freqüência do sinal EMG (HOSTENS et al., 2003, GONÇALVES, 2003). O sucesso no cálculo das variáveis espectrais do sinal EMG, FM e FMed, envolve a aplicação de técnicas adequadas para a obtenção do espectro de freqüência do sinal. Como já citado anteriormente, a técnica mais utilizada envolve o uso do algoritmo da Transformada Rápida de Fourier (FFT). Entretanto, preconiza-se a aplicação desta técnica em trechos considerados estacionários do sinal (HOSTENS et al., 2003).

Outras técnicas para obtenção do espectro de freqüência do sinal EMG também são utilizadas no sentido de se reduzir a influência de possíveis erros gerados por esta aproximação. Destaca-se como técnica alternativa a transformada de Wavelet. A idéia básica por trás da análise via Wavelet consiste em expressar um sinal como uma combinação linear de um particular ajuste de funções, obtidas através da modificação e expansão de uma única função chamada de "Mother 
Wavelet". A característica central da análise via Wavelet está na localização do tempo-freqüência do sinal, fator diretamente ligado a resolução de freqüência. Dessa forma, a análise via Wavelet do sinal EMG permite revelar traços relacionados com o transiente natural da ativação muscular, os quais não são detectados pela FFT, principalmente em situações dinâmicas (HOSTENS et al., 2003). É importante ressaltar que o uso da Wavelet no processamento do sinal EMG ainda é fracamente descrito diferentemente da aplicação da FFT, que se apresenta bem descrita na literatura.

\subsection{Considerações adicionais sobre a determinação do Limiar de Fadiga Eletromiográfico.}

\subsubsection{Introdução aos métodos de indução à fadiga.}

Fundamentalmente, os métodos para determinação do Limiar de Fadiga Eletromiográfico (LFE) podem ser divididos em duas etapas: i) Indução da fadiga muscular; ii) processamento do sinal EMG. Do ponto de vista metodológico, os índices propostos para a monitoração do processo de fadiga muscular, são interdependentes das variáveis contidas em ambas as etapas. Portanto, a escolha e o ajuste adequado dos parâmetros do exercício e do algoritmo, irão determinar se o limiar obtido através do protocolo escolhido é representativo ou não do processo de fadiga muscular localizada.

A proposta em se obter um Limiar de Fadiga Eletromiografico (LFE) diz respeito à determinação de uma intensidade de exercício, crítica, que não provoque alterações nos parâmetros temporais e de freqüência do sinal EMG. Ou seja, um sujeito submetido a um exercício com esta intensidade crítica, teoricamente, poderia executar o exercício por um período prolongado de tempo sem sofrer a ação do processo de fadiga muscular localizada (MORITANI et al., 1993, GONÇALVES, 2003). 
Vários pesquisadores têm se dedicado ao desenvolvimento de métodos para a determinação do LFE. No entanto, percebe-se a inexistência de um consenso com relação a um protocolo definitivo que resulte em um indicador ou limiar confiável. Vários são os fatores que contribuem para que este seja um processo complexo, do ponto de vista metodológico. Um desses fatores diz respeito ao protocolo de exercício utilizado para induzir a fadiga muscular (MORITANI et al., 1993; HOUSH et al., 1996; DeVRIES et al., 1990)

Dentro deste contexto pode-se inferir que o conceito de fadiga é aplicado para a monitoração de um processo de perda no desempenho muscular. Usualmente o "ponto de falência" muscular é verificado através do desempenho mecânico do músculo sendo definido como o momento em que ele não é mais capaz de sustentar um determinado nível de força (MERLETTI et al., 1991).

É claro que para a determinação do LFE é necessário que o processo de fadiga muscular localizada seja induzido através de um protocolo de exercício com carga externa. Neste sentido, percebe-se na literatura uma preferência pelos protocolos baseados no exercício isométrico. No entanto, têm-se utilizado em menor escala exercícios, ditos como, isotônicos. De uma forma geral, parece que o único consenso em relação ao protocolo de exercício é que este deve, antes de tudo, garantir que o processo de perda no desempenho muscular seja realmente induzido (POTVIN e BENT, 1997; MERLETTI et al., 1991).

Se esta garantia não for observada e sendo as alterações no sinal EMG dependentes dos fenômenos fisiológicos ocasionados pelo processo de fadiga induzido pelo exercício, pode-se ter uma situação na qual o índice ou limiar determinado não apresente relação com o fenômeno fisiológico avaliado. Embora o protocolo de exercício seja um componente do método para determinação do LFE, o entendimento das respostas metabólicas do músculo ao exercício é igualmente importante para a análise da eficiência de um protocolo de exercício dentro do processo de determinação do LFE (MORITANI et al., 1992; GREEN, 1987).

É fato que cada tipo de exercício faz com que o sistema muscular apresente uma resposta metabólica específica. Ou seja, a resposta metabólica muscular não é somente dependente do tipo de exercício, mas também das variáveis ligadas a sua execução, como por exemplo, o tempo de execução, a intensidade da carga e até 
mesmo a posição com que o exercício é realizado. A importância desta última variável fica mais evidente nos protocolos de exercício isométrico (POWERS e HOWLEY, 2000).

O fundamento básico que sustenta o monitoramento da fadiga muscular através da análise de parâmetros do sinal EMG, está na relação de dependência destes parâmetros com os processos fisiológicos ocasionados pela fadiga muscular. Por exemplo, se o monitoramento da fadiga muscular é feito através da taxa de incremento da intensidade do sinal EMG, sabe-se que este incremento acontece como conseqüência do recrutamento de mais unidades motoras, que tem por finalidade compensar a saturação de fibras que já estão fadigadas, evitando a falência imediata do sistema, figura 4A (MORITANI et al., 1987,1984, 1993, 2005). Já o monitoramento da compressão do espectro de freqüência do sinal EMG, para as raias de baixa freqüência, fundamenta-se no fato de que durante o exercício a concentração de ácido láctico aumenta em função do aumento da exigência da via metabólica glicolítica (anaeróbico). Este aumento na concentração de acido láctico faz com que o pH intracelular aumente causando a diminuição da velocidade de despolarização da fibra muscular, figura 4B (ESPOSITO et al., 1998; SADOYAMA e MIYANO, 1981).

A

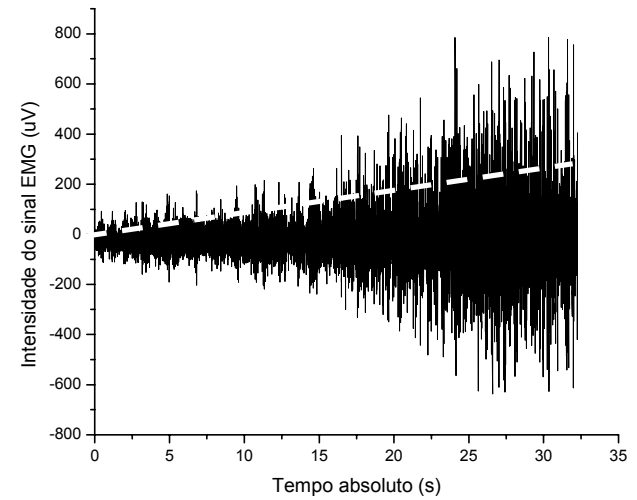

B

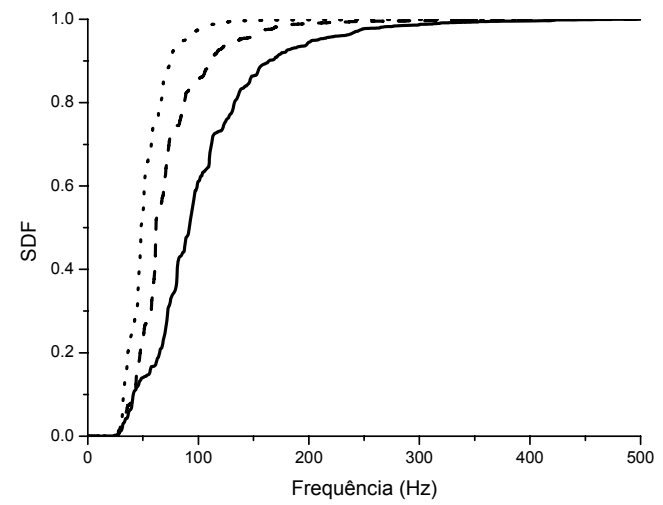

Figura 04- Gráfico "A" apresenta o comportamento temporal - RMS (linha branca tracejada) do sinal EMG em função do tempo de execução de um exercício isométrico até a exaustão. O gráfico "B" apresenta o comportamento da função de distribuição espectral (SDF) calculada através do mesmo sinal, observa-se a compressão do espectro para as bandas de freqüência mais baixa. 
Esta breve descrição serve para demonstrar que o protocolo de exercício e as variáveis que o compõe devem ser adequadamente escolhidos e dimensionados a fim de que os efeitos fisiológicos da fadiga muscular sejam induzidos. Possibilitando assim, que as alterações no sinal EMG possam ser consideradas representativas deste fenômeno fisiológico.

Sabe-se que o exercício de curta duração e de alta intensidade exige essencialmente das vias metabólicas anaeróbicas. O quanto a produção de ATP é dominada pelo sistema ATP-CP ou pela glicólise depende primariamente da duração da atividade. Teoricamente o sistema ATP-CP predomina em eventos com duração de até 6 segundos. Em eventos de até 45 segundos existe uma combinação dos três sistemas energéticos, ATP-CP, glicólise e aeróbico. Em geral, o exercício intenso com duração de aproximadamente 1 minuto utiliza a produção de energia de $70 \%$ / $30 \%$ (anaeróbica / aeróbica), enquanto os eventos com duração de até dois minutos utilizam as vias metabólicas aeróbicas e anaeróbicas de uma maneira praticamente equalizada, tabela 1 (POWERS e HOWLEY, 2000; ENOKA e STUART, 1992).

Entende-se assim, que os protocolos de exercício utilizados no processo de determinação do LFE devem apresentar uma relação entre o tempo de execução e intensidade de carga, que favoreça as vias anaeróbicas para obtenção de energia. Principalmente se o monitoramento do processo de fadiga for realizado através do comportamento do espectro de freqüência do sinal EMG (PETROFSKY e LIND, 1978).

O estudo apresentado nesta tese compreende a determinação do LFE em três protocolos de exercício diferentes, um isométrico, um isotônico com peso fixo e um isotônico em um cicloergômetro. Justifica-se esta escolha pelas diferentes respostas metabólicas que cada um destes exercícios induz no músculo durante a sua execução. O exercício isométrico é caracterizado pelo curto período de tempo que os sujeitos conseguem executá-lo, com intensidades de carga entre 40 e $60 \%$ do máximo, em média por 2 minutos. Apresentando um grande decréscimo neste tempo em função do aumento da intensidade, a $80 \%$ do máximo os sujeitos conseguem em média executar 30 segundos de exercício. Por estas características pode-se dizer que o exercício isométrico favorece a obtenção de energia, fundamentalmente, 
através das vias anaeróbicas (POWERS e HOWLEY, 2000; GIANNESINI et al., 2003).

TABELA 1- Contribuição da produção aeróbica / anaeróbica de ATP durante o exercício máximo como função da duração do evento, adaptado de POWERS e HOWLEY (2000).

\begin{tabular}{|c|c|c|c|c|c|c|c|c|c|}
\hline & \multicolumn{9}{|c|}{ Duração do Exercício Máximo } \\
\hline & \multicolumn{3}{|c|}{ Segundos } & \multicolumn{6}{|c|}{ Minutos } \\
\hline & 10 & 30 & 60 & 2 & 4 & 10 & 30 & 60 & 120 \\
\hline $\begin{array}{c}\% \\
\text { produção } \\
\text { aeróbica }\end{array}$ & 10 & 20 & 30 & 40 & 65 & 85 & 95 & 98 & 99 \\
\hline$\%$ & & & & & & & & & \\
\hline $\begin{array}{l}\text { produção } \\
\text { anaeróbica }\end{array}$ & 90 & 80 & 70 & 60 & 35 & 15 & 5 & 2 & 1 \\
\hline
\end{tabular}

O exercício isotônico com o peso fixo apresenta diferenças em relação ao isométrico quando são observadas as respostas musculares induzida pela sua execução. A principal delas diz respeito à configuração mecânica do sistema durante a execução do exercício. Esta configuração faz com que a intensidade nominal da carga imposta ao sistema varie conforme a posição angular da articulação. Este efeito pode ser minimizado através da execução do exercício em dispositivos específicos. Entretanto neste estudo este efeito é desejado, pois é esta variação que faz com que o tempo de exercício isotônico seja um pouco maior quando comparado à isometria (AZEVEDO, 2003; OTA et al., 2005).

Neste sentido, o exercício isotônico com peso fixo representa, sob o ponto de vista fisiológico, uma situação intermediária entre um exercício puramente anaeróbio e um puramente aeróbio como é o caso do exercício isotônico no ciclo ergômetro. Alguns estudos realizados em dinamômetros isocinéticos sugerem que o exercício isotônico pode, em cargas mais baixas, favorecer a obtenção de energia através das vias aeróbicas. No entanto nestes equipamentos existe a possibilidade de se isolar 
as contrações durante o ciclo do movimento (HOUSH et al., 1995; LIU-ROMAN et al., 2004; MORITANI et al., 2005). MORITANI et al. (1987) tentou verificar se a ocorrência dos dois tipos de contração, no mesmo ciclo, associado a carga mais alta pode favorecer a obtenção intermediária de energia através das vias aeróbica e anaeróbica.

Dos protocolos isotônicos seguramente o que é encontrado com maior freqüência na literatura é o executado em um cicloergômetro. Do ponto de vista fisiológico este exercício, em qualquer intensidade de carga, favorece a obtenção de energia, fundamentalmente, através das vias aeróbicas. É interessante observar na literatura que a maioria dos estudos que utilizam este protocolo, analisa os parâmetros temporais do sinal EMG para a determinação do LFE, como por exemplo, o RMS. São poucos os estudos que utilizam os parâmetros espectrais para a determinação do LFE.

Fica claro que cada tipo de protocolo induz o processo de fadiga muscular localizada de uma forma específica, e a análise de sua eficiência dentro do processo de determinação do LFE é um passo importante para a proposição futura de um protocolo padrão.

\subsubsection{Processamento do sinal eletromiográfico.}

Existem várias propostas com relação aos índices utilizados para monitorar o processo de fadiga muscular localizada. Entretanto, todos os índices propostos são determinados através do monitoramento de alguma variável do sinal EMG durante um determinado tipo de exercício. Percebe-se que na literatura existe uma preferência pelo uso de variáveis temporais do sinal EMG, como por exemplo, o RMS e a Integral do sinal (IEMG). Mais recentemente têm-se utilizado varáveis no domínio da freqüência do sinal EMG, como por exemplo, a Freqüência Média $(F m)$ e a Freqüência Mediana (Fmed), para monitorar o processo de fadiga muscular (HOUSH et al., 1995, 1996;.deVRIES et al., 1990). Entretanto, é importante ressaltar a ausência na literatura, nas bases consultadas, de estudos que utilizem parâmetros no domínio da freqüência para a determinação do Limiar de Fadiga Eletromiográfico. 
Entende-se que esta lacuna deve-se as dificuldades inerentes ao processamento do sinal EMG para obtenção destes parâmetros.

As variáveis obtidas no domínio temporal do sinal EMG, representam uma forma mais simples e bem determinada, do ponto de vista do processamento do sinal, para o monitoramento do processo de fadiga. Entretanto, estas variáveis apresentam algumas limitações, principalmente ligadas à relação entre o recrutamento das unidades motoras e a área de captação do eletrodo (DeLUCA, 1997). Entende-se que a análise no domínio temporal do sinal EMG seria bem aplicada ao monitoramento de músculos com volume reduzido. Também sua aplicação é bem sucedida em exercício no qual a resposta metabólica é fundamentalmente aeróbica, por exemplo, nos exercícios executados no cicloergômetro (DeLUCA e BASMAJIAN, 1985; SABAPATHY et al., 2003; HUG et al., 2003; JAMMES et al. 1998; DAVIS et al., 1976).

O monitoramento do processo de fadiga através de variáveis no domínio da freqüência do sinal, de certa forma é um procedimento mais complexo, e que vêm sendo estudado mais recentemente. Talvez por isso, observa-se na literatura uma série de não concordâncias a respeito dos procedimentos que envolvem o processamento do sinal EMG nesta situação. A obtenção de variáveis como a Freqüência Mediana (Fmed) é cercada por uma série de pressuposições ligadas as características estatísticas do sinal EMG.

O LFE, no entanto, é determinado através das alterações que ocorrem nestas variáveis em função do tempo de exercício. Para executar esta determinação são propostos diferentes métodos. O mais comum, é o cálculo da taxa de compressão do espectro de freqüência do sinal, obtido através de regressões lineares de variáveis como a Fmed. Outros métodos mais complexos envolvem a obtenção de uma reta "padrão" que possa descrever o comportamento do processo de fadiga muscular localizada (HOUSH et al., 1995, 1996;.DeVRIES et al., 1990).

Estes métodos fundamentam-se na pressuposição de que o comportamento do espectro de freqüência do sinal EMG é dependente da intensidade de exercício. Dessa forma, se um sujeito realiza uma série de exercícios, até a exaustão, com intensidades de carga diferentes o comportamento da inclinação das retas ajustadas 
aos dados de Fmed em cada série de exercício deve apresentar um comportamento específico. Tal comportamento deve ser diretamente proporcional à intensidade do exercício, ou seja, quanto maior a intensidade maior a inclinação negativa da reta (MORITANI et al., 1993).

O método para determinação do LFE é baseado no uso de variáveis temporais do sinal de EMG (RMS e IEMG). Mas porque não utilizar a variação da Fmed em função da carga de exercício de forma similar? Esta é a proposta para determinação do LFE no presente estudo. Imagina-se então uma situação na qual o sujeito realiza uma série de quatro exercícios, até a exaustão, com intensidades de carga diferentes. A partir deste procedimento pressupõe-se que o comportamento das intensidades de carga em função dos coeficientes angulares das retas, ajustadas aos dados de Fmed obtidos durante a execução de cada série, deveria ser linear. Se esta pressuposição for verdadeira a função linear que ajusta estes dados seria representativa do comportamento das Fmed em todas as situações possíveis de intensidade de carga. Sabendo-se que o limiar de fadiga eletromiográfico representa uma intensidade de carga, que durante o exercício não altera os parâmetros do sinal EMG. Pode-se concluir que a extrapolação desta função para a inclinação zero, fornecerá um resultado de intensidade que teoricamente pode ser considerado como o LFE (MORITANI et al., 1993).

Como se pretende utilizar a Fmed para determinação do LFE, existe a necessidade de se revisar o processamento do sinal EMG que neste caso é mais complexo. Pode-se dizer que o foco central neste processamento é o cálculo de sua distribuição espectral. Procedimento realizado através da TDF - Transformada Discreta de Fourier - ou FFT - Transformada Rápida de Fourier (JACKSON, 1989; BENDAT e PIERSOL, 1986). A seqüência temporal aplicada a TDF precisa contemplar algumas características dentre elas, a mais importante diz que a seqüência deve apresentar característica estacionária sob o ponto de vista estatístico. O respeito a esta regra deve ser observado para que seja aplicável o algoritmo da TDF, que decompõe o sinal em suas respectivas raias de freqüência através de um método matemático denominado de periodograma (BILODEAU et al., 1997; JACKSON, 1989; BENDAT e PIERSOL, 1986). 
Resumidamente, o periodograma correlaciona diferentes intervalos de um mesmo sinal a fim de identificar períodos que se repetem ao longo do sinal. Identificado estes períodos o algoritmo da TDF realiza a decomposição do sinal em suas respectivas raias de freqüência. A saber, o fator que diferencia a TDF da FFT se relaciona apenas ao tamanho dos trechos que serão submetidos à correlação. $\mathrm{Na}$ FFT estes trechos devem apresentar um número de amostras múltiplo de dois. Este procedimento foi muito útil quando os recursos computacionais ainda eram escassos e com a adoção deste procedimento os cálculos eram facilitados. Por este motivo a denominação de Transformada "Rápida" de Fourier (BILODEAU et al., 1997; JACKSON, 1989; BENDAT e PIERSOL, 1986).

Nos algoritmos baseados na TDF geralmente o valor padrão para o tamanho da janela de correlação é de 1024 dados podendo-se ainda aplicar ou não a sobreposição dos dados. No entanto deve-se tomar o cuidado de não submeter um trecho de sinal que apresenta um número de amostras inferior ao tamanho da janela de correlação. A não observância desta recomendação pode gerar nos resultados um efeito denominado de "alising", que é o aparecimento de sinais em raias de freqüência que não existem (BLACKMAN e TUKEY, 1958; JACKSON, 1989; BENDAT e PIERSOL, 1986; BILODEAU et al., 1997).

Basicamente um sinal EMG apresenta uma característica não determinística, ou seja, sua descrição não pode ser feita através de fórmulas ou funções. Neste caso o conceito de processos estocásticos (randômicos) deve ser considerado no sentido de descrever matematicamente este sinal e aproximá-lo da característica pertinente a sua correta aplicação ao algoritmo da TDF (PAPOULIS, 1984). Uma série temporal de característica randômica deve contemplar três condições para garantir a correta obtenção da sua distribuição espectral, são elas: i) o processo randômico deve apresentar uma distribuição Gaussiana; ii) a série temporal deve ser estacionária; iii) e seu valor médio deve ser igual à zero (BLACKMAN e TUKEY, 1958).

No que tange a segunda condição, a saber, um processo pode ser dito completamente estacionário se suas propriedades estatísticas forem invariantes a um deslocamento na origem, ou seja, se os processos $\mathbf{X}(\mathbf{n})$ e $\mathbf{X}\left(\mathbf{n}+\mathbf{n}_{\mathbf{0}}\right)$ apresentarem as mesmas características para qualquer valor de $\mathbf{n}_{0}$ (PAPOULIS, 1984). Em particular, um processo é estacionário no sentido amplo, se a média e a variância 
forem constantes para qualquer deslocamento do sinal no tempo. Para a decomposição espectral ser executada de forma correta, é necessário que o sinal submetido ao algoritmo da TDF atenda dentro de alguma aproximação o critério de estacionaridade.

Como o sinal não assume característica estacionária, recomenda-se que o cálculo do espectro de freqüência do sinal seja feito em seqüências nas quais a estacionaridade seja garantida. No intuito de se identificar tais trechos dentro de uma série temporal, Bendat e Piersol (1986) apresentaram dois testes: o teste de seqüências de Wald-Wolfowitz (run test) e o teste de arranjo reverso. Percebe-se, na literatura, a ampla utilização do primeiro, fato que levou alguns autores a fazerem sugestões sobre alguns padrões no que diz respeito ao tamanho do espaço amostral (janelas) do sinal EMG aplicado a TDF (PAPOULIS et al., 1984).

$\mathrm{Na}$ literatura observa-se que vários pesquisadores buscam determinar intervalos limites, de sinais EMG, adequados ao processamento via TDF, neste estudo alguns deles serão considerados. Para sinais obtidos através de contrações isométricas esta condição é bem determinada, pois o sinal é considerado como um processo estocástico estacionário com uma distribuição Gaussiana das amplitudes. Em contrações de nível baixo, 20-30\% da contração máxima, o sinal apresenta característica estacionária em períodos de até 40 segundos. Em contrações de nível alto, $50-80 \%$ da contração máxima, o período estacionário é de no máximo 1 segundo (MERLETTI et al., 1992, BILODEAU et al., 1997).

No entanto, em condições de contração dinâmica, o sinal EMG gerado não apresenta um comportamento estacionário bem definido como na situação anterior. Tal fato nos leva a uma aproximação no processamento deste tipo de sinal, que considera um período máximo estacionário de 500ms (POTVIN e BENT, 1997; MERLETTI et al., 1992, BILODEAU et al., 1997).

Entende-se que uma discussão metodológica que envolve a determinação do LFE nas diferentes etapas dos domínios experimental e de processamento do sinal EMG, pode representar uma importante contribuição para à prescrição de programas de exercícios, fundamentados em valores quantitativos representativos da condição fisiológica do sujeito. 


\section{OBJETIVOS.}

\subsection{Objetivo geral.}

O presente estudo tem por objetivo geral avaliar o uso da Freqüência Mediana (Fmed) do sinal EMG, como parâmetro, para a determinação do Limiar de Fadiga Eletromiográfico (LFE). Tal objetivo compreende ainda a determinação do LFE para as porções musculares do Vasto Lateral (VL), Vasto medial (VM) e Reto Femoral $(\mathrm{RF})$, durante a execução de exercícios em três modalidades distintas: isométrico; isotônico com peso fixo; isotônico no cicloergômetro.

\subsection{Objetivos específicos.}

Entretanto, como complemento ao objetivo geral pretende-se:

i) caracterizar os LFE determinados durante os testes descontínuos;

ii) avaliar a freqüência mediana quanto a sua qualidade como um indicador de fadiga utilizado no processo de determinação do Limiar de Fadiga Eletromiográfico;

iii) realizar análises complementares que possam indicar melhorias no processo de determinação do Limiar de Fadiga Eletromiográfico. 


\section{MATERIAIS E MÉTODOS.}

\subsection{Delineamento experimental.}

O presente estudo constitui análises baseadas em modelos experimentais, os quais foram fundamentados na metodologia exposta e discutida neste capítulo. Serão apresentados os métodos e as ferramentas utilizadas no processo de determinação dos Limiares de Fadiga Eletromiográfico (LFE) nos testes descontínuos isométrico, isotônico com peso fixo e isotônico no cicloergômetro.O fluxograma apresentado na figura 5 representa, resumidamente, as etapas experimentais deste estudo, caracterizando portanto o protocolo experimental concebido para atendimento aos propósitos científicos já descritos.

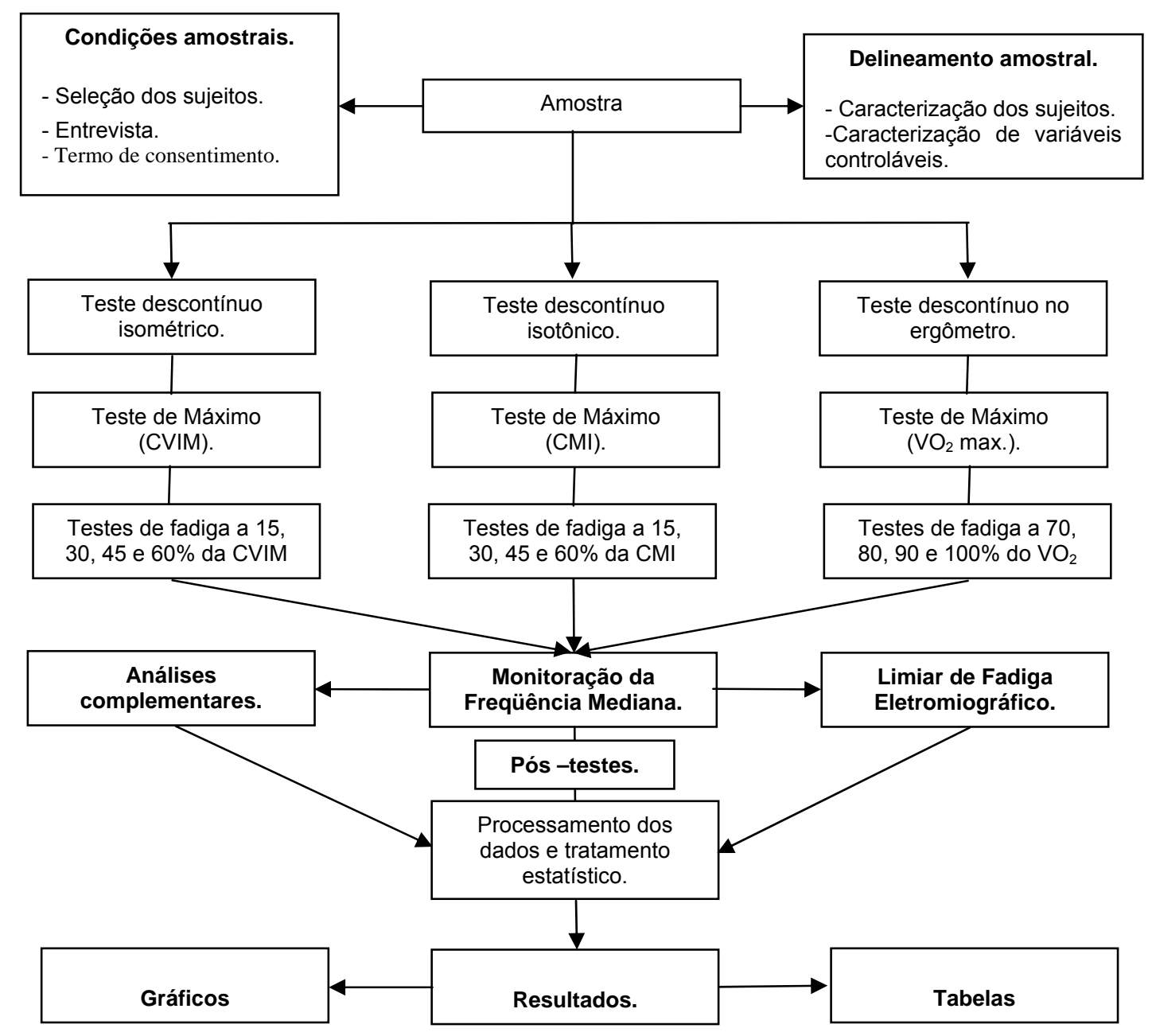

FIGURA 05 - Fluxograma representando o delineamento experimental deste estudo. 


\subsection{Descrição dos protocolos experimentais.}

Para fins de padronização, considerou-se neste estudo as seguintes definições:

i) teste descontínuo - corresponde ao conjunto de quatro testes de fadiga realizados em uma mesma seção com intervalos de descanso.

ii) teste de máximo - corresponde a determinação da carga máxima realizada através de procedimento específico para cada modalidade de exercício.

iii) teste de fadiga - corresponde ao exercício executado pelo sujeito até a exaustão, com cargas determinadas através do teste máximo;

iv) pós-teste - corresponde a um teste de fadiga realizado com carga representativa do LFE determinado para cada sujeito a partir dos testes descontínuos.

Considerando que o Limiar de Fadiga Eletromiográfico (LFE) é determinado através dos testes descontínuos, é necessário que o sujeito execute quatro testes de fadiga em uma mesma modalidade de exercício. Assim a cada teste de fadiga, 0 sujeito executa até a exaustão, o exercício em uma das modalidades estabelecidas, isométrica, isotônica com peso fixo ou no ergômetro, com uma das quatro cargas, referenciadas a partir do teste de máximo. Portanto, para a determinação do LFE, cada sujeito realizou três testes descontínuos, sendo um para cada modalidade de exercício. Também, cada sujeito realizou três pós-testes, nas mesmas modalidades de exercício, para a caracterização do LFE determinado. 


\subsubsection{Teste descontínuo isométrico.}

Este teste foi executado em um aparelho denominado mesa extensora de perna da marca VITTALY®, modelo convergent $\circledast$ (figura 6). O sujeito foi posicionado sentado, e os ajustes do apoio para as costas e do comprimento da alavanca para apoio do membro foram feitos. O membro contralateral foi estabilizado por uma faixa. O ângulo da articulação do joelho foi limitado a $60^{\circ}$, pois estudos anteriores constatam que esta posição favorece a maior geração de força por parte do quadríceps, figura 7 (OTA, 2006; PINCIVERO, 2003, 2000).

O teste foi realizado em duas etapas: i) teste máximo - determinação da Contração Isométrica Voluntária Máxima (CVIM); ii) teste de fadiga - execução de exercícios com cargas referenciadas a partir da CVIM.

Para determinar a CVIM o sujeito realizou três contrações sustentadas por 6 segundos com um descanso de 10 minutos. Dos 6 segundos foram desconsiderados da análise os dois primeiros e dois últimos. Assim, considerou-se como CVIM a média geral dos dados obtidos neste intervalo para as três contrações figura 8.

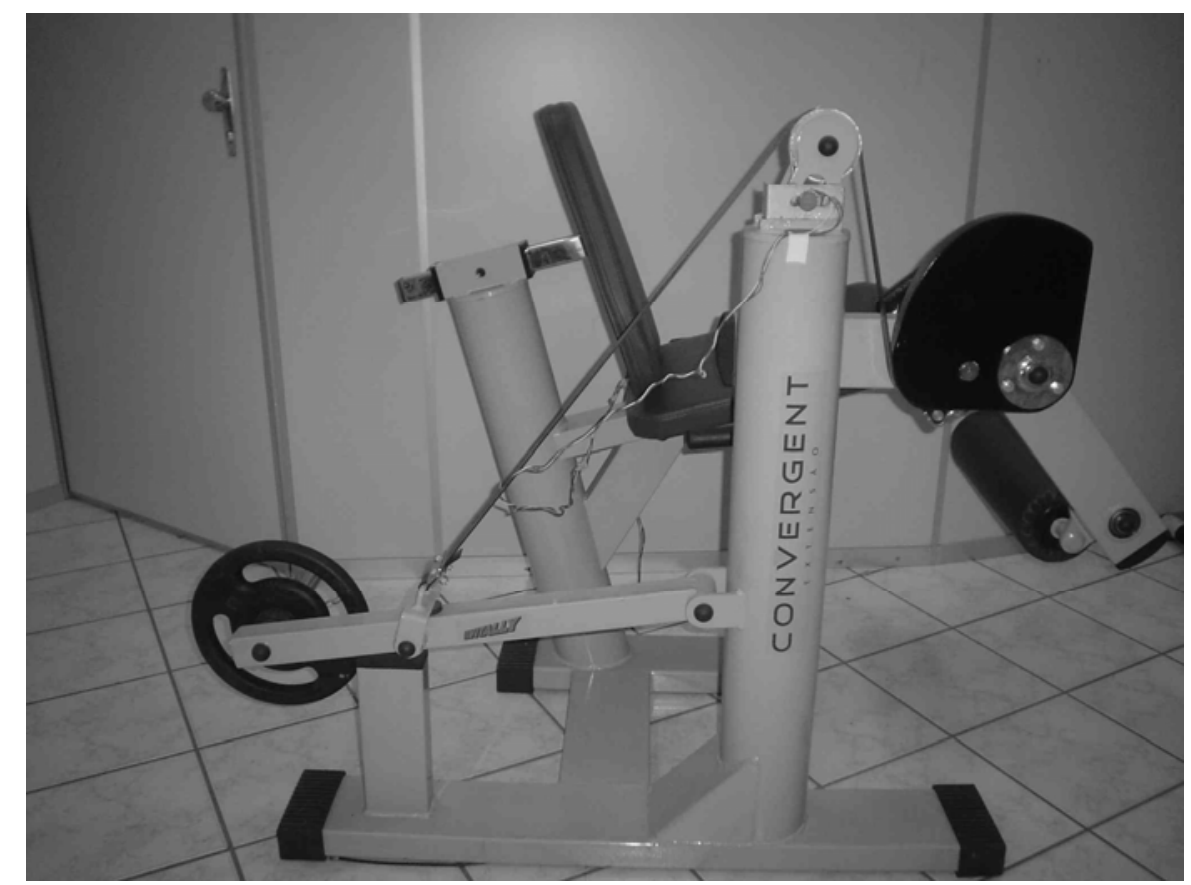

FIGURA 06- Aparelho de ginástica, para extensão de perna, utilizado nos protocolos de exercício isométrico e isotônico com peso fixo. 


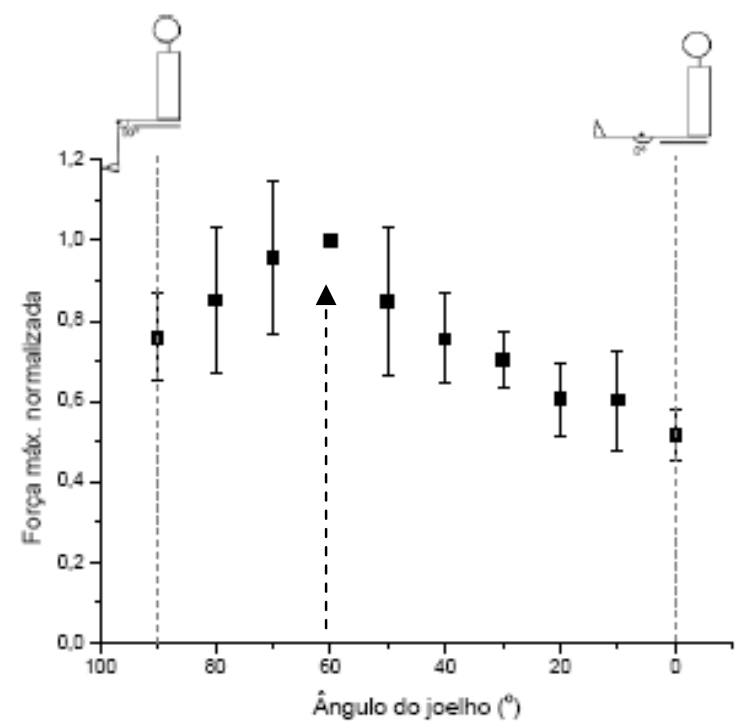

FIGURA 07 - Força média (SD) exercida pela perna com contração isométrica máxima do músculo quadríceps, em função do ângulo de extensão $(n=10)$, Observa-se o máximo de força em $60^{\circ}$ (seta pontilhada). Adaptado de OTA (2006).

$\mathrm{Na}$ segunda etapa do teste o sujeito executou quatro séries de exercício com intensidades de carga iguais a 15\%, 30\%, 45\% e 60\% do CVIM máximo. Em cada série o sujeito foi orientado a sustentar a carga até a exaustão. Considerou-se como exaustão o momento em que o sujeito cessou completamente o exercício ou apresentou incapacidade na manutenção da carga, pré-determinada, representada pela queda de $10 \%$ na sua intensidade. Para auxiliar no controle da intensidade da carga, a força aplicada foi monitorada em tempo real através da célula de carga, representando, dessa forma, um feedback visual para o sujeito. 


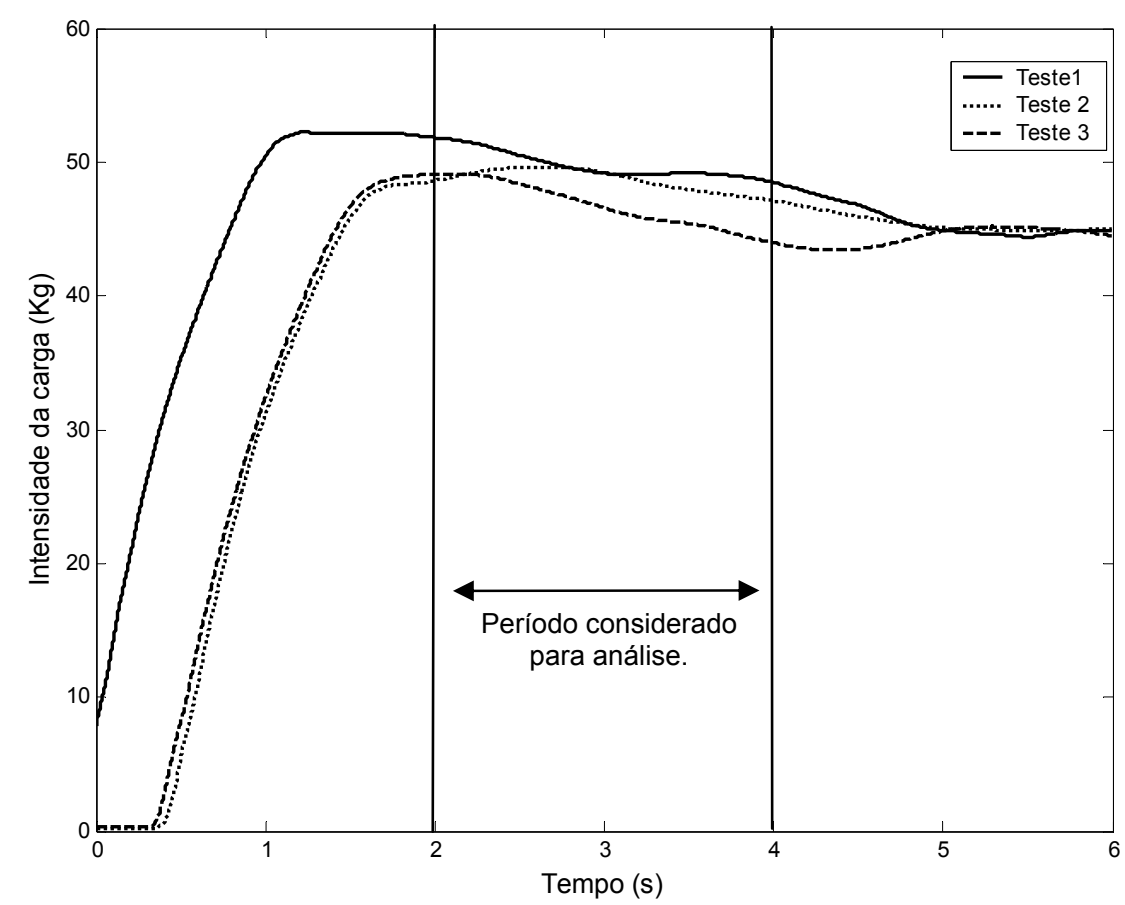

FIGURA 08 - Exemplo de sinais de força obtidos durante um teste de contração isométrica voluntária maxima (CVIM). Considerou-se para análise o período central de dois segundos.

4.2.2. Teste descontínuo isotônico com peso fixo.

O teste de fadiga isotônico com o peso fixo, também foi realizado na mesa extensora apresentada na figura 6. Os procedimentos para o posicionamento do sujeito foram os mesmos do teste anterior. Exceto pela posição inicial da articulação do joelho que foi de $90^{\circ}$.

Assim como no teste anterior a execução deste também foi dividida em duas etapas: i) teste máximo - determinação da Contração Máxima Isotônica (CMI); ii) teste de fadiga - execução de exercícios com cargas referenciadas a partir da CMI.

A determinação da carga máxima isotônica foi realizada através da execução de três extensões de perna, completas e consecutivas, com uma carga estipulada. Considerou-se como máximo $(100 \% \mathrm{CMI})$ a última carga em que o sujeito conseguiu realizar as três extensões completas e consecutivas. A cada nova tentativa a carga 
era incrementada, e entre as tentativas foi respeitado um intervalo de 5 minutos. Os sujeitos realizaram, em média, $4 \pm 1.6$ tentativas.

$\mathrm{Na}$ segunda etapa do teste o sujeito executou quatro séries de exercício com intensidades de carga iguais a 15\%,30\%, 45\% e 60\% do CMI máximo. Em cada série o sujeito foi orientado a executar o movimento de extensão (contração concêntrica) e flexão (contração excêntrica) em um ritmo de $1 \mathrm{~Hz}$ até a exaustão, utilizando-se para marcação um metrônomo. Considerou-se como exaustão o momento no qual o sujeito cessou completamente o exercício ou apresentou incapacidade em realizar a amplitude máxima de extensão da perna, até $20^{\circ}\left(0^{\circ}=\right.$ extensão completa), por três repetições consecutivas. Para auxiliar no controle da amplitude de movimento da perna, a posição angular da articulação do joelho foi monitorada em tempo real através do eletrogoniômetro, representando, dessa forma, um feedback visual para o sujeito.

Antes de cada teste descontínuo os sujeitos foram orientados a executar os movimentos de forma contínua em sincronia com ritmo pré-definido pelo metrônomo. Este procedimento teve por objetivo: i) evitar a recuperação da musculatura devido a pequenos períodos de inatividade entre dois batimentos; ii) padronizar a velocidade de execução do movimento para as diferentes cargas. É importante ressaltar que a padronização da velocidade não caracteriza o seu controle, apenas tenta-se estabelecer um ritmo que permita uma fluidez padronizada nos movimentos executados pelos diferentes sujeitos.

\subsubsection{Teste descontínuo isotônico no cicloergômetro.}

Este protocolo foi executado em um cicloergômetro marca $\mathrm{KIKOS} \circledast$, modelo CARDIOTEST尺, com sistema micro-processado de frenagem eletromagnética. $O$ sujeito foi posicionado sentado, após o ajuste de altura do assento e do apoio para os membros superiores.

A execução deste teste também foi dividida em duas etapas: i) teste máximo determinação da carga verificada para o consumo máximo de oxigênio $\left(\mathrm{VO}_{2}\right.$ 
máximo); ii) teste de fadiga - execução de exercícios com intensidades de carga referenciadas a partir do $\mathrm{VO}_{2}$ máximo.

A determinação do $\mathrm{VO}_{2}$ máximo foi realizada a partir de um exercício com carga incremental, baseado nos seguintes procedimentos:

i) $\quad 0$ incremento de potência foi calculado individualmente através da equação de WASSERMAN et al. (1999). Como as variáveis, altura, idade e massa corporal, apresentaram valores bastante próximos, no grupo amostral, o valor de incremento obtido para todos sujeitos foi aproximado para 25W/min;

ii) o sujeito foi posicionado no cicloergômetro e após colocação e ajuste da máscara para coleta dos gases, passou por uma fase de aquecimento de 5 minutos sem carga e cadência de 70rpm (figura 9);

iii) após a fase de adaptação, na mesma cadência, o sujeito iniciou o teste com 50W, e foram realizados incrementos discretos de $25 \mathrm{~W}$ a cada 2 minutos, até a sua exaustão (SABAPATHY et al., 2003; HUG et al., 2003; JAMMES et al. 1998; DAVIS et al., 1976, 1979);

iv) neste caso considerou-se como exaustão o momento em que o sujeito cessou completamente o exercício, ou quando percebida a incapacidade do sujeito em manter a cadência de 70 rpm;

v) considerou-se o estágio de carga representativo do $\mathrm{VO}_{2}$ máximo aquele em que não foi verificado um aumento acima de $150 \mathrm{ml} / \mathrm{min}$ no consumo de $\mathrm{O}_{2}$. Quando este critério não foi verificado, utilizou-se o valor máximo da curva de $\mathrm{VO}_{2}$ como referência para determinar o estágio de carga representativo do $\mathrm{VO}_{2}$ máximo, figura 10.

$\mathrm{Na}$ segunda etapa do teste descontínuo o sujeito executou quatro séries de exercício com intensidades de carga igual a $70 \%, 80 \%, 90 \%$ e $100 \%$ daquela relativa ao $\mathrm{VO}_{2}$ máximo. Em cada teste de fadiga ele foi orientado a pedalar em uma cadência de 70rpm, até a exaustão. Considerou-se como exaustão o momento em que o sujeito cessou completamente o exercício ou apresentou incapacidade da manutenção da cadência por um período maior que 6 segundos. 


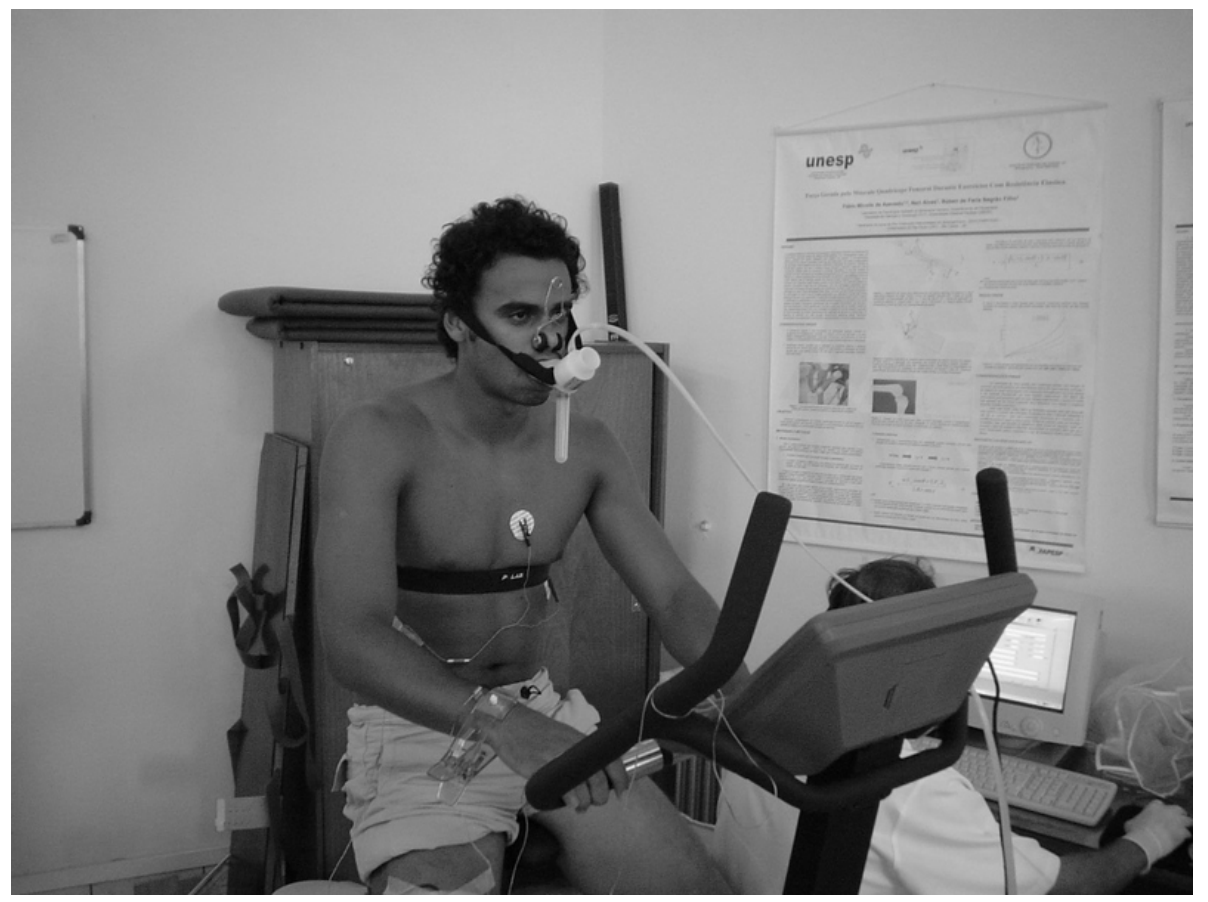

FIGURA 09- Sujeito posicionado no cicloergômetro, preparado para realizar um teste máximo no cicloergômetro.

$$
\mathrm{IP}=\frac{[(\text { altura }- \text { idade }) \times \mathrm{N}]-[150+(6 \times \mathrm{mc})]}{100}
$$

Onde, segundo WASSERMAN et al. (1999).

$\mathrm{IP}=$ Incremento de potência em $\mathrm{W}$

$\mathrm{N}=20$ (para sexo masculino)

$\mathrm{mc}=$ massa corporal $\mathrm{em} \mathrm{Kg}$

altura em $\mathrm{cm}$

idade em anos 

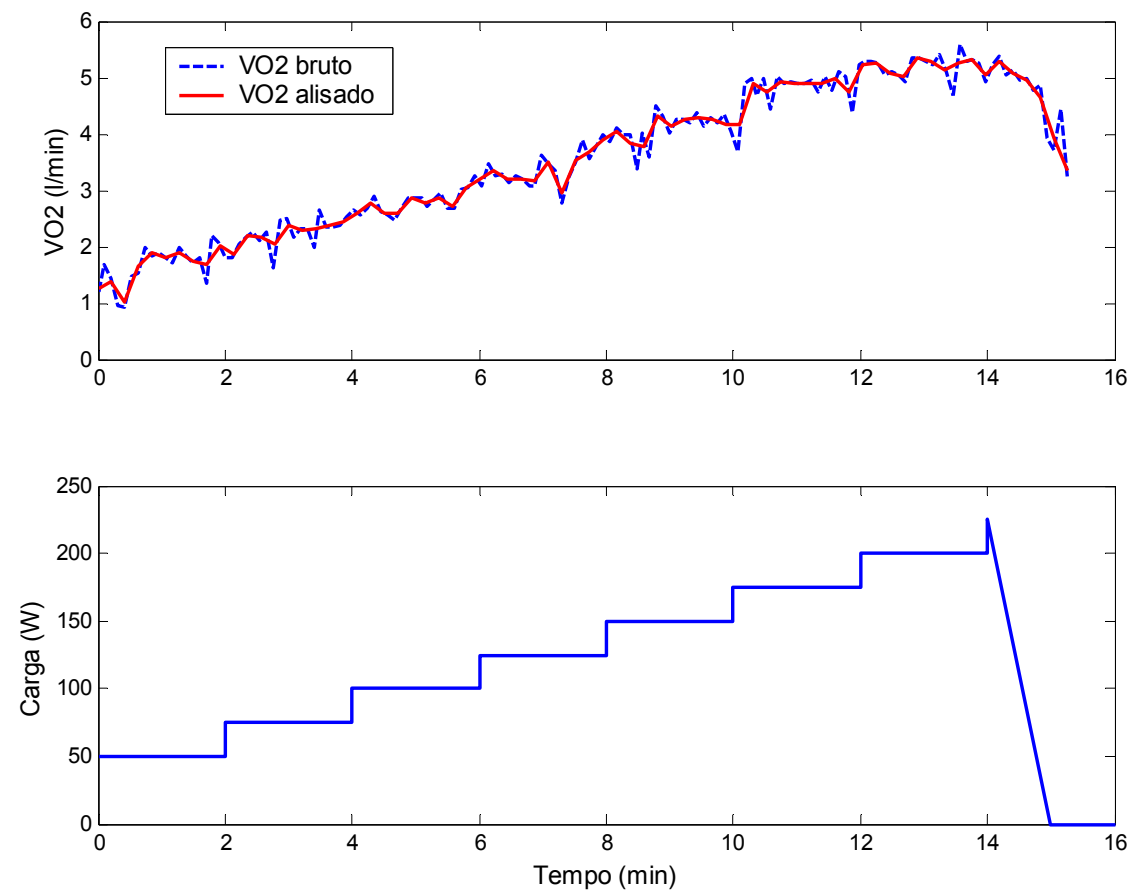

FIGURA 10 - Acima, exemplo de monitoração no $\mathrm{VO}_{2}$ de um sujeito durante um teste máximo. Abaixo, representação dos estágios de incremento de carga durante o teste.

Algumas considerações gerais são necessárias a cerca dos testes descontínuos apresentados nos itens anteriores:

i) durante a execução dos testes descontínuos, foram captados os sinais EMG das porções do vasto lateral, vasto medial e reto femoral, do músculo quadríceps femoral;

ii) a monitoração do consumo de oxigênio somente foi realizada durante o teste máximo na modalidade de exercício no ergômetro;

iii) entre os testes de fadiga foi respeitado um intervalo de vinte minutos. Da mesma forma, entre a execução do teste máximo e os testes de fadiga foi respeitado um intervalo mínimo de 48 horas;

iv) as cargas dos testes de fadiga foram aplicadas de forma aleatória, através de sorteio. 


\subsubsection{Pós-testes.}

Como já citado anteriormente, alguns autores sugerem que o LFE representa a carga de exercício na qual, por um período de tempo prolongado, não são observadas alterações no sinal EMG que indiquem a instalação do processo de fadiga muscular (MORITANI et al., 1993;.Pavlat et al., 1995; deVRIES et al., 1982). Tomando-se esta hipótese como verdadeira, propôs-se neste estudo caracterizar o LFE determinado durante os testes descontínuos segundo sua condição teórica. Esta análise foi realizada através de um procedimento denominado de pós-teste.

Basicamente a execução do pós-teste seguiu os mesmos procedimentos já descritos anteriormente, para os testes de fadiga, em cada modalidade de exercício. Diferenciando-se apenas na consideração do valor médio do LFE, para as três porções musculares, como a carga em que o sujeito executou o exercício neste teste. Os sinais EMG das porções do VL, RF e VM também foram captados conforme os procedimentos já determinados neste capítulo.

Entende-se, neste estudo, que a evidência na instalação do processo de fadiga está relacionada com o comportamento das Fmed em função do tempo de exercício. Tomando-se como referência o comportamento do coeficiente de inclinação $(\mathrm{Cl})$ da reta ajustada a estes valores pode-se observar dois comportamentos distintos: i) o $\mathrm{Cl}$ apresenta um valor significativo diferente de zero, caracterizando uma efetiva alteração no comportamento do sinal EMG; ii) o Cl não apresenta um valor significativo diferente de zero, não caracterizando uma efetiva alteração no comportamento do sinal EMG.

Neste contexto os sinais EMG coletados durante o pós-teste foram submetidos a um tratamento com o objetivo de se identificar dois momentos críticos definidos como:

i) momento de início da fadiga - tempo decorrido desde o início do exercício até onde o coeficiente de inclinação, da reta ajustada as Fmed, não apresenta diferença significativa de zero; 
ii) momento de exaustão - tempo decorrido desde o início do exercício até o momento em que o sujeito atingiu a condição de exaustão, descrita anteriormente, para cada uma das modalidades de exercício.

Assim, a caracterização de um LFE segundo sua condição teórica poderia ser evidenciada a partir da observação destes momentos em um pós-teste. Ou seja, quanto menor o período entre estes momentos, mais próximo de sua característica teórica se encontra o LFE testado. Complementando esta análise, também foi observado o comportamento da Fmed no momento de início da fadiga e no momento de exaustão.

\subsection{Grupo amostral.}

Foram selecionados 15 sujeitos, do sexo masculino, idade: $22 \pm 2.6$ anos; altura: $175 \pm 4.6 \mathrm{~cm}$; massa: $76 \pm 4.7 \mathrm{~kg}$. Na amostra foram excluídos os sujeitos que apresentaram alguma desordem neuro-musculares e/ou articulares, no membro inferior dominante, em um período inferior a 18 meses. O membro dominante foi determinado baseando-se na preferência do sujeito em realizar um gesto de chute, de acordo com Ebersole et al. (1999).

Os sujeitos também foram classificados com relação ao seu grau de atividade física, através da aplicação de um questionário denominado de International of Physical Activity Questionnaire - IPAQ (APÊNDICE I). Este questionário é um instrumento, validado, designado para a observação da atividade física entre adultos (15-69 anos). Na sua forma curta, utilizada neste estudo, ele apresenta três grupos de questões que permitem classificar um sujeito em três níveis distintos de atividade física: i) baixo (abaixo de 600 MET-min/semana); ii) moderado (abaixo de 3000 METmin/semana); iii) alto (acima de 3000 MET-min/semana) (GUEDES et al., 2005; CRAIG et al., 2003; PARDINI et al., 2001).

Antes da realização dos testes, todos os sujeitos selecionados visitaram o laboratório para serem orientados sobre sua participação no estudo e procedimentos adotados. Após os esclarecimentos eles assinaram um termo de consentimento livre 
e esclarecido (APÊNDICE II). Os procedimentos utilizados neste estudo foram analisados pela comissão de ética local, da FCT-UNESP Campus de Presidente Prudente, obtendo parecer favorável através do processo número 114/2006.

\subsection{Instrumentação}

\subsubsection{Eletromiógrafo e eletrodos}

Para a aquisição do sinal EMG foram utilizados 3 pares de eletrodos de superfície, modelo Meditrace ${ }^{\circledR}$ da marca $3 \mathrm{M} \circledast$, com superfícies de captação de $\mathrm{AgCl}$ com $10 \mathrm{~mm}$ de diâmetro. Os eletrodos foram posicionados paralelamente, separados entre si por $20 \mathrm{~mm}$ (figura 11). No cabo do eletrodo estava presente um circuito préamplificador com ganho de 20 vezes, CMRR (Common Mode Rejection Ratio) maior que 80 dB e impedância de $1012 \Omega$.

Os sinais foram captados em um módulo condicionador de sinais da marca LYNX®, modelo BIO EMG 1000, figura 11. Neste módulo três canais para a aquisição de sinais EMG foram configurados com um filtro digital, passa-baixa com freqüência de corte de $500 \mathrm{~Hz}$ e um passa-alta com freqüência de corte de $20 \mathrm{~Hz}$. Todos os canais apresentavam ganho final de 1000 e freqüência de amostragem de $4000 \mathrm{~Hz}$.

A aquisição e o armazenamento dos sinais em arquivos de dados foram feitos através do software Bioinspector 1.8, também da LYNX®. 

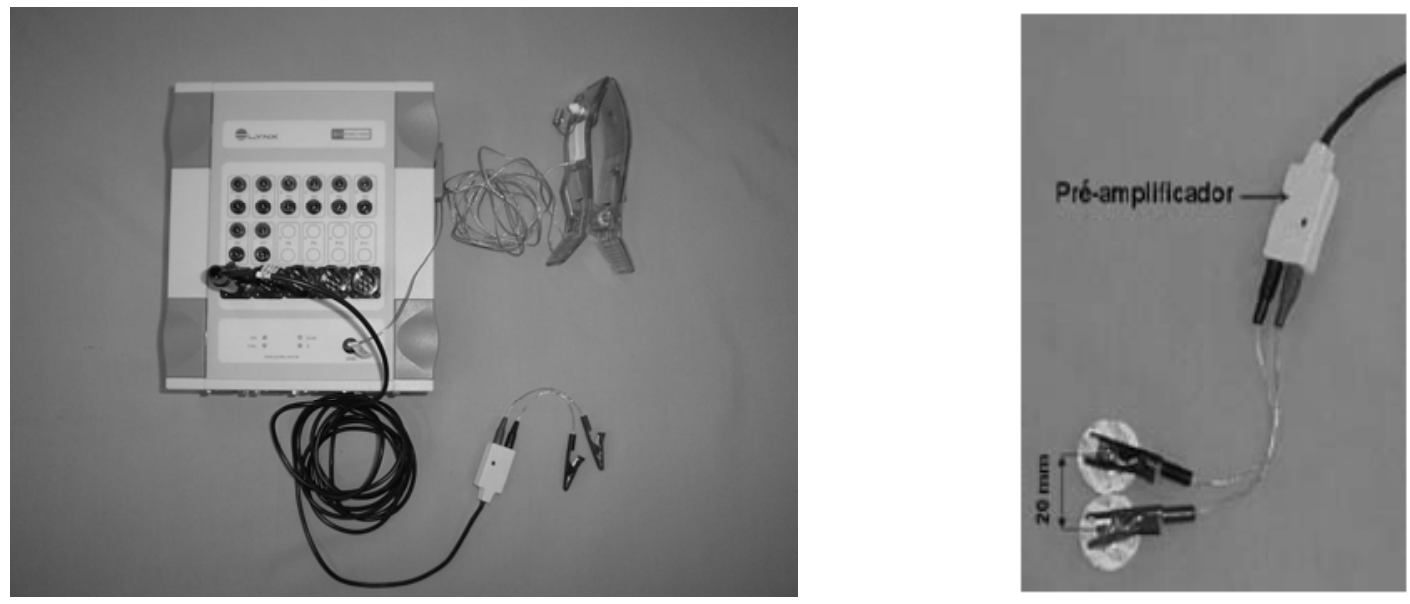

FIGURA 11 - A esquerda, condicionador de sinais utilizado para integração dos sinais de EMG e instrumentação, modelo EMG 1000 da marca Lynx. A direita, eletrodos descartáveis e pré-amplificador.

\subsubsection{Fixação dos eletrodos.}

Antes da execução dos testes, os eletrodos para captação do sinal EMG foram fixados sobre as porções do Vasto Lateral (VL), Reto Femoral (RF) e Vasto medial (VM), do músculo quadríceps femoral (figura 12).

Para fixação dos eletrodos, primeiro localizou-se o ponto motor na região do ventre da porção muscular. Este procedimento foi realizado utilizando-se um aparelho de eletroestimulação modelo Neurodyn, marca Ibramed(C e um eletrodo tipo "caneta". Após a localização e marcação do ponto, foi feita a tricotomia e a limpeza da região. Os eletrodos foram fixados logo abaixo do ponto localizado (DeLUCA e BASMAJIAN, 1985; DeLUCA, 1997). 

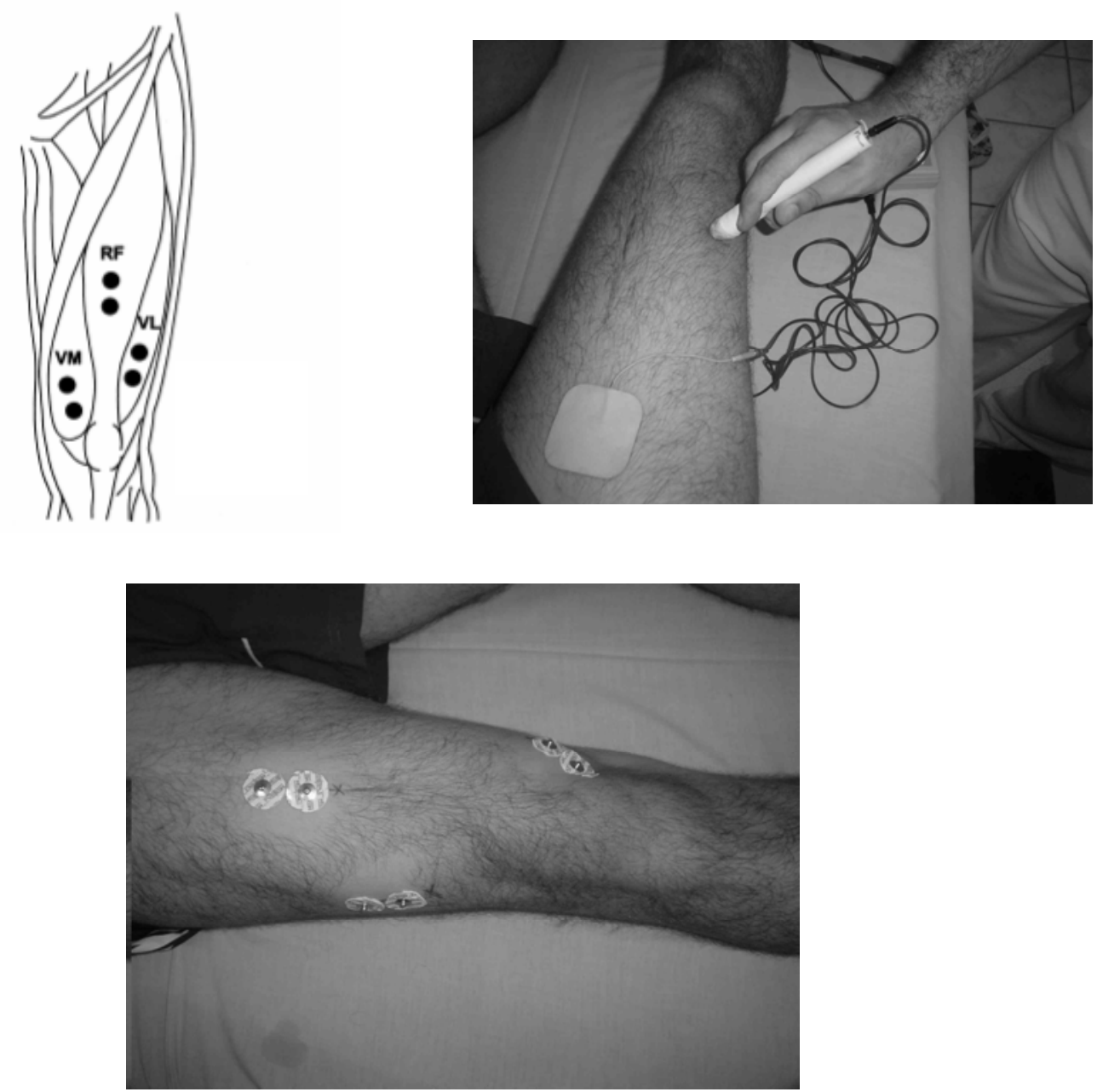

FIGURA 12 - Acima e a esquerda, esquema representativo da posição dos eletrodos sobre o músculo Reto Femoral (RF), Vasto Lateral (VL) e Vasto Medial (VM), adaptado de Cifrek (2000). À direita, procedimento para detecção de um ponto motor através de eletroestimulação. Abaixo, posicionamento dos eletrodos nas porções musculares indicadas.

\subsubsection{Eletrogoniômetro e célula de carga.}

A monitoração da posição angular da articulação do joelho durante o exercício isotônico com peso fixo, foi realizada através de um potenciômetro linear de precisão, com $50 \mathrm{~K} \Omega$. Este dispositivo foi utilizado como um eletrogoniômetro e foi adaptado ao aparelho em que o sujeito realizou o exercício, figura 13a.

Durante o teste isométrico a monitoração da força aplicada pelo sujeito foi realizada através de uma célula de carga, modelo MM da marca Kratos $®$, figura 13b. 
Dois canais no condicionador de sinais foram configurados para a aquisição dos sinais provenientes da célula de carga e eletrogoniômetro. Em ambos os canais foram habilitados um filtro digital passa baixa de $100 \mathrm{~Hz}$.
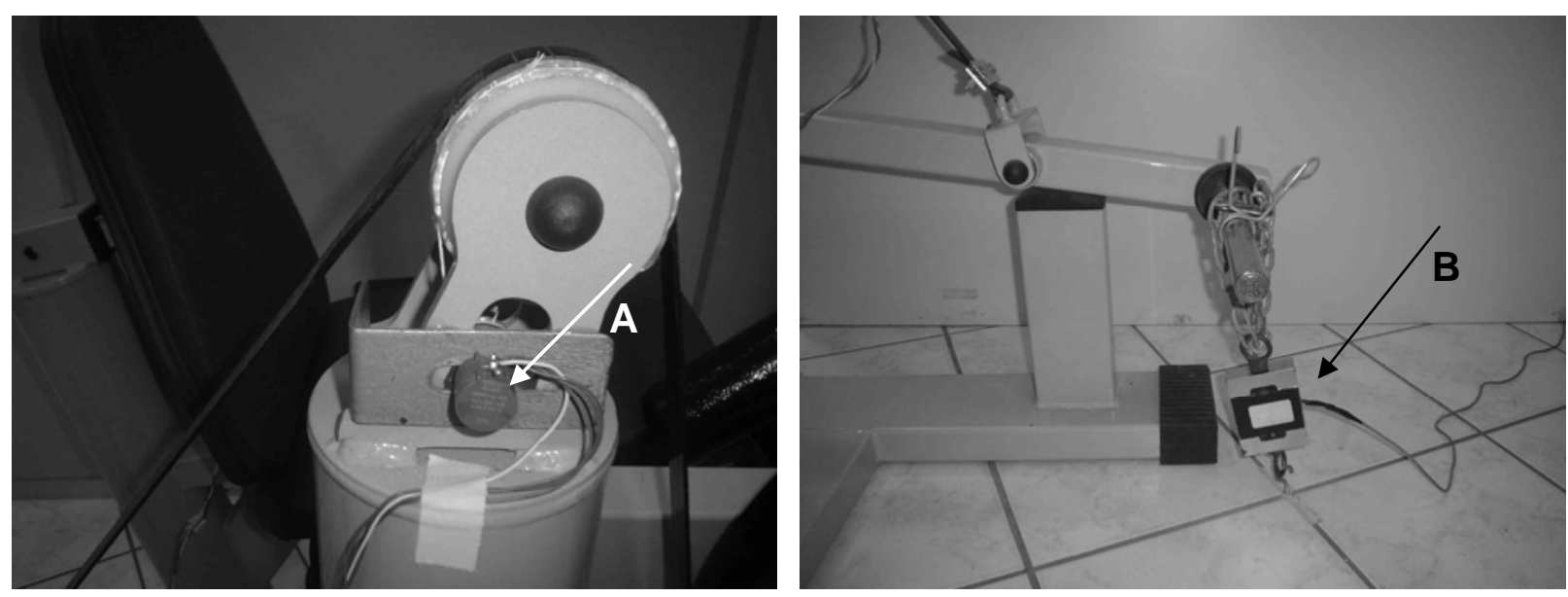

FIGURA 13 - À esquerda (A), eletrogoniômetro acoplado a mesa extensora para monitoração da posição angular do joelho durante o movimento de flexão e extensão da perna durante o exercício isotônico. À direita $(\mathbf{B})$, célula de carga utilizada para monitorar a força aplicada pelo sujeito durante o teste máximo e de fadiga isométrico.

4.4.4. Transdutor para análise metabólica.

Para realizar a medição do consumo de oxigênio $\left(\mathrm{VO}_{2}\right)$ foi utilizado um transdutor modelo VO2000, marca MedGraphics ${ }^{\circledR}$, figura 14. Neste transdutor a análise de $\mathrm{O}_{2}$ é feita através de um sensor tipo fluido galvânico e a de $\mathrm{CO}_{2}$ é feita por um sensor infravermelho.

Durante os experimentos o equipamento foi calibrado através de sua função de auto-calibração e configurado para executar as medidas a cada 3 ciclos expiratórios. A aquisição e armazenamento dos dados foram realizados através do software Aerograph 2.3, também da MedGraphics. 


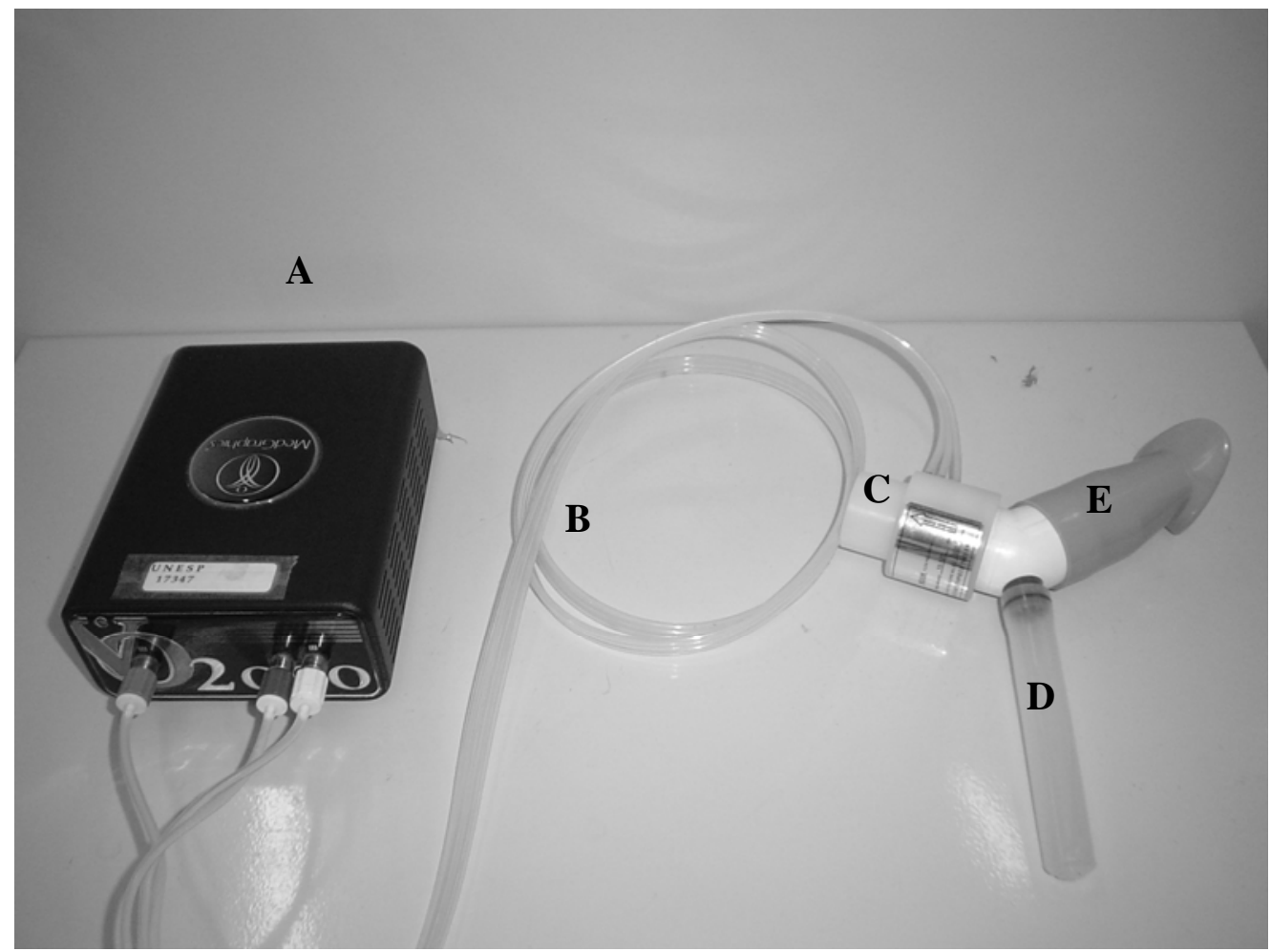

FIGURA 14- (A) Transdutor para análise metabólica modelo VO2000 da marca MedGraphics $\AA$; (B) circuito para coleta das amostrar de ar expirado; (C) "pneumotac"; (D) coletor de saliva; (E) bocal.

\subsection{Processamento dos sinais.}

4.5.1. Processamento dos sinais eletromiográficos para determinação do Limiar de Fadiga eletromiográfico.

Os sinais de EMG, força e posição angular coletados durante os testes descontínuos foram processados através de um algoritmo desenvolvido em ambiente MatLabß. A seqüência deste algoritmo é apresentada abaixo, seguida da descrição detalhada das suas etapas (ANEXO I).

- Etapa 1 - Entrada dos dados.

- Etapa 2 - Filtragem dos sinais EMG.

- Etapa 3 - Classificação automática dos sinais EMG. 
- Etapa 4 - Seleção automática das séries temporais.

- Etapa 5 - Cálculo do espectro de potência das séries selecionadas, através da Transformada discreta de Fourier (TDF).

- Etapa 6 - Cálculo das Fmed.

- Etapa 7 - Ajuste das Fmed e determinação dos coeficientes de inclinação.

- Etapa 8 - Ajuste dos coeficientes de inclinação em função das cargas de exercício e determinação do LFE.

Etapa 1: Carregam-se no algoritmo quatro arquivos que representam os quatro testes de fadiga de um determinado teste descontínuo.

Etapa 2: Na primeira fase de processamento através do algoritmo, aplica-se ao sinal EMG bruto um filtro digital passa-banda tipo Butterworth de $4^{\mathrm{a}}$ ordem e freqüência de corte entre 20 e $500 \mathrm{~Hz}$. Faz-se necessário o uso de um filtro nesta etapa, principalmente para se retirar do sinal bruto componentes abaixo de $20 \mathrm{~Hz}$, que caracterizam artefatos de movimento entre o músculo e a pele, sobre a região de captação, que podem aparecer durante a execução dos testes com maior quantidade de movimento.

Etapa 3: O algoritmo neste módulo, automaticamente, classifica o sinal com relação a sua morfologia. Se um sinal não apresenta descontinuidades ao longo de sua série temporal, é classificado como proveniente de um exercício isométrico (figura 15 a). Do contrário, se o sinal apresenta descontinuidades ao longo da série temporal, é classificado como proveniente de exercício isotônico (figura 15 b) (Di FABIO, 1987). 


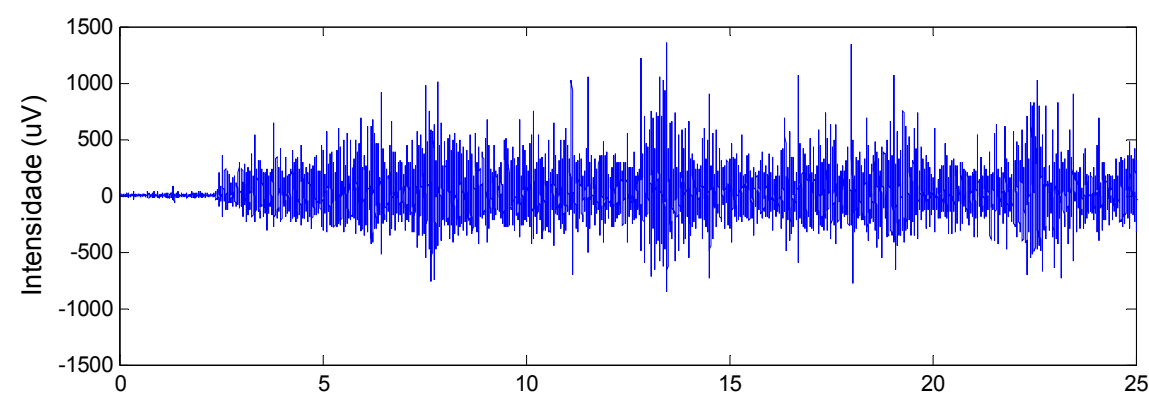

A

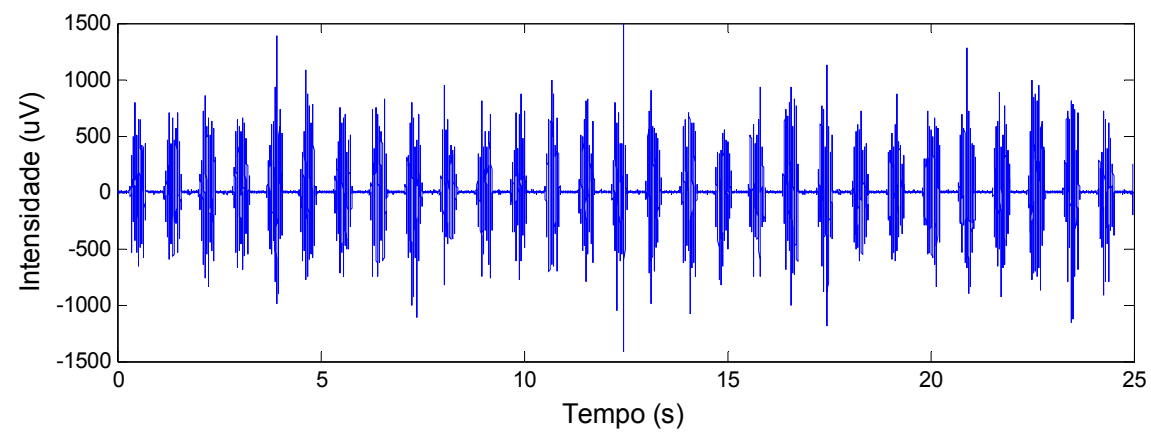

B

FIGURA 15 - O gráfico "A" apresenta um sinal bruto proveniente de uma contração isométrica e o gráfico "B" apresenta um sinal bruto proveniente de uma contração isotônica.

Etapa 4: Este módulo seleciona as séries temporais que serão aplicadas a TDF para o cálculo do espectro de potência. A forma como estes trechos são selecionados dependem do tipo de teste a qual o sinal é proveniente, conforme é descrito a seguir:

i) Teste de fadiga isométrico.

As séries temporais dos sinais provenientes deste teste foram selecionadas em períodos de $1000 \mathrm{~ms}$ com sobreposição (overlap) de $500 \mathrm{~ms}$, conforme mostra a figura 16. 


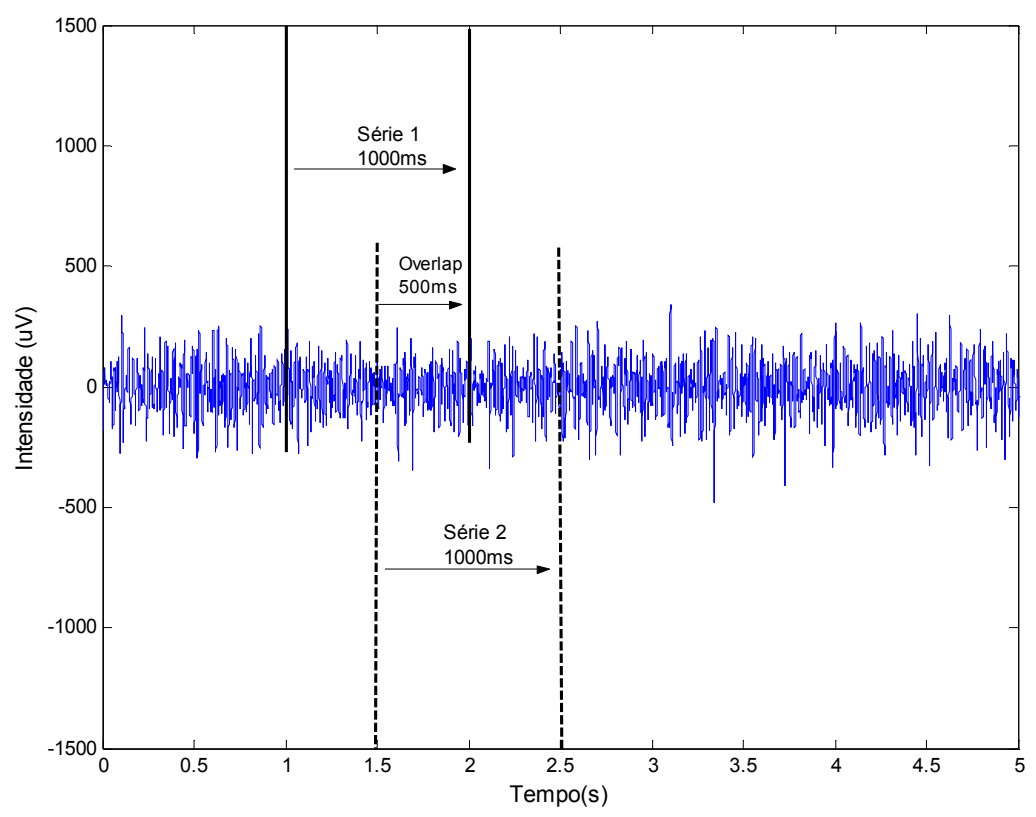

FIGURA 16 - Exemplo da seleção das séries temporais em um sinal proveniente de um teste de fadiga isométrico.

ii) Teste de fadiga isotônico com peso fixo.

As séries temporais dos sinais provenientes deste teste foram selecionadas a partir da referência fornecida pelo eletrogoniômetro, entre $30^{\circ}$ e $80^{\circ}$ do movimento de extensão da perna. Sendo $0^{\circ}$ considerado a extensão completa.

Nesta etapa o sinal bruto do eletrogoniômetro foi filtrado através de um filtro passa-baixa tipo Butterworth com freqüência de corte de $5 \mathrm{~Hz}$. A detecção dos trechos de interesse foi realizada automaticamente através de uma rotina específica.

Também se aproveitou a monitoração da posição da articulação do joelho, para o cálculo da velocidade angular entre o trecho de $30^{\circ}$ a $80^{\circ}$ do movimento de extensão da perna. Este cálculo foi efetuado derivando-se a função determinada pelo deslocamento angular da articulação em função do tempo. 
iii) Teste de fadiga no ergômetro.

As séries temporais dos sinais provenientes deste teste foram selecionadas a partir da aplicação de uma rotina específica onde: i) o sinal bruto foi retificado por onda completa; ii) aplicou-se um filtro passa-baixa com freqüência de corte de $1 \mathrm{~Hz}$. A figura $17 \mathrm{a}, \mathrm{b}$ apresentam estas etapas.

A partir da obtenção desta componente de baixa freqüência (figura 17c), seus picos foram detectados automaticamente e usados como referência para a seleção da série temporal (300ms).

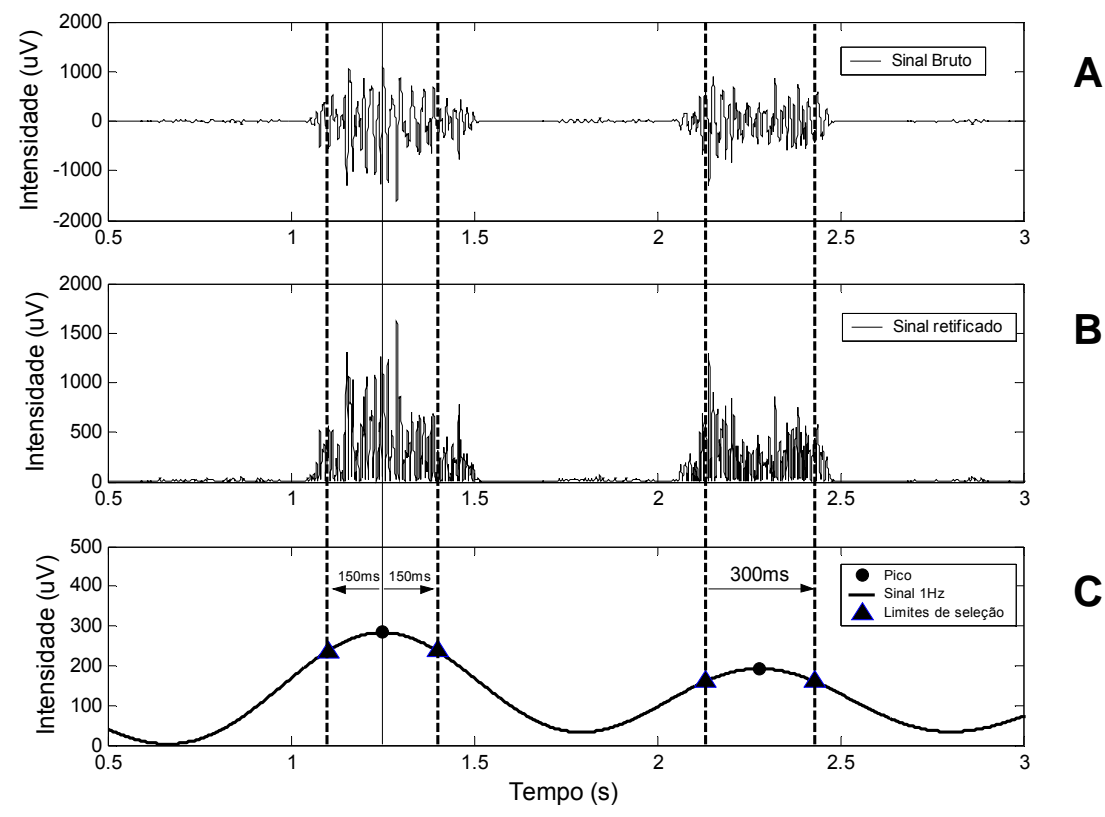

FIGURA 17 - Exemplo de processamento do sinal EMG proveniente do teste no ergômetro. Observase de cima para baixo: a) sinal bruto; b) sinal retificado; c) componente de baixa freqüência e as referências para selecão das séries temporais.

Etapa 5: Os sinais contidos nas janelas selecionadas anteriormente, são aplicados à função PSD do software MatLab® para a obtenção do espectro de potência. Nesta função o periodograma constituiu-se de uma amostragem de 256 dados seqüenciais, com sobreposição de metade deste valor. A partir do espectro de 
potência foi calculada a freqüência mediana ( $F m e d)$, considerada como a freqüência que divide o espectro de potência do sinal em duas áreas iguais.

Etapa 6: As Fmed calculadas, para cada série de exercício do teste descontínuo, são armazenadas.

Etapa 7: É realizado um ajuste linear para cada conjunto de Fmed referente a cada uma das séries de exercícios executadas durante o teste descontínuo, figura 18. O coeficiente angular de cada ajuste é armazenado para uso na próxima etapa.
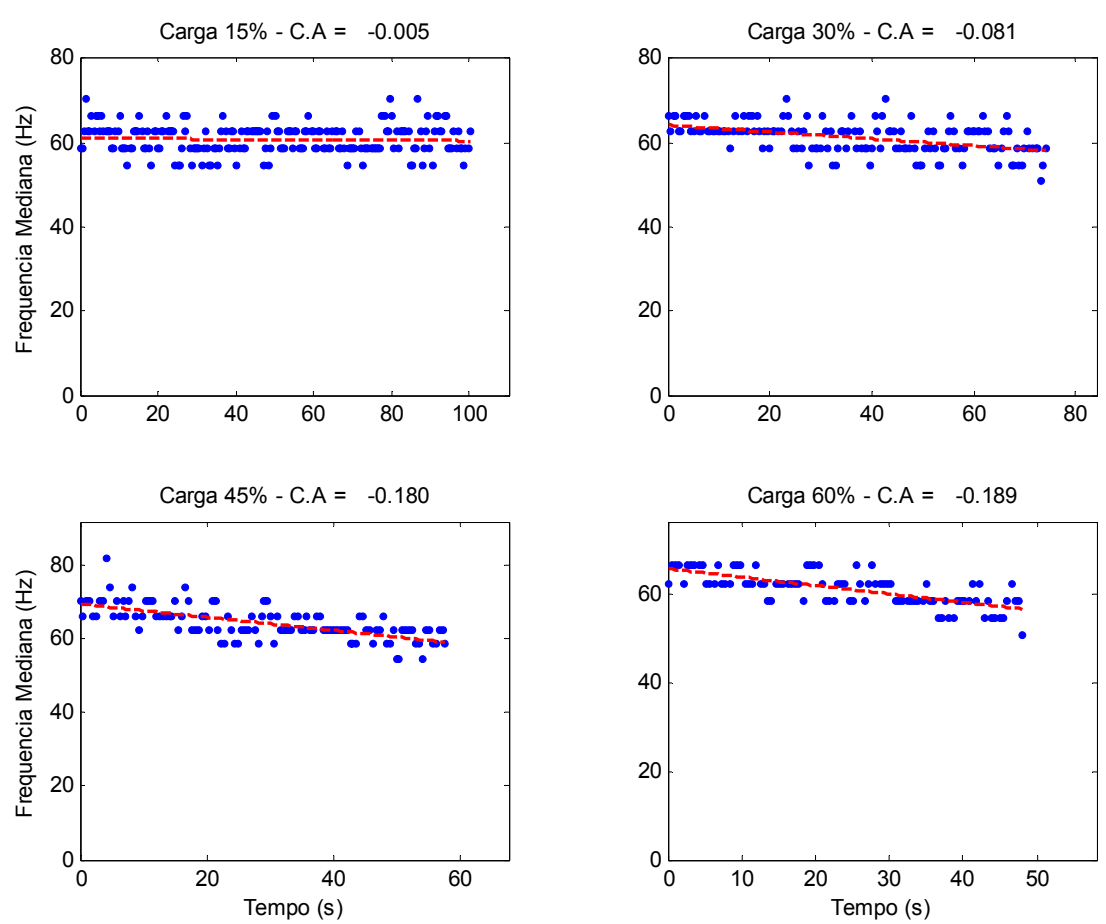

FIGURA 18 - Exemplo de processamento para obtenção dos coeficientes de inclinação dos ajustes realizados nas Fmed em função do tempo. Músculo VL, teste isométrico.

Etapa 8: As intensidades de carga, de cada uma das séries de exercício, são ajustadas em função dos coeficientes angulares obtidos na etapa anterior. Este ajuste é extrapolado até a inclinação zero, determinando assim o valor de carga 
interceptado pela reta. Este valor é considerado como o Limiar de Fadiga Eletromiográfico, figura 19.

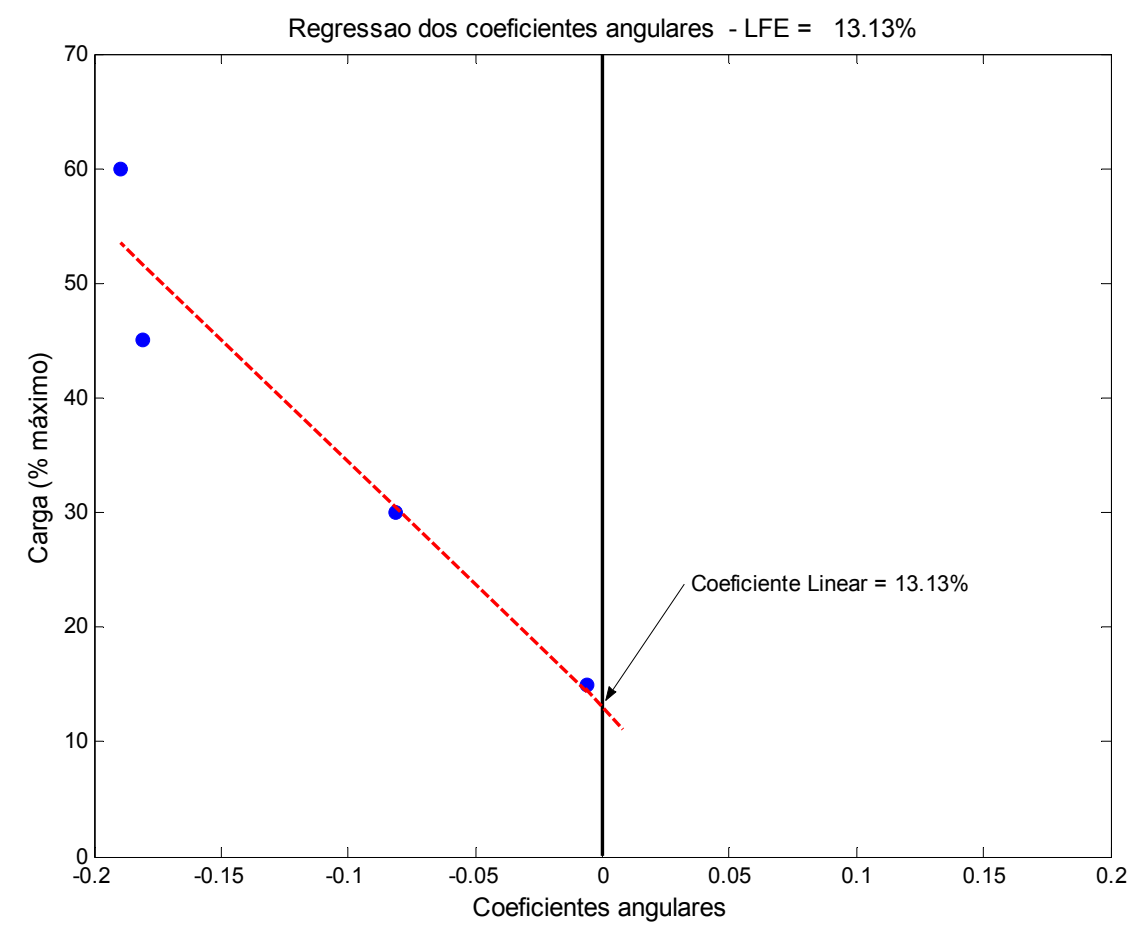

FIGURA 19 - Exemplo de determinação do Limiar de Fadiga Eletromiográfico para a porção do VL em um teste descontínuo isométrico. O valor do limiar é dado em porcentagem da carga máxima.

4.5.2. Processamentos dos sinais eletromiográficos no Pós-teste.

Os sinais de EMG coletados durante o pós-teste foram processados através do algoritmo descrito anteriormente até a etapa de cálculo das Fmed. Para a determinação do momento de fadiga o seguinte procedimento foi adotado (ANEXO II):

i) um ajuste linear foi aplicado a cada 5 segundos do tempo de exercício, de forma progressiva, sempre a partir da origem, até o momento de exaustão; 
ii) em cada trecho o coeficiente de inclinação da reta ajustada aos valores de Fmed, o seu valor para o teste $t$ e sua significância foram analisados;

iii) foi considerado como momento de fadiga o último trecho onde o coeficiente de inclinação, da reta ajustada as amostras de Fmed, não apresentou diferença significativa de zero (figura 20).

Também, foram selecionadas as Fmed contidas em um período de 5 segundos antes do momento de início da fadiga e antes do momento de exaustão. Os valores de Fmed selecionados nestes períodos foram normalizados pela Fmed do início do exercício e considerou-se para análise seus valores médios.

Ressalta-se que o momento de fadiga representa um limiar entre dois regimes distintos do trabalho muscular. Previamente a este momento o músculo estabelece um regime de trabalho normal, aqui denominado de fisiológico. Após o momento de fadiga sugere-se que o declínio no desempenho mecânico do músculo caracterize um regime de trabalho muscular não fisiológico, porém este estado é momentâneo, uma vez que ao cessar o exercício o músculo tende a se recuperar espontaneamente.

\subsection{Análises complementares do sinal eletromiográfico.}

Algumas variáveis foram submetidas a outros tipos de tratamento com o objetivo de se complementar uma posterior discussão a cerca dos métodos empregados neste estudo para determinação do LFE.

4.6.1. Análise do comportamento da Freqüência Mediana inicial e final durante os testes de fadiga.

Dos testes de fadiga executados pelos sujeitos, foram extraídas as amostras de Fmed contidas dos primeiros e últimos 10 segundos do tempo total de exercício. 
Assim considerou-se como freqüência inicial a média do conjunto de amostras, de Fmed, extraídos do início do exercício e que representam o sujeito "descansado". Considerou-se como freqüência final a média do conjunto de amostras extraídos 10 segundos antes do momento de exaustão e que representam o sujeito já "fadigado".

Os valores de freqüência inicial e de freqüência final foram normalizados respectivamente: i) pelo desvio padrão do conjunto de freqüências contidas nos 10 segundos iniciais do tempo total de exercício; ii) pela freqüência inicial.

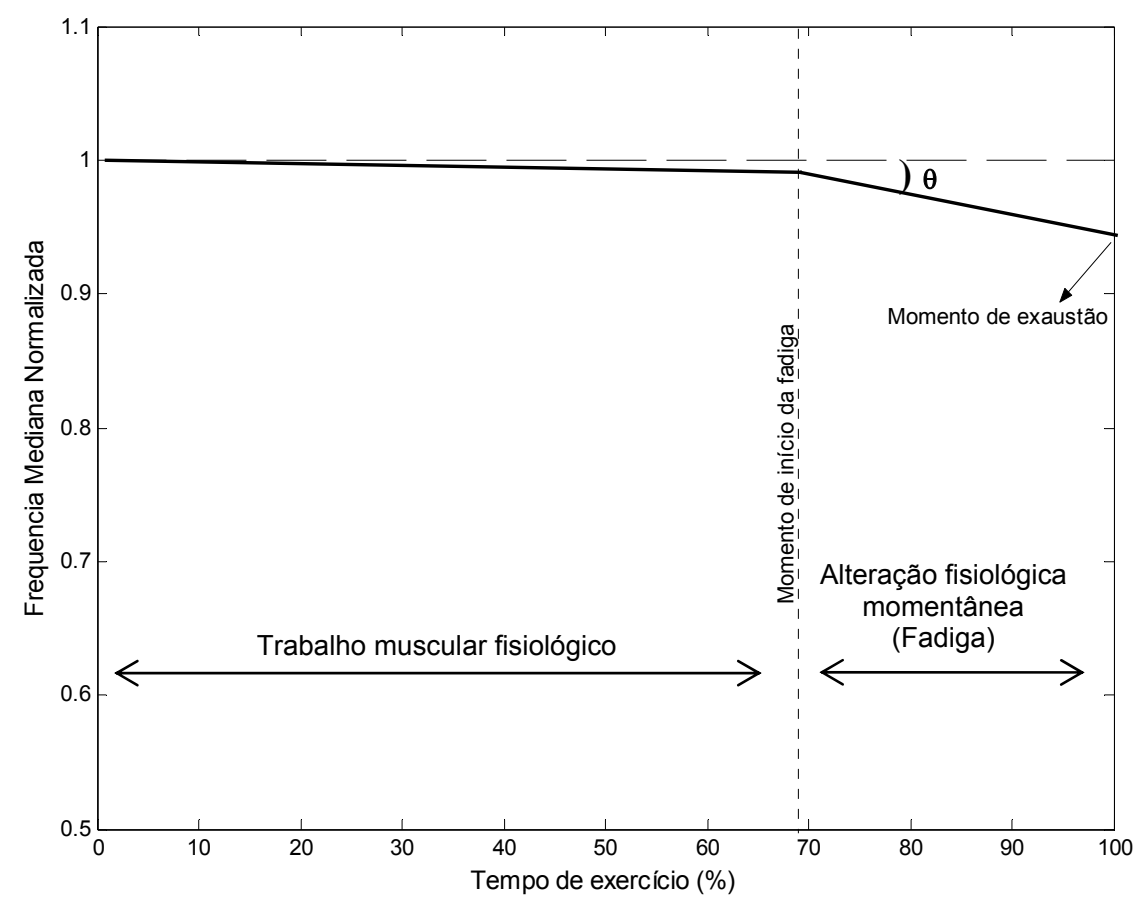

FIGURA 20 - Gráfico exemplificando a determinação do momento de fadiga em um pós-teste. No gráfico considera-se o início da fadiga o momento onde o valor do coeficiente de inclinação, dado pela tangente de $\theta$, apresenta valor significativo diferente de zero $(p<0.05)$.

4.6.2. Análise descritiva dos parâmetros das regressões dos testes de fadiga.

Fundamentalmente para a determinação do LFE pressupõe-se que a variação da freqüência mediana deve ser linear. Ou seja, espera-se um comportamento, em seu valor, inversamente proporcional ao tempo de exercício. Neste sentido, uma 
análise dos parâmetros que qualificam estas regressões representa uma importante informação no contexto geral deste estudo. Os parâmetros selecionados para análise foram (ANEXO III):

i) valor de t e sua significância para o valor do coeficiente de inclinação. Entende-se que um teste de fadiga deve apresentar em seu ajuste uma inclinação negativa diferente de zero. Do contrário pode-se inferir que a carga a que o sujeito esta sendo submetido, representa um valor abaixo do LFE.

ii) coeficiente de correlação produto momento de Pearson (r). Entende-se que quanto mais próximo este valor estiver de 1, maior a associação entre as variáveis. No caso, este coeficiente pode representar que a variável Fmed descreve um comportamento linear em função do tempo de exercício.

4.6.3. Análise multivariada das bandas de freqüência através do método das componentes principais.

No contexto deste estudo este método foi empregado para caracterizar o comportamento individual das diferentes bandas de freqüência, que compõe o espectro de potência do sinal EMG, em uma situação no início e no final do exercício. Buscou-se com o uso deste método verificar quais destas bandas de freqüência são efetivamente responsáveis pela variação global do espectro entre estas duas situações.

As bandas de freqüência para a referida análise foram obtidas através de um algoritmo especifico desenvolvido em ambiente MatLab, cuja principais etapas são descritas a seguir (ANEXO IV): 
i) foram selecionadas séries temporais consecutivas dos sinais EMG conforme descrito na etapa 5 do item 4.5. O espectro de potência de cada série foi calculado conforme a etapa 6 do item 4.5 , figura $22 \mathrm{a}$.

ii) os espectros foram normalizados através da derivação de sua função de distribuição espectral (SDF), figura 22b,c;

iii) as bandas de freqüência foram tomadas na faixa de $0-400 \mathrm{~Hz}$ com intervalos de $20 \mathrm{~Hz}$. Entende-se que nesta faixa as variações do espectro são mais evidentes entre o início do exercício e o momento de exaustão, figura 21 .

Após a separação das bandas os dados foram tabulados em uma matriz conforme padrão usado no método de análise de principal componente (PCA).

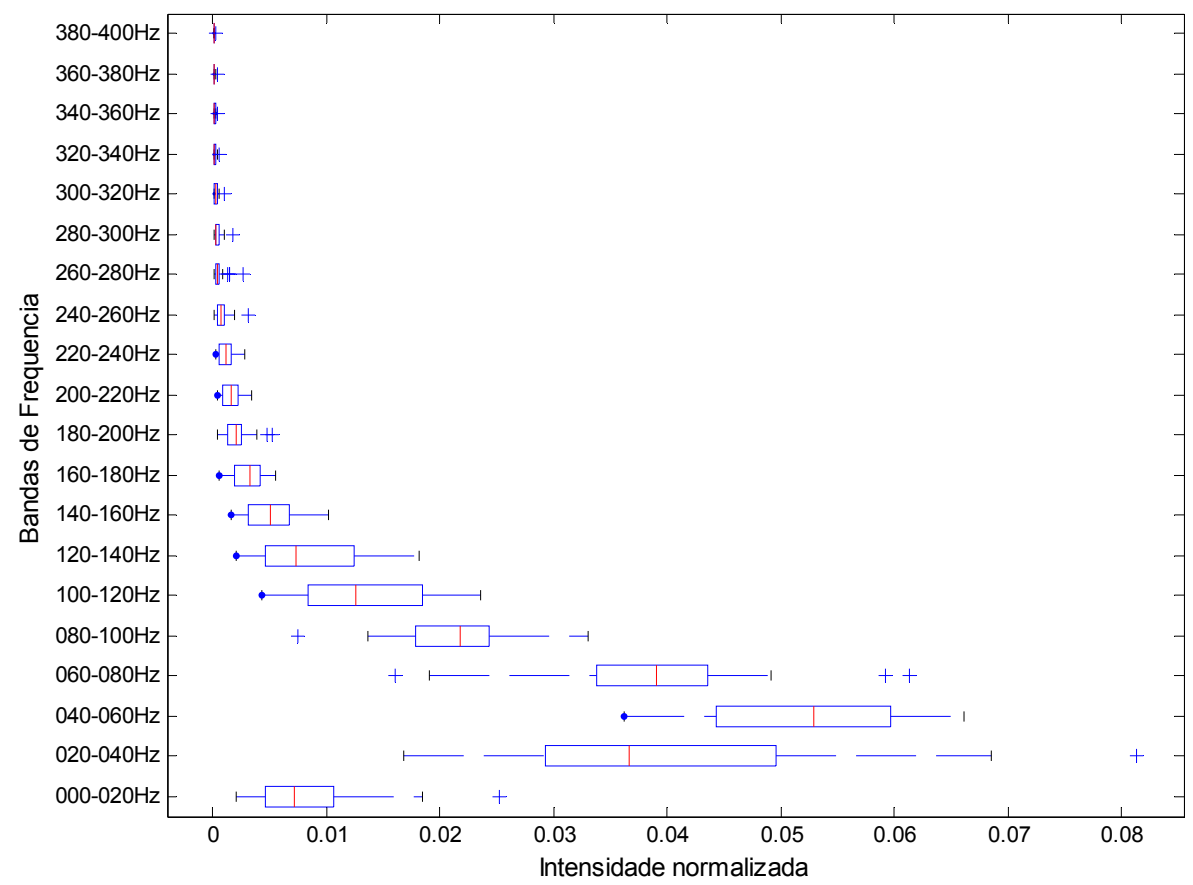

FIGURA 21 - Exemplo da variação nas bandas de freqüência entre o início e o fim de um teste de fadiga $(n=15)$. Nota-se na figura que as variações são mais evidentes a partir da faixa de $220-240 \mathrm{~Hz}$. 

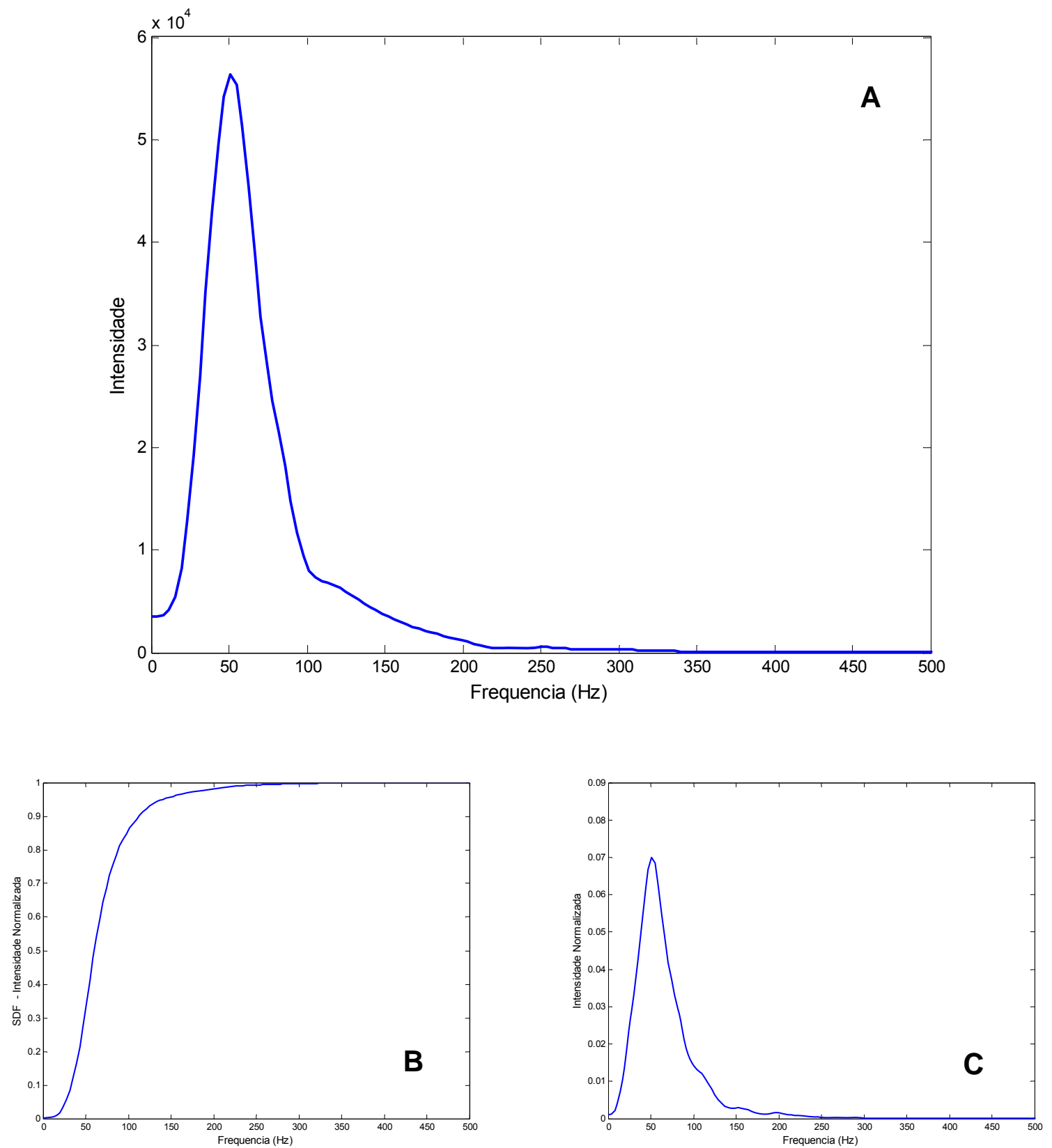

FIGURA 22 - Acima, (A) exemplo do espectro de potência de uma série temporal selecionado de um sinal EMG proveniente de um teste de fadiga isométrico, para a porção do VL. Abaixo a esquerda (B), sua respectiva Função de Distribuição Espectral. À direita (C), distribuição espectral com intensidade normalizada obtida através da derivação da SDF. 


\subsection{Tratamento estatístico dos dados.}

\subsubsection{Tratamento estatístico paramétrico e não paramétrico.}

Inicialmente um teste de normalidade foi aplicado nos dados de interesse neste estudo. Utilizou-se, neste caso, o teste de Shapiro-Wilks, que observa a correlação entre a amostra dos dados com seu correspondente score normal, dado pelo valor de W. Quando W é igual a um, considera-se a distribuição da amostra perfeitamente normal. Porém para considerar uma amostra como tendo distribuição normal, basta que o valor de $\mathbf{W}$ não apresente diferença significativa de um.

Assim as comparações realizadas entre as variáveis de interesse foram estabelecidas da seguinte forma: i) os dados que apresentaram distribuição normal foram submetidos a Análise de Variância através da ANOVA com um fator (one-way) ou dois fatores (two-way). Neste caso foi utilizado o teste Post Hoc de Tukey (POMPEU, 2006); ii) aos dados que não apresentaram distribuição normal aplicou-se a prova de Friedman. Entende-se nestes casos que as pressuposições exigidas pela análise de variância estão comprometidas (POMPEU, 2006; VEIRA, 2003).

Para todos os testes foi considerado um nível de significância de $5 \%$.

4.7.2. Tratamento estatístico multivariado através de componentes principais.

As componentes principais (PCA) ou transformação de Karhunen-Loeve, é um método estatístico multivariado que cria um novo sistema de eixos através de combinações lineares dos dados originais, buscando sempre a máxima variabilidade dos resultados e a mínima perda de informações. As combinações lineares são efetuadas de modo que os dados possam ser representados por um número menor de fatores descritivos, reduzindo a dimensão do conjunto analisado. Por esse motivo o PCA é amplamente usado para facilitar a interpretação, projeção, descrição e extração de características de conjuntos multivariados (HU e NENOV, 2004; KIRYU et al., 1997). 
Neste tipo de tratamento as variáveis são caracterizadas como fatores que exercem influência sobre a amostra testada, neste caso esta análise pode ser realizada de duas formas: i) separadamente servindo para interpretar o peso das variáveis originais na combinação das componentes principais mais importantes; ii) visualizando o conjunto da amostra apenas pelo gráfico das duas primeiras componentes principais, denominado de "Component Scores"1", sabendo-se que essas detêm maior parte da informação estatística.

\subsection{Delimitações e controle do erro experimental.}

Em qualquer estudo experimental sempre existirão delimitações relacionadas aos seus procedimentos. Em alguns casos seu controle pode representar um aumento na qualidade dos resultados pretendidos. Entretanto, tal fato não é determinante na condição de que todas as minúcias metodológicas, empregadas no delineamento experimental, possam ser controladas. Existem condições que podem ser melhoradas, talvez "equacionadas", mas também existem aquelas que independem da influência do pesquisador. Dentro deste contexto, pretende-se neste item discutir algumas delimitações experimentais, julgadas relevantes, com o objetivo de facilitar a interpretação dos dados que serão apresentados no próximo capítulo.

4.8.1. Delimitações e os procedimentos de coleta de dados.

Todo o procedimento de coleta de dados foi realizado em um ambiente e em uma situação incomum aos sujeitos, a lembrar: i) as instruções a que o sujeito deveria atender e a atenção as informações de feedback durante o processo de indução a fadiga; ii) o posicionamento dos sujeitos nos equipamentos; iii) a fixação dos eletrodos sobre a pele. Dadas estas restrições, pode-se ter condicionado algum tipo de alteração nas variáveis que estavam sendo monitoradas, esta condição é

\footnotetext{
${ }^{1}$ Termo técnico sem tradução para o português.
} 
denominada de efeito retroativo. Para minimizar este efeito, ofereceu-se a oportunidade do sujeito visitar o ambiente do laboratório para se familiarizar com os procedimentos conforme descrito no item 4.3.

4.8.2. Delimitações e os procedimentos dos testes máximos.

Neste estudo foram utilizados três métodos para a determinação da condição máxima do sujeito, já descritos nos itens 4.2.1, 4.2.2 e 4.2.3. O teste máximo realizado através do protocolo de exercício no cicloergômetro, utilizando como referência o consumo de oxigênio é considerado padrão e não representa, necessariamente, uma delimitação metodológica. Entretanto um apontamento pode ser feito: o consumo de oxigênio do sujeito não reflete diretamente sua máxima condição de resistência muscular. Neste caso buscou-se aproximar o resultado a máxima condição muscular, com o objetivo de se determinar o LFE para esta modalidade de exercício.

Com relação ao teste de carga máxima isotônico, tem-se uma situação de tentativa e erro inerente ao próprio teste de três repetições máximas. Ressalta-se que um excesso de repetições poderia ocasionar um efeito acumulativo, levando o músculo testado à fadiga, fato que provavelmente iria mascarar o resultado do teste. Tentou-se minimizar o número repetições utilizando as informações de carga máxima previamente estabelecida no teste isométrico.

Pode-se dizer que o teste de carga máxima em isometria, reflete diretamente a condição de força máxima muscular, pois seu método se baseia na medição de sua força externa aplicada a um sensor. Entende-se que seu resultado é dependente da posição do membro, de métodos para determinação do máximo da curva medida, entre outros fatores. Neste aspecto ressalta-se apenas a ausência de uma padronização para aplicação do método.

Excluindo-se a determinação da carga máxima através do consumo de oxigênio, já bem padronizado na literatura, resta uma questão, direcionada aos outros dois métodos empregados neste estudo: Como saber se o sujeito realmente atingiu seu máximo? Levando-se em conta que o processo de determinação do LFE 
exige que esta condição seja contemplada, a ausência de uma resposta representa uma fonte de erro inerente ao processo de determinação do LFE.

4.8.3. Delimitações relacionadas aos instrumentos de medidas.

Com relação ao analisador de gases, o modelo utilizado foi o portátil denominado de VO2000. Verifica-se que para testes científicos ele é pouco utilizado, pois é um equipamento desenvolvido especialmente para o trabalho de campo. Sua maior limitação está no processo calibração, que é feito através de sua função de "auto-calibração", que segundo seus usuários não é a mais recomendada para uso em coleta de dados científicos. Porém esta limitação não caracteriza uma condição sine qua non para seu uso dentro do propósito deste estudo. Para melhorar a confiabilidade dos dados coletados foi realizada no equipamento uma revisão, na qual foi solicitada sua calibração através de gases nas concentrações recomendadas pelo fabricante $\left(\mathrm{O}_{2}\right.$ e $\left.\mathrm{CO}_{2}\right)$, troca da célula de medição de $\mathrm{O}_{2}$ e testes gerais.

Todo trabalho que envolve a análise do sinal eletromiográfico sempre aborda um tema controverso. Em se tratando especificamente do sistema de aquisição do sinal se destaca o eletrodo: em relação ao seu posicionamento, área de captação e artefatos de movimento. 


\section{RESULTADOS.}

Neste capítulo serão apresentados os resultados obtidos através do processamento e análises dos dados coletados nos experimentos, de acordo com os métodos e procedimentos descritos no capítulo anterior.

Os resultados foram estruturados de forma a compor três módulos. O primeiro apresenta uma caracterização dos sujeitos submetidos aos testes e o comportamento de algumas variáveis experimentais básicas. O segundo módulo apresenta os resultados representativos do objetivo geral deste estudo mais os resultados referentes aos dois primeiros objetivos específico, e é composto pelos itens: i) resultados do teste descontínuo isométrico; ii) resultados do teste descontínuo isotônico com peso fixo; iii) resultados do teste descontínuo no ergômetro.

No último modulo organizou-se os resultados referentes ao último objetivo específico, apresentando as análises das bandas de freqüência isoladas, através do método das principais componentes (PCA). O item que compõe este módulo apresenta dados periféricos ao foco central deste estudo, mas que serão de fundamental importância no processo de discussão global deste capítulo.

\subsection{Caracterização dos sujeitos da amostra.}

Inicialmente a tabela 2 apresenta os resultados dos testes de $\mathrm{VO}_{2}$ máximo e a pontuação do questionário IPAQ, para cada sujeito. O valor do coeficiente de variação $(\mathrm{CV})$ para o $\mathrm{VO}_{2}$ máximo, apresenta uma dispersão em torno da média na ordem de $15 \%$. Para a pontuação no questionário IPAQ o CV calculado é de $23 \%$.

\subsection{Parâmetros temporais relacionados aos testes de fadiga.}

Neste estudo o tempo total de exercício foi considerado como o momento de exaustão do sujeito. Os parâmetros que determinam este momento variam para cada teste de acordo com a figura 20 no item 4.6.1. 
TABELA 2- Valores do $\mathrm{VO}_{2}$ máximo e pontuação do questionário IPAQ para o grupo de sujeitos selecionados para este estudo.

\begin{tabular}{cccc}
\hline & VO $_{2}$ máximo & \multicolumn{2}{c}{ Pontuação IPAQ } \\
\cline { 2 - 4 } Sujeitos & ml/kg/min & $\begin{array}{c}\text { MET - } \\
\text { min/semana }\end{array}$ & Classificação \\
\hline 1 & 54.6 & 2844 & Moderado \\
2 & 39.8 & 1297 & Moderado \\
3 & 44.2 & 3900 & Alto \\
4 & 51.1 & 2900 & Moderado \\
5 & 47.3 & 2718 & Moderado \\
6 & 58.8 & 3800 & Alto \\
7 & 39.8 & 3700 & Alto \\
8 & 41.2 & 3850 & Alto \\
9 & 59.5 & 2500 & Moderado \\
10 & 64.1 & 4200 & Alto \\
11 & 52.2 & 3900 & Alto \\
12 & 41.6 & 2560 & Moderado \\
13 & 46.4 & 3250 & Alto \\
14 & 51.4 & 3600 & Alto \\
15 & 46.6 & 3250 & Alto \\
\hline Média (SD) & $49.2 \pm 7.5$ & $3217 \pm 762$ & \\
CV & $15 \%$ & $\mathbf{2 3 \%}$ & \\
\hline
\end{tabular}

A figura 23 apresenta os valores médios (SD) para o tempo total do exercício durante os testes de fadiga isométrico e isotônico com peso fixo. Nestes pode-se observar uma tendência de queda entre o tempo total do teste e a porcentagem de carga. Quando os valores médios dos tempos, em cada teste, são comparados verifica-se diferença significativa entre $15 \%-30 \%, 15 \%-45 \%, 15 \%-60 \%, 30 \%$ $45 \%$ e $30 \%-60 \%$, para ambos os testes. Apenas nas cargas $45 \%$ e $60 \%$ observouse diferença significativa entre os testes.

Os valores médios (SD) do tempo total de exercício do teste no ergômetro, são apresentados na figura 24. Nesta figura, também, se observa uma tendência de queda entre o tempo total do teste e a porcentagem de carga. A comparação dos tempos demostrou diferença significativa entre as cargas $70 \%-90 \%, 70 \%-100 \%$, $80 \%-90 \%$ e $80 \%-100 \%$. 


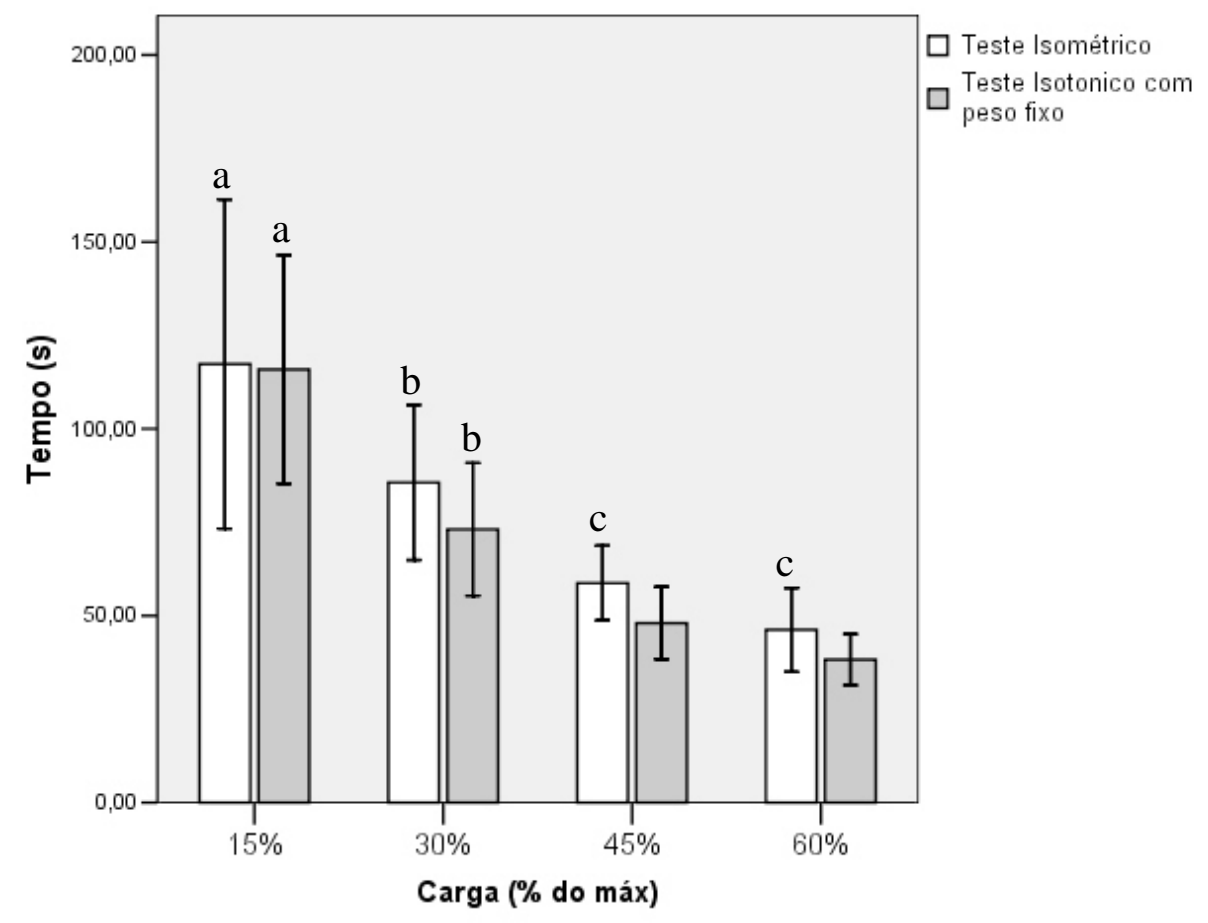

FIGURA 23 - Valores médios e desvio padrão do tempo de exercício no teste isométrico e isotônico com peso fixo a $15 \%, 30 \%, 45 \%$ e $60 \%$ correpondente a carga máxima $(n=15)^{a}$ Diferença significativa em relação a carga $30 \%, 45 \%$ e $60 \%$. ${ }^{b}$ Diferença significativa em relação a carga $45 \%$ e $60 \%$. ${ }^{\circ}$ Diferença significativa em relação ao teste isotônico.

Um parâmetro temporal importante na padronização do teste de fadiga isotônico foi a velocidade angular com que o sujeito executou os movimentos. A figura 25 apresenta a distribuição das velocidades calculadas entre $30^{\circ}$ e $80^{\circ}$ da extensão de perna. Ressalta-se que o sujeito realizou este teste a um ritmo de 60 bpm, conforme descrito no 4.2.3 do capítulo anterior.

Uma análise descritiva da figura indica uma leve tendência a queda da velocidade em função do aumento da carga. A velocidade média para os 15 sujeitos nas cargas $15 \%, 30 \%, 45 \%$ e $60 \%$ foram de $167 \pm 22.3 \%$ s, $160.6 \pm 19.3 \%$ s, 148.6 $\pm 18.2 \%$ s, $141.3 \pm 12.6 \%$, respectivamente. Quando os valores médios da velocidade são comparados, não se observou diferença significativa entre as cargas $(p>0.05)$. 


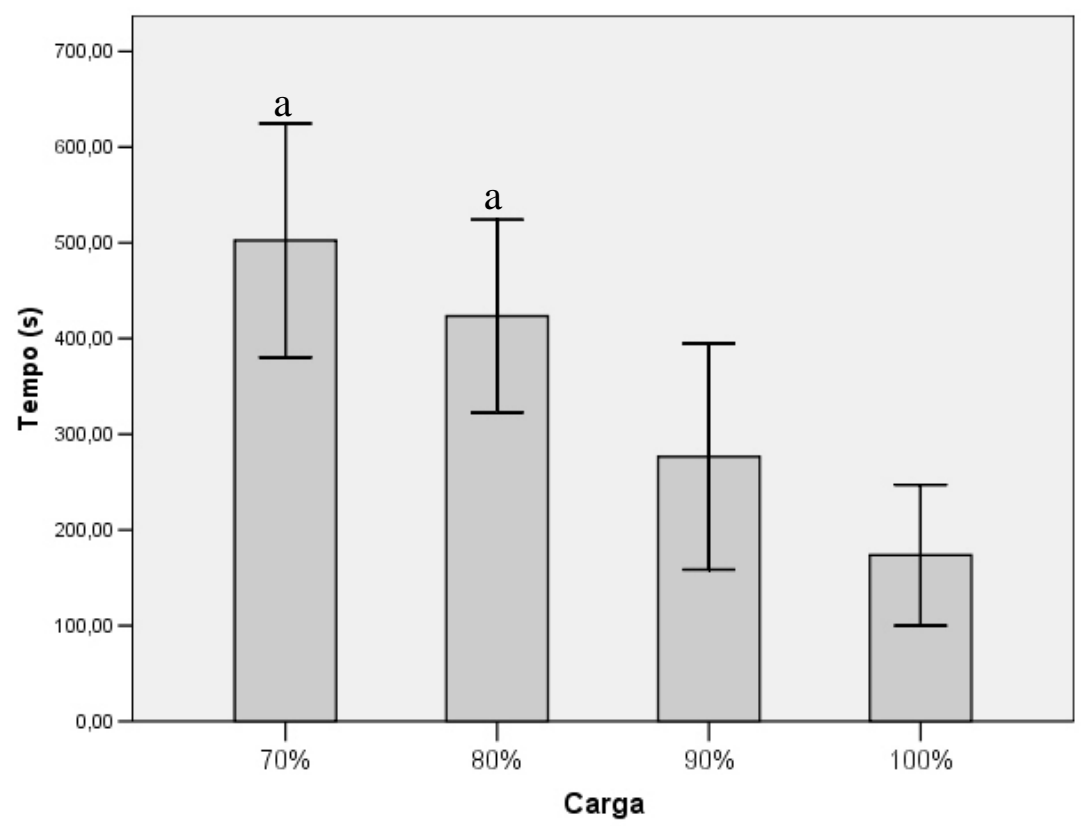

FIGURA 24 - Valores médios e desvio padrão do tempo de exercício do teste no ergômetro a 70\%, $80 \%, 90 \%$ e $100 \%$ correpondente ao $\mathrm{VO}_{2}$ máximo $(\mathrm{n}=15) .{ }^{\mathrm{a}}$ Diferença significativa em relação a carga $90 \%$ e $100 \%$.

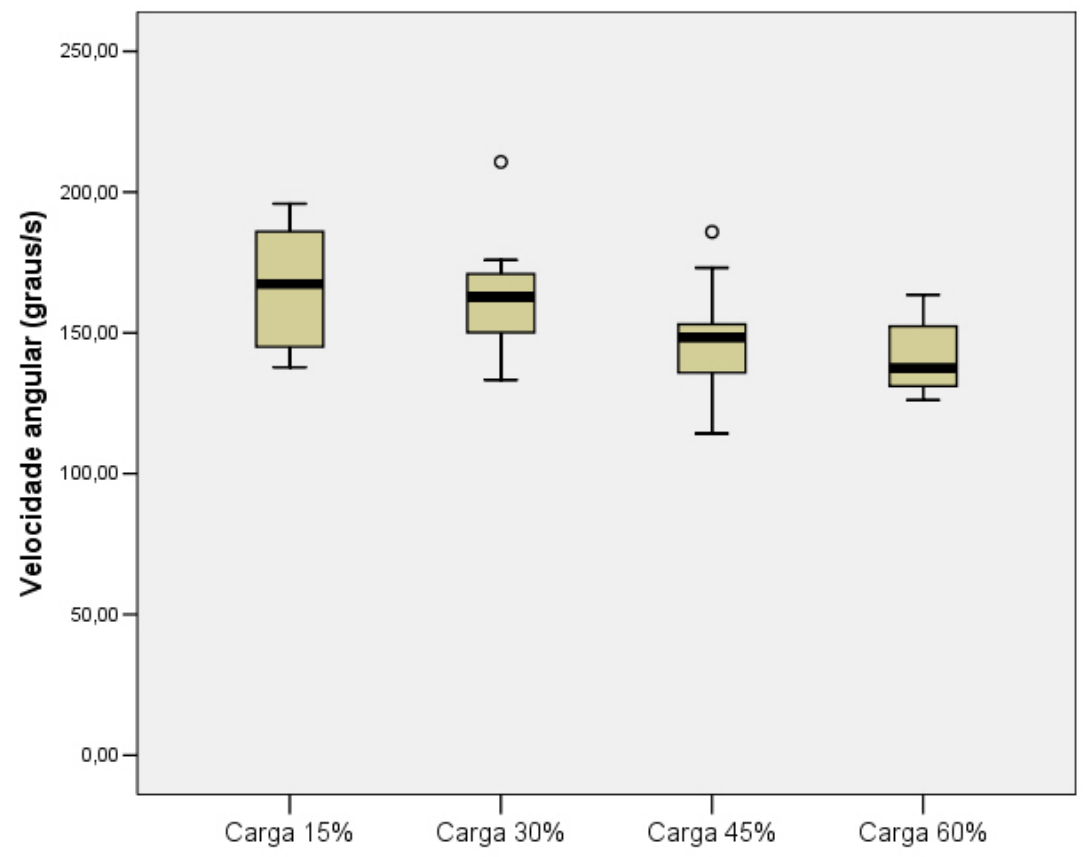

FIGURA 25 - Distribuição das velocidades calculadas entre $30^{\circ}$ e $80^{\circ}$ da extensão de perna, para $15 \%, 30 \% 45 \%$ e $60 \%$ referentes a carga máxima no teste isotônico. 


\subsection{Resultados do teste descontínuo isométrico.}

5.3.1. Coeficientes de inclinação e limiar de fadiga eletromiográfico.

A figura 26 apresenta a distribuição dos coeficientes de inclinação obtidos do ajuste entre as Fmed e o tempo de exercício nos testes de fadiga. A análise descritiva do comportamento destes coeficientes indica um aumento linear, em módulo, na inclinação da reta ajustada aos valores de freqüência mediana, relativo à carga executada pelo sujeito durante o teste. Percebe-se também uma menor variação dos coeficientes nas cargas mais baixas (15-30\%), para as três porções musculares.

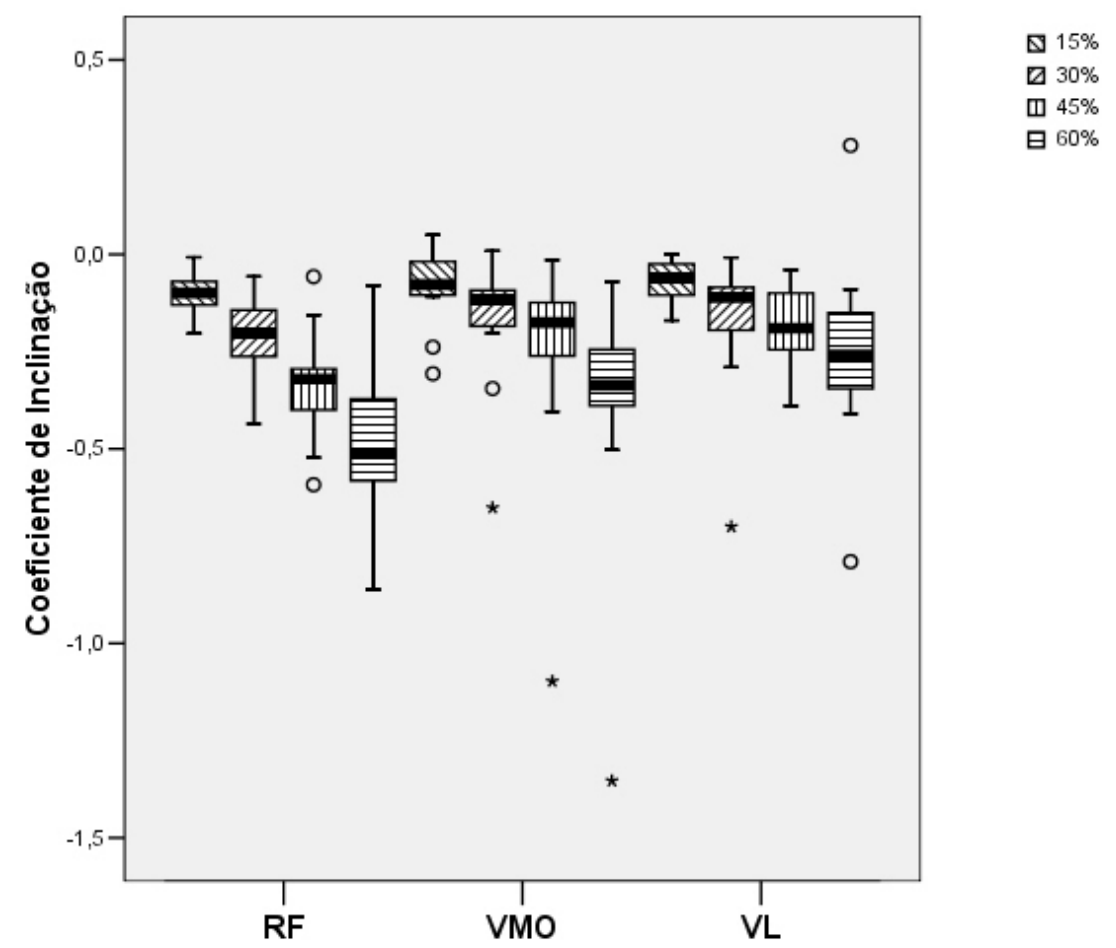

FIGURA 26 - Coeficientes de inclinação obtidos nas três porções do músculo quadríceps. 
A tabela 3 mostra a comparação entre os valores médios dos coeficientes, obtidos a partir do tratamento estatístico, para um mesmo músculo nas diferentes cargas e para uma mesma carga nos diferentes músculos.

$\mathrm{Na}$ comparação entre os músculos, observa-se diferença significativa apenas entre o vasto lateral e o reto femoral para a carga $60 \%$. Comparando-se as cargas para um mesmo músculo, observaram-se diferenças significativas: i) no vasto lateral entre $15-45 \%$, 15-60\%, 30-60\% e 45-60\%; ii) na porção do reto femoral para $15-30 \%$, $15-45 \%, 15-60 \%$; iii) na porção do vasto medial para $15-60 \%$ e $30-60 \%$. A partir desta análise percebe-se que existem diferenças principalmente entre as cargas não adjacentes.

TABELA 3- Valores médios $( \pm S D)$ dos coeficientes de inclinação da freqüência mediana em função do tempo de exercício, para as porções do VL, VM e RF durante o teste de fadiga isométrico a $15 \%, 30 \%, 45 \%$ e $60 \%$ correspondente a carga máxima $(\mathrm{n}=15)$.

\begin{tabular}{|c|c|c|c|c|c|}
\hline & b 15\% & b 30\% & b 45\% & b 60\% & $p$ \\
\hline RF & $\begin{array}{c}-0,1^{b, c, d} \\
\pm 0,04\end{array}$ & $\begin{array}{c}-0,21 \\
\pm 0,1\end{array}$ & $\begin{array}{l}-0,34 \\
\pm 0,13\end{array}$ & $\begin{array}{l}-0,47 \\
\pm 0,19\end{array}$ & $<0.05$ \\
\hline VM & $\begin{array}{l}-0,08^{d} \\
\pm 0,09\end{array}$ & $\begin{array}{l}-0.16^{d} \\
\pm 0,15\end{array}$ & $\begin{array}{l}-0,24 \\
\pm 0,25\end{array}$ & $\begin{array}{l}-0,38 \\
\pm 0,22\end{array}$ & $<0.05$ \\
\hline VL & $\begin{array}{c}-0,07^{c, d} \\
\pm 0,05\end{array}$ & $\begin{array}{l}-0,16^{d} \\
\pm 0,16\end{array}$ & $\begin{array}{c}-0,18^{d} \\
\pm 0,1\end{array}$ & $\begin{array}{l}-0,24^{a} \\
\pm 0,22\end{array}$ & $<0.05$ \\
\hline$p$ & NS & NS & NS & $<0.05$ & 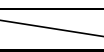 \\
\hline
\end{tabular}

Sabe-se que os coeficientes de inclinação, apresentados anteriormente, são obtidos através de ajustes lineares das Fmed em função do tempo de exercício. Assim, para estabelecer a qualidade destes ajustes, analisou-se o coeficiente de correlação ( $r$ ) e o $\mathbf{p}$ valor para o teste $\mathbf{t}$ do coeficiente de inclinação da reta. A tabela 4 apresenta uma análise descritiva dos valores destes parâmetros. Sobre o coeficiente de correlação (r), observa-se que existe a tendência na melhora da 
associação entre a Fmed e o tempo de exercício, à medida que a carga aumenta. Mesmo os valores mínimos de $\mathbf{r}$ indicam melhor correlação entre as variáveis nas cargas mais altas (45 - 60\%). A porção do RF foi a que apresentou, em média, a melhor correlação para todas as cargas.

Tabela 4 - Parâmetros relacionados a qualidade dos ajustes lineares das Fmed em função do tempo de exercício, durante os testes de fadiga na modalidade de exercício isométrico.

\begin{tabular}{|c|c|c|c|c|c|c|c|c|c|c|c|c|c|c|c|c|}
\hline & \multicolumn{4}{|c|}{ Carga 15\% } & \multicolumn{4}{|c|}{ Carga 30\% } & \multicolumn{4}{|c|}{ Carga 45\% } & \multicolumn{4}{|c|}{ Carga $60 \%$} \\
\hline & \multicolumn{2}{|c|}{ Correlação (r) } & \multicolumn{2}{|c|}{ Inclinação (Cl) } & \multicolumn{2}{|c|}{ Correlação (r) } & \multicolumn{2}{|c|}{ Inclinação (Cl) } & \multicolumn{2}{|c|}{ Correlação (r) } & \multicolumn{2}{|c|}{ Inclinação (Cl) } & \multicolumn{2}{|c|}{ Correlação (r) } & \multicolumn{2}{|c|}{ Inclinação (Cl) } \\
\hline & $\mathrm{m}(\mathrm{sd})$ & $\begin{array}{l}\text { Max.I } \\
\text { min. }\end{array}$ & $\mathrm{m}(\mathrm{sd})$ & $\mathrm{P}<0.05$ & $\mathrm{~m}(\mathrm{sd})$ & $\begin{array}{l}\text { Max.I } \\
\text { min. }\end{array}$ & $\mathrm{m}(\mathrm{sd})$ & $P<0.05$ & $\mathrm{~m}(\mathrm{sd})$ & $\begin{array}{l}\text { Max.I } \\
\text { min. }\end{array}$ & $\mathrm{m}(\mathrm{sd})$ & $P<0.05$ & $\mathrm{~m}(\mathrm{sd})$ & $\begin{array}{l}\text { Max.I } \\
\text { min. }\end{array}$ & $\mathrm{m}(\mathrm{sd})$ & $P<0.05$ \\
\hline RF & $\begin{array}{c}0.58 \\
\pm 0.16\end{array}$ & $\begin{array}{l}0.80 / \\
0.26\end{array}$ & $\begin{array}{c}-0,1 \\
\pm 0,04\end{array}$ & $100 \%$ & $\begin{array}{c}0.76 \\
\pm 0.13\end{array}$ & $\begin{array}{l}0.921 \\
0.51\end{array}$ & $\begin{array}{l}-0,21 \\
\pm 0,1\end{array}$ & $94 \%$ & $\begin{array}{c}0.83 \\
\pm 0.08\end{array}$ & $\begin{array}{l}0.921 \\
0.64\end{array}$ & $\begin{array}{c}-0,34 \\
\pm 0,13\end{array}$ & $94 \%$ & $\begin{array}{c}0.84 \\
\pm 0.12\end{array}$ & $\begin{array}{l}0.96 / \\
0.46\end{array}$ & $\begin{array}{r}-0,47 \\
\pm 0,19\end{array}$ & $94 \%$ \\
\hline VMO & $\begin{array}{c}0.44 \\
\pm 0.24\end{array}$ & $\begin{array}{c}0.87 / \\
0\end{array}$ & $\begin{array}{l}-0,08 \\
\pm 0,09\end{array}$ & $80 \%$ & $\begin{array}{c}0.58 \\
\pm 0.26\end{array}$ & $\begin{array}{l}0.871 \\
0.04\end{array}$ & $\begin{array}{c}-0.16 \\
\pm 0,15\end{array}$ & $87 \%$ & $\begin{array}{c}0.63 \\
\pm 0.22\end{array}$ & $\begin{array}{l}0.921 \\
0.07\end{array}$ & $\begin{array}{r}-0,24 \\
\pm 0,25\end{array}$ & $87 \%$ & $\begin{array}{c}0.77 \\
\pm 0.13\end{array}$ & $\begin{array}{l}0.91 / \\
0.33\end{array}$ & $\begin{array}{r}-0,38 \\
\pm 0,22\end{array}$ & $87 \%$ \\
\hline VL & $\begin{array}{c}0.46 \\
\pm 0.26\end{array}$ & $\begin{array}{c}0.79 / \\
0\end{array}$ & $\begin{array}{l}-0,07 \\
\pm 0,05\end{array}$ & $74 \%$ & $\begin{array}{c}0.57 \\
\pm 0.25\end{array}$ & $\begin{array}{c}0.871 \\
0\end{array}$ & $\begin{array}{c}-0,16 \\
\pm 0,16\end{array}$ & $94 \%$ & $\begin{array}{c}0.62 \\
\pm 0.22\end{array}$ & $\begin{array}{l}0.89 / \\
0.13\end{array}$ & $\begin{array}{l}-0,18 \\
\pm 0,1\end{array}$ & $80 \%$ & $\begin{array}{c}0.70 \\
\pm 0.17\end{array}$ & $\begin{array}{l}0.96 / \\
0.27\end{array}$ & $\begin{array}{c}-0,24 \\
\pm 0,22\end{array}$ & $87 \%$ \\
\hline
\end{tabular}

A quantidade de ajustes cuja inclinação não se diferenciou significativamente de zero $(p<0.05)$, foi em média de $13 \%$. Nestes casos observou-se que apesar da inclinação da reta ajustada apresentar um valor negativo, este não era estatisticamente diferente de zero.

A partir destes coeficientes de inclinação foram obtidos os Limiares de Fadiga para as três porções musculares. A figura 27 apresenta a distribuição dos limiares de fadiga muscular localizada obtidos nos testes descontínuos em isometria $(n=15)$. Os valores médios $( \pm S D)$ do LFE para as porções do RF, $V M, V L$ e foram respectivamente $7.9 \pm 5.1 \%, 14.2 \pm 13.0 \%$ e $15 \pm 13.1 \%$ em porcentagem da CVIM. Comparando-se estes valores não se observou diferenças significativas entre as porções $(p>0.05)$. 


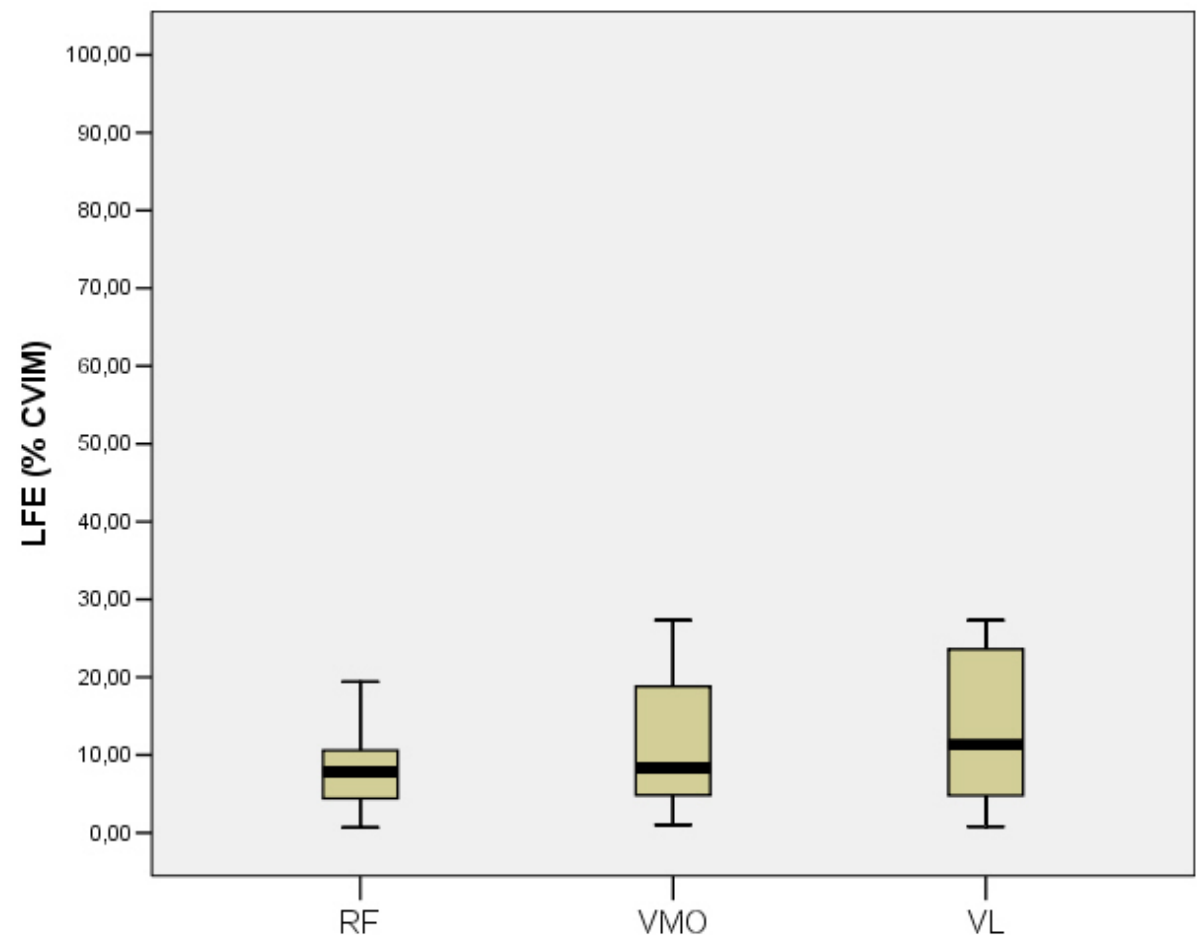

FIGURA 27- Limiares de fadiga eletromiográfico obtidos durante o teste de fadiga isométrico.

Uma análise descritiva da figura 27 indica uma menor dispersão nos valores do LFE para a porção do RF. Apesar do VL e VM apresentarem uma dispersão maior nos valores do LFE, o comportamento das medianas estão próximos para as três porções.

5.3.2. Resultados da análise do comportamento da freqüência mediana inicial e final durante os testes de fadiga isométrico.

Os resultados referentes às análises das freqüências medianas no início do exercício e quando o sujeito se encontra no estado de exaustão são apresentados nas tabelas 5 e 6 , respectivamente.

Comparando os valores médios, normalizados, da Fmed no início do exercício para as quatro cargas, somente observou-se diferença significativa para o músculo VL entre a carga $15 \%$ e $60 \%$. 
TABELA 5 - Valores médios $( \pm S D)$, normalizados ${ }^{2}$, da Fmed no início do exercício para as porções do VL, VM e RF durante o teste de fadiga isométrico a $15 \%, 30 \%, 45 \%$ e $60 \%$ correspondente a carga máxima $(n=15)$.

\begin{tabular}{cccc}
\hline \multirow{2}{*}{ Cargas } & \multicolumn{3}{c}{ Músculos } \\
\cline { 2 - 4 } & RF & VM & VL \\
\cline { 2 - 4 } $15 \%$ & 21.0 & 22.8 & $20.8^{\text {a }}$ \\
& \pm 9.3 & \pm 9.5 & \pm 7.5 \\
\cline { 2 - 4 } $30 \%$ & 27.7 & 25.0 & 25.2 \\
& \pm 9.7 & \pm 8.0 & \pm 5.5 \\
\cline { 2 - 4 } $45 \%$ & 25.2 & 25.5 & 25.4 \\
& \pm 9.9 & \pm 8.3 & \pm 7.0 \\
\cline { 2 - 4 } $60 \%$ & 24.6 & 27.2 & 30.0 \\
& & \pm 9.0 & \pm 10.5 \\
\hline $\mathbf{p}$ & NS & NS & $<0.05$ \\
\hline
\end{tabular}

${ }^{a}$ Diferença significativa em relação a $60 \%$.

Quando comparado os valores médios, normalizados, da Fmed no final do exercício (exaustão), para as quatro cargas, observou-se diferença significativa: i) para o músculo RF entre $15-45 \%$ e $15-60 \%$; ii) para o músculo VM entre $15-60 \%$. Para o músculo RF não foram observadas diferenças significativas. A queda média do valor da Fmed do início para o fim do exercício (exaustão), nas quatro cargas, foram de $24 \%$ para a porção do RF, $18 \%$ para o VL e $19 \%$ para o VM.

\subsubsection{Resultados do pós-teste isométrico.}

Como descrito no item 4.2.4 do capítulo anterior, os sujeitos retornaram ao laboratório para realizar o exercício na intensidade do seu respectivo LFE. Nestes testes analisou-se o tempo de fadiga e exaustão com referência ao tempo total de exercício na carga $15 \%$, tabela 7 . Também analisou-se os valores da Fmed em três

\footnotetext{
${ }^{2}$ Normalizado conforme procedimento descrito no item 4.6.1 do capítulo anterior.
} 
momentos distintos: início do exercício, início da fadiga e exaustão, tabela 8. Lembrando que os momentos denominados de início da fadiga e exaustão, foram determinados conforme os procedimentos descritos no item 4.4 .5 do capítulo anterior.

TABELA 6 - Valores médios ( \pm SD), normalizados ${ }^{1}$, da Fmed no final do exercício (exaustão) para as porções do VL, VM e RF durante o teste de fadiga isométrico a $15 \%$, $30 \%, 45 \%$ e $60 \%$ correspondente a carga máxima $(n=15)$.

\begin{tabular}{cccc}
\hline \multirow{2}{*}{ Cargas } & \multicolumn{3}{c}{ Músculos } \\
\cline { 2 - 4 } & RF & VM & VL \\
\hline \multirow{2}{*}{$15 \%$} & $0.83^{\text {a,b }}$ & $0.88^{\mathbf{b}}$ & 0.84 \\
& \pm 0.08 & \pm 0.11 & \pm 0.1 \\
\cline { 2 - 4 } $30 \%$ & 0.76 & 0.8 & 0.82 \\
& \pm 0.09 & \pm 0.09 & \pm 0.07 \\
\cline { 2 - 4 } $45 \%$ & 0.74 & 0.8 & 0.84 \\
& \pm 0.09 & \pm 0.08 & \pm 0.05 \\
\hline $60 \%$ & 0.73 & 0.77 & 0.81 \\
& & \pm 0.09 & \pm 0.05 \\
\hline $\mathbf{p}$ & $<0.05$ & $<0.05$ & $\mathrm{NS}$ \\
\hline
\end{tabular}

${ }^{a}$ Diferença significativa em relação à $45 \%$.

${ }^{\mathrm{b}}$ Diferença significativa em relação à $60 \%$.

A figura 28 mostra os gráficos representativos da distribuição dos valores da Fmed nos três momentos, para as três porções musculares. Analisando a figura, constata-se que para a porção do VM e VL, existe uma queda nos valores da Fmed entre os momentos selecionados. Na porção do RF esta queda é mais acentuada entre o início do exercício e o momento de exaustão. Ainda, no momento de exaustão existe uma maior dispersão das amostras nos seus extremos, porém os valores centrais bem como a mediana estão coerentes com os encontrados para as outras porções musculares no mesmo momento. 


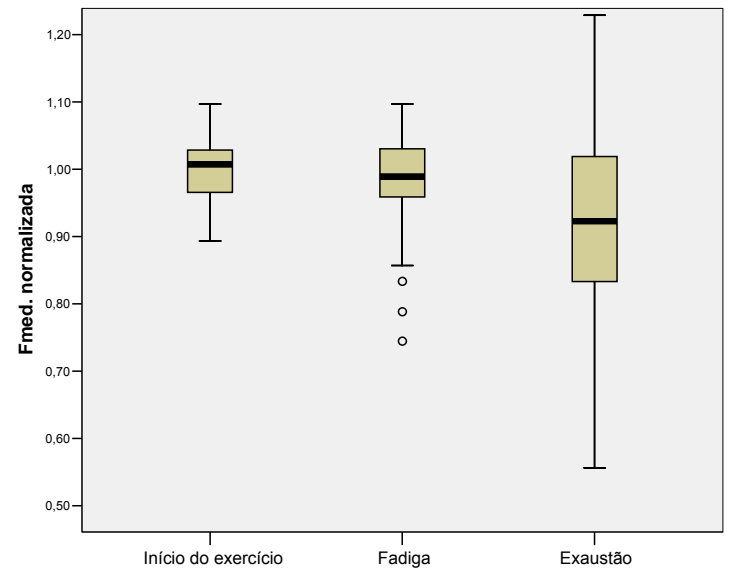

RF

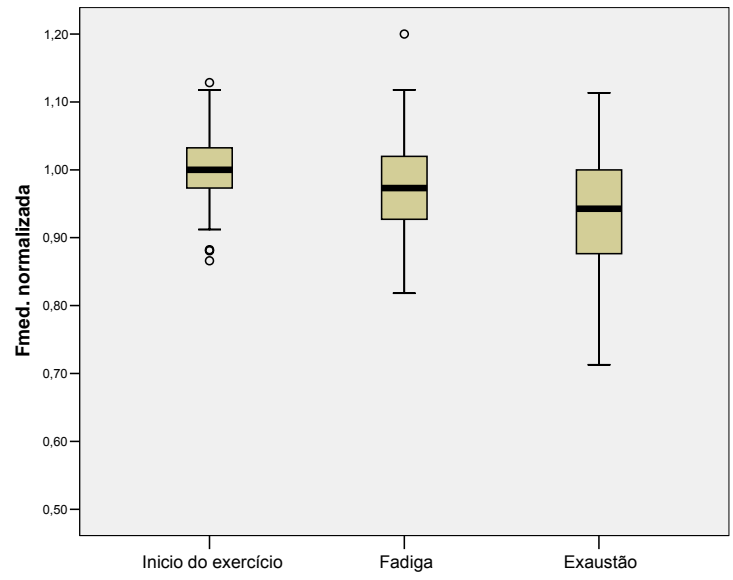

VM

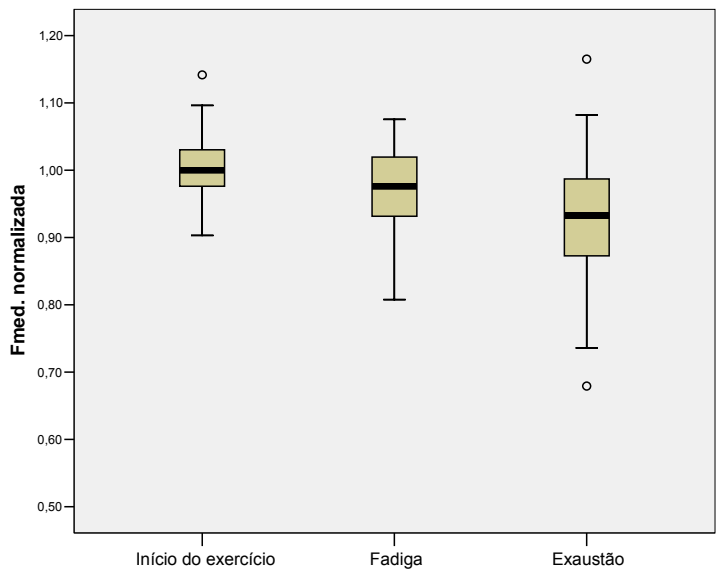

VL

FIGURA 28- Gráficos representativos da distribuição das amostras durante os três momentos selecionados no pós-teste isométrico, para as três porções musculares: RF, VM e VL.

Quando comparado os valores médios da Fmed no momento de exaustão do pós-teste em relação à exaustão durante o teste com carga de $15 \%$, observou-se diferença significativa $(p<0.05)$ para o VL, RF e VM. No teste com carga de $15 \%$ os valores da Fmed foram em média 7\% menores que no momento de exaustão do pósteste, para todas as porções musculares.

O momento de fadiga durante o pós-teste foi menor que tempo total de exercício na carga $15 \%$, para as três porções musculares. Outro fato é que, em média, o tempo de fadiga no pós-teste, para as três porções, foi de $54 \%$ em relação ao tempo de exaustão. Este por sua vez foi, em média, 34\% maior que o tempo total de exercício do teste com carga de $15 \%$. Também não se observou diferenças 
significativas ( $p>0.05)$ na comparação entre os tempos médios de fadiga no pósteste, quando considerado todas as porções musculares.

TABELA 7 - Valores médios ( \pm SD), da Fmed normalizada ${ }^{3}$ para as porções do VL, VM e RF nos momentos de início do exercício, fadiga e exaustão no pós-teste $(n=15)$.

\begin{tabular}{|c|c|c|c|}
\hline \multirow{2}{*}{ Momentos } & \multicolumn{3}{|c|}{ Músculos } \\
\hline & $\mathbf{R F}$ & VM & VL \\
\hline Início do exercício & $\begin{array}{l}1.00^{\mathbf{a}, \mathbf{b}} \\
\pm 0.04\end{array}$ & $\begin{array}{c}0.99^{\mathbf{a}, \mathbf{b}} \\
\pm 0.4\end{array}$ & $\begin{array}{l}0.99^{b} \\
\pm 0.04\end{array}$ \\
\hline Fadiga & $\begin{array}{l}0.97^{b} \\
\pm 0.07\end{array}$ & $\begin{array}{l}0.97^{b} \\
\pm 0.05\end{array}$ & $\begin{array}{l}0.98^{b} \\
\pm 0.06\end{array}$ \\
\hline Exaustão & $\begin{array}{c}0.93 \\
\pm 0.08\end{array}$ & $\begin{array}{c}0.92 \\
\pm 0.08\end{array}$ & $\begin{array}{c}0.91 \\
\pm 0.12\end{array}$ \\
\hline $\mathbf{p}$ & $<0.05$ & $<0.05$ & $<0.05$ \\
\hline
\end{tabular}

\footnotetext{
${ }^{a}$ Diferença significativa em relação ao momento de fadiga.

${ }^{\mathrm{b}}$ Diferença significativa em relação ao momento de exaustão.
}

TABELA 8 - Valores médios ( $\pm S D$ ), dos tempos, em segundos, para as porções do VL, VM e RF nos momentos de fadiga e exaustão durante o pós-teste e o tempo total de exercício na carga $15 \%$ do teste de fadiga isométrico $(n=15)$.

\begin{tabular}{cccc}
\hline & & Músculos & \\
Tempos (s) & RF & VM & VL \\
\cline { 2 - 4 } & $120^{\mathrm{a}}$ & $120^{\mathrm{a}}$ \\
Tempo total carga 15\% & \pm 29 & \pm 29 & $120^{\mathrm{a}}$ \\
\cline { 2 - 4 } & $85^{\mathrm{a}}$ & $110^{\mathrm{a}}$ & $103^{\mathrm{a}}$ \\
Tempo da fadiga & \pm 65 & \pm 62 & $\pm 77^{2}$ \\
pós-teste & 183 & 183 & 183 \\
Tempo da exaustão & \pm 63 & \pm 63 & \pm 63 \\
pós-teste & $<0.05$ & $<0.05$ & $<0.05$
\end{tabular}

${ }^{a}$ Diferença significativa em relação ao tempo da exaustão no pós-teste.

\footnotetext{
${ }^{3}$ Normalizado conforme procedimento descrito no item 4.5 .2 do capítulo anterior.
} 


\subsection{Resultados do teste descontínuo isotônico com peso fixo.}

\subsubsection{Coeficiente de inclinação e limiar de fadiga eletromiográfico.}

A figura 29 apresenta a distribuição dos coeficientes de inclinação obtidos do ajuste entre as Fmed e o tempo de exercício nos testes de fadiga. A análise descritiva do comportamento dos coeficientes indica um aumento linear, em módulo, na inclinação da reta ajustada aos valores de freqüência mediana, relativo à carga executada pelo sujeito durante o teste. Assim como no teste isométrico, percebe-se também uma menor variação das amostras nas cargas mais baixas $15-30 \%$, para as três porções musculares, com exceção da carga $45 \%$ no VL.

Comparando os valores médios dos coeficientes para um mesmo músculo nas diferentes cargas e para uma mesma carga nos diferentes músculos, obteve-se os resultados compilados na tabela 9 . Na comparação dos coeficientes de inclinação, entre os músculos, não se observa diferença significativa entre as porções musculares $(p>0.05)$. Comparando-se as cargas para um mesmo músculo, verificaram-se diferenças significativas: i) no vasto lateral entre $15-45 \%$ e $15-60 \%$; ii) na porção do vasto medial entre $15-45 \%$ e $15-60 \%$; iii) na porção do reto femoral, também, entre $15-45 \%$ e $15-60 \%$.

Assim como no teste anterior, também analisou-se o coeficiente de correlação (r) e $\circ \mathbf{p}$ valor para o teste $\mathbf{t}$ do coeficiente de inclinação da reta. A tabela 10 apresenta os resultados de uma análise descritiva dos valores destes parâmetros. $O$ coeficiente $r$ indica que existe a tendência na melhora da associação entre a Fmed e o tempo de exercício, à medida que a carga aumenta. Entretanto se compararmos estes resultados com os do teste anterior, verifica-se que os valores médios de $r$ são ligeiramente maiores no exercício isométrico, principalmente nas cargas 45 e 60\%.

Já a quantidade de ajustes cuja inclinação não se diferenciou significativamente de zero $(p<0.05)$, foi superior ao teste isométrico. Nestes casos observou-se que apesar da inclinação da reta ajustada apresentar um valor negativo, este não era estatisticamente diferente de uma inclinação igual a zero. 


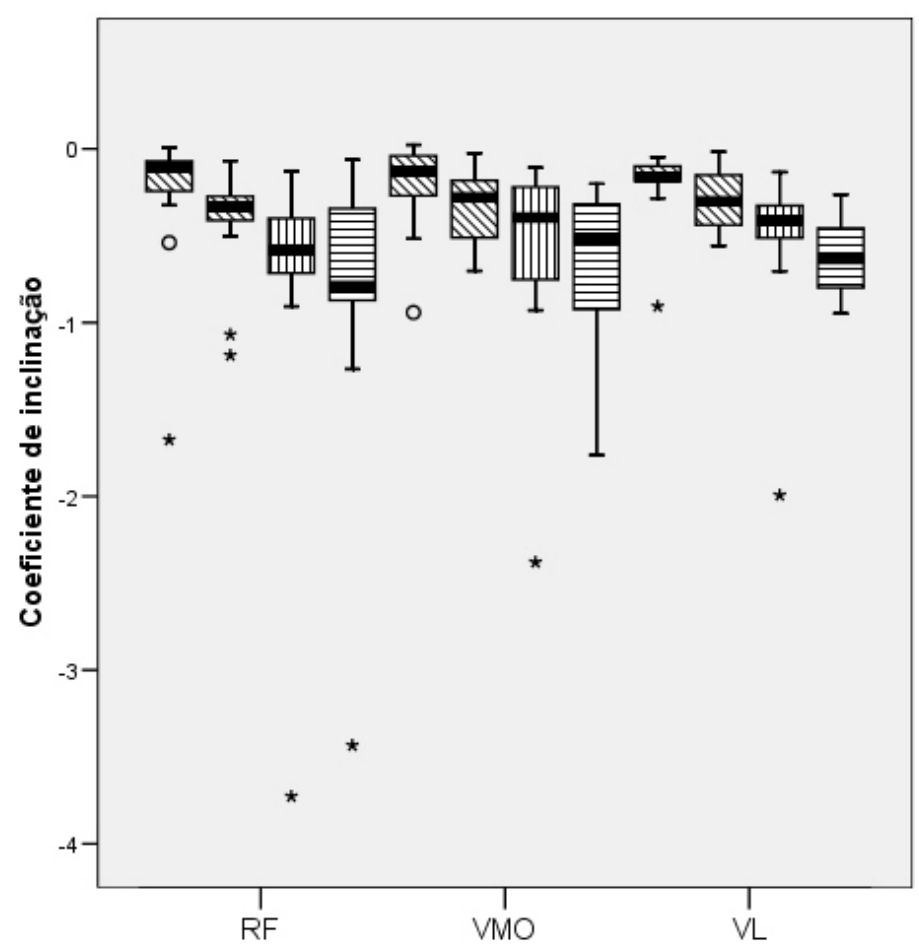

FIGURA 29- Coeficientes de inclinação obtidos durante o teste isotônico com peso fixo, nas três porções do músculo quadríceps.

TABELA 9- Valores médios $( \pm S D$ ) dos coeficientes de inclinação entre a freqüência mediana em função do tempo de exercício, para as porções do VL, VM e RF durante o teste de fadiga isotônico com peso fixo a $15 \%, 30 \%, 45 \%$ e $60 \%$ correspondente a carga máxima $(n=15)$.

\begin{tabular}{|c|c|c|c|c|c|}
\hline & b 15\% & b 30\% & b 45\% & b 60\% & $p$ \\
\hline RF & $\begin{array}{c}-0.25^{\mathrm{a}, \mathrm{b}} \\
\pm 0.41\end{array}$ & $\begin{array}{c}0.41 \\
\pm 0.31\end{array}$ & $\begin{array}{l}-0.73 \\
\pm 0.85\end{array}$ & $\begin{array}{l}-0.81 \\
\pm 0.8\end{array}$ & NS \\
\hline VM & $\begin{array}{c}-0.20^{a, b} \\
\pm 0.25\end{array}$ & $\begin{array}{r}-0.30 \\
\pm 0.19\end{array}$ & $\begin{array}{l}-0.54 \\
\pm 0.43\end{array}$ & $\begin{array}{l}-0.67 \\
\pm 0.47\end{array}$ & $<0.05$ \\
\hline VL & $\begin{array}{c}-0.19^{a, b} \\
\pm 0.20\end{array}$ & $\begin{array}{l}-0.29 \\
\pm 0.16\end{array}$ & $\begin{array}{l}-0.51 \\
\pm 0.43\end{array}$ & $\begin{array}{l}-0.63 \\
\pm 0.22\end{array}$ & $<0.05$ \\
\hline$p$ & NS & NS & NS & NS & \\
\hline
\end{tabular}

${ }^{a}$ Diferença significativa em relação a b45\%.

${ }^{\mathrm{b}}$ Diferença significaiva em relação a b60\%. 
TABELA 10 - Parâmetros relacionados à qualidade dos ajustes lineares das Fmed em funcãa do tempo de exercício, durante os testes de fadiga na modalidade de exercício isotônico com peso fixo.

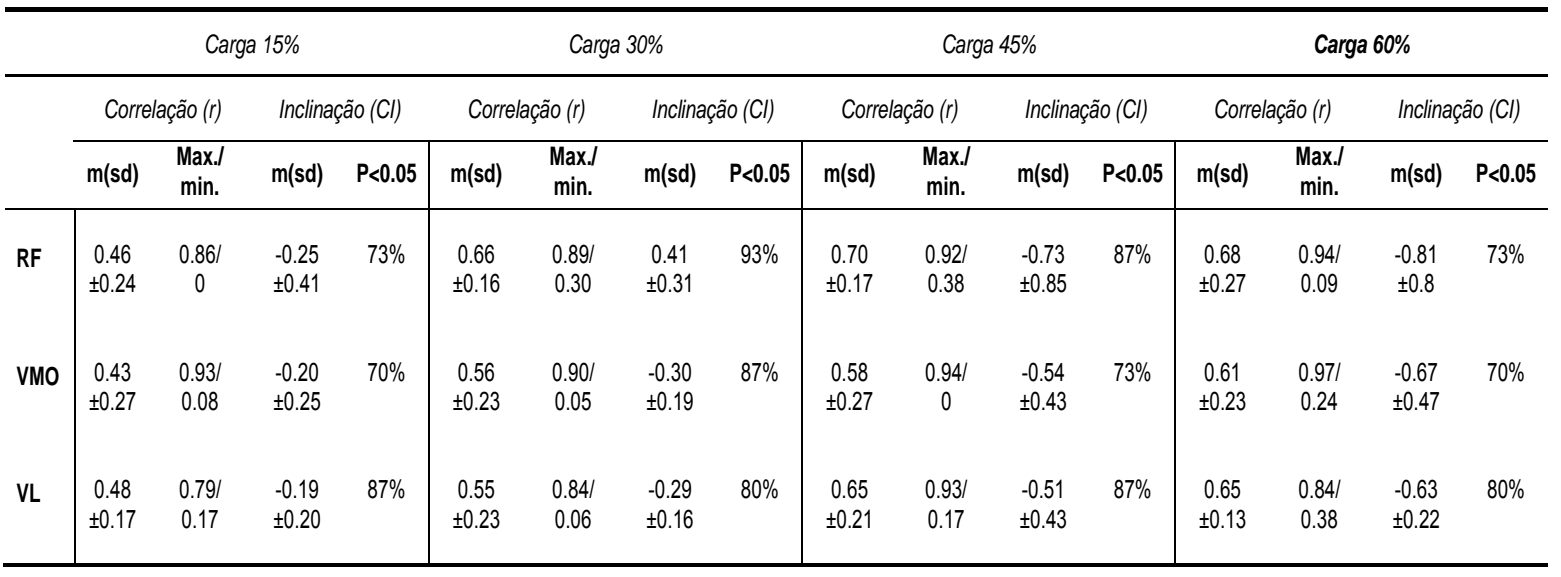

A figura 30 apresenta a distribuição dos limiares de fadiga muscular localizada, obtidos durante o teste de fadiga isotônico com peso fixo $(n=15)$. Os valores médios ( $\pm S D$ ) obtidos para as porções do RF, VM e VL foram respectivamente $11.5 \% \pm 9.5 \%$, 14.7 $\pm 8.3 \%$, $14.2 \pm 15 \%$, em porcentagem da CMI. Comparando-se os valores médios do LFE, não se observou diferenças significativas entre as porções ( $p>0.05)$. Quando estes valores são comparados aos limiares obtidos no teste isométrico, não são verificadas diferenças significativas entre as porções musculares $(p>0.05)$.

Assim como no teste isométrico, a figura 30 indica uma melhor distribuição das amostras para a porção do RF, quando considerado o comportamento das amostras entre o $25^{\circ}$ e $75^{\circ}$ percentil. Comparando-se o comportamento do VM e VL neste teste, em relação ao isométrico, nota-se uma menor dispersão nos valores dos limiares.

5.4.2. Resultados da análise do comportamento da freqüência mediana inicial e final durante os testes de fadiga isotônico com peso fixo.

Os resultados referentes às análises das freqüências medianas no início do exercício e quando o sujeito se encontra no momento de exaustão, são apresentados nas tabelas 11 e 12 , respectivamente. 
Comparando os valores médios, normalizados, da Fmed no início do exercício para as quatro cargas, não foram encontradas diferenças significativas $(p>0.05)$. 0 mesmo comportamento foi observado quando verificado os valores médios da Fmed no final do exercíco (exaustão), também para as quatro cargas.

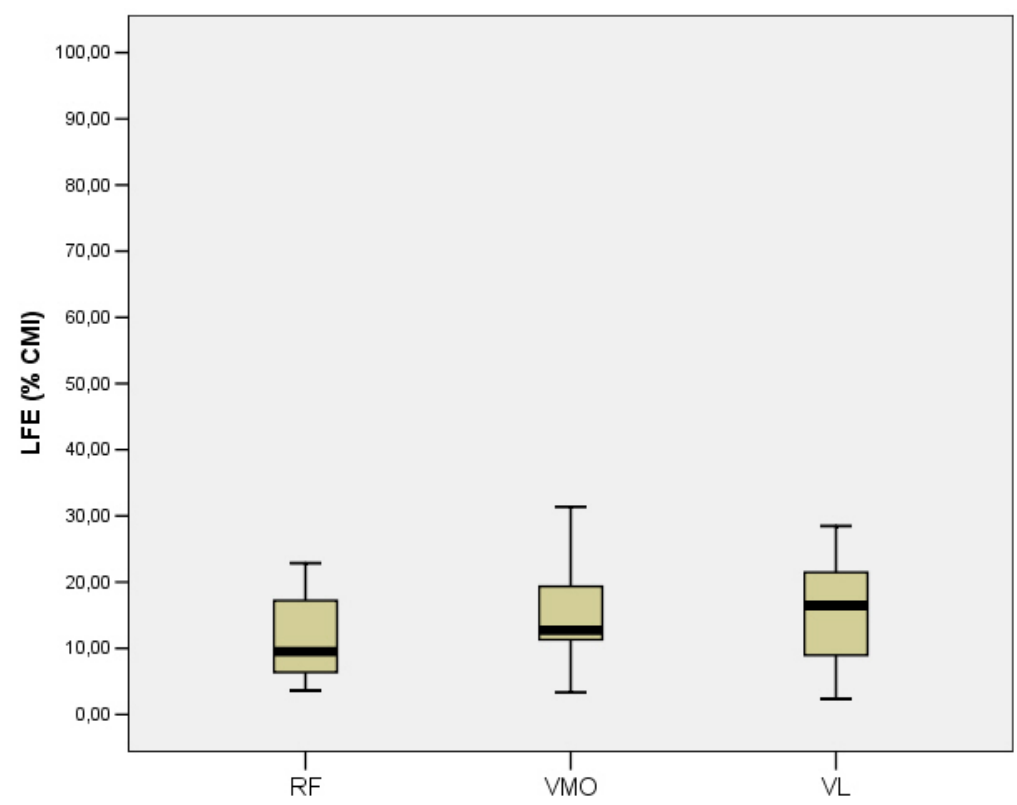

FIGURA 30- Limiares de fadiga muscular localizada obtidos durante o teste de fadiga isotônico com peso fixo.

TABELA 11- Valores médios $( \pm S D)$, normalizados ${ }^{1}$, da Fmed no início do exercício para as porções do VL, VM e RF durante o teste de fadiga isotônico com peso fixo a $15 \%, 30 \%, 45 \%$ e $60 \%$ correspondente a carga máxima $(n=15)$.

\begin{tabular}{cccc}
\hline \multirow{2}{*}{ Cargas } & \multicolumn{3}{c}{ Músculos } \\
\cline { 2 - 4 } & RF & VM & VL \\
\hline \multirow{2}{*}{$15 \%$} & 11.0 & 13.0 & 10.5 \\
& \pm 3.5 & \pm 6.5 & \pm 5.5 \\
\cline { 2 - 4 } $30 \%$ & 12.0 & 17.5 & 13.5 \\
& \pm 5.0 & \pm 9.0 & \pm 6.0 \\
\cline { 2 - 4 } $45 \%$ & 13.3 & 15.5 & 15.0 \\
& \pm 8.8 & \pm 7.0 & \pm 10.0 \\
\cline { 2 - 4 } $60 \%$ & 14.3 & 12.3 & 11.7 \\
& \pm 5.3 & \pm 4.0 & $\mathbf{1}$ \\
\hline $\mathbf{p}$ & $\mathrm{NS}$ & $\mathrm{NS}$ & $\mathrm{NS}$ \\
\hline
\end{tabular}


TABELA 12 - Valores médios ( \pm SD), normalizados ${ }^{1}$, da Fmed no final do exercício (exaustão) para as porcões do VL, e RF durante o teste de fadiga isotônico com peso fixo a $15 \%, 30 \%, 45 \%$ e $60 \%$ correspondente a carga máxima $(n=15)$.

\begin{tabular}{cccc}
\hline \multirow{2}{*}{ Cargas } & \multicolumn{3}{c}{ Músculos } \\
\cline { 2 - 4 } & RF & VM & VL \\
\hline \multirow{2}{*}{$15 \%$} & 0.85 & 0.86 & 0.85 \\
& \pm 0.11 & \pm 0.13 & \pm 0.05 \\
\cline { 2 - 4 } $30 \%$ & 0.82 & 0.82 & 0.85 \\
& \pm 0.08 & \pm 0.08 & \pm 0.06 \\
\cline { 2 - 4 } $45 \%$ & 0.83 & 0.83 & 0.87 \\
& \pm 0.07 & \pm 0.07 & \pm 0.05 \\
\hline $60 \%$ & 0.87 & 0.89 & 0.87 \\
& \pm 0.06 & \pm 0.08 & \pm 0.05 \\
\hline $\mathbf{p}$ & $\mathrm{NS}$ & $\mathrm{NS}$ & $\mathrm{NS}$ \\
\hline
\end{tabular}

5.4.3. Resultados do pós-teste isotônico com peso fixo.

Assim como no teste isométrico, foram analisados o tempo de fadiga e exaustão com referência ao tempo total de exercício na carga 15\%, tabela 14 . Também foram analisados os valores da Fmed em três momentos distintos: início do exercício, fadiga e exaustão, tabela 13. Vale ressaltar que os momentos denominados de fadiga e exaustão foram determinados conforme os procedimentos descritos no item 4.6.1 do capítulo anterior.

A figura 31 mostra os gráficos representativos da distribuição dos valores de Fmed nos três momentos, para as três porções musculares. Analisando a figura, percebe-se uma queda mais acentuada nos valores da Fmed, entre os momentos selecionados, para a porção do RF e VL. Verifica-se que no momento de início da fadiga há um processo de declínio mais acentuado na Fmed.

Observa-se que a queda no valor da Fmed entre o início do exercício e o momento de fadiga foi, em média, de $6 \%$ para a porção do RF e VL, enquanto que para o VM o declínio foi de $3 \%$. Em relação ao momento de exaustão a queda foi, em média, de $20 \%$ também para porção do RF e VL, enquanto que para o VM foi de $7 \%$. 
Quando comparado os valores médios da Fmed no momento de exaustão do pós-teste em relação à exaustão no teste com carga de $15 \%$, observou-se diferença significativa $(p<0.05)$ somente para o VM. Sendo o valor da Fmed, no teste com carga de $15 \%$, em média $7 \%$ menor que no momento de exaustão do pós-teste, para a porção do VM.

Em relação à análise dos tempos, verifica-se que o tempo de fadiga durante o pós-teste foi inferior ao tempo total de exercício na carga 15\%, para as três porções musculares. Outro fato é que, em média, o tempo de fadiga no pós-teste, foi de $73 \%$ em relação ao tempo de exaustão. Este por sua vez foi, em média, $20 \%$ maior que o tempo total de exercício na carga $15 \%$. Também não se observou diferenças significativas ( $p>0.05)$ na comparação entre os tempos médios de fadiga no pósteste, para as três porções musculares.

TABELA 13 - Valores médios ( \pm SD), da Fmed normalizada ${ }^{2}$ para as porções do $V L$, VM e RF nos momentos de início do exercício, fadiga e exaustão no pós-teste $(n=15)$.

\begin{tabular}{cccc}
\hline \multirow{2}{*}{ Momentos } & \multicolumn{3}{c}{ Músculos } \\
\cline { 2 - 4 } & $\mathbf{R F}$ & $\mathrm{VM}$ & $\mathrm{VL}$ \\
\hline \multirow{2}{*}{ Início do exercício } & $1.0^{\mathrm{a}, \mathrm{b}}$ & $1^{\mathrm{b}}$ & $1^{\mathrm{a}, \mathrm{b}}$ \\
& \pm 0.09 & \pm 0.08 & \pm 0.09 \\
\cline { 2 - 4 } Fadiga & $0.94^{\mathrm{b}}$ & $0.97^{\mathrm{b}}$ & $0.94^{\mathrm{b}}$ \\
& \pm 0.07 & \pm 0.09 & \pm 0.06 \\
\cline { 2 - 4 } Exaustão & 0.81 & 0.93 & 0.84 \\
& \pm 0.14 & \pm 0.11 & \pm 0.11 \\
\cline { 2 - 4 } $\mathbf{p}$ & $<0.05$ & $<0.05$ & $<0.05$ \\
\hline
\end{tabular}

${ }^{a}$ Diferença significativa em relação ao momento de fadiga.

${ }^{\mathrm{b}}$ Diferença significativa em relação ao momento de exaustão. 


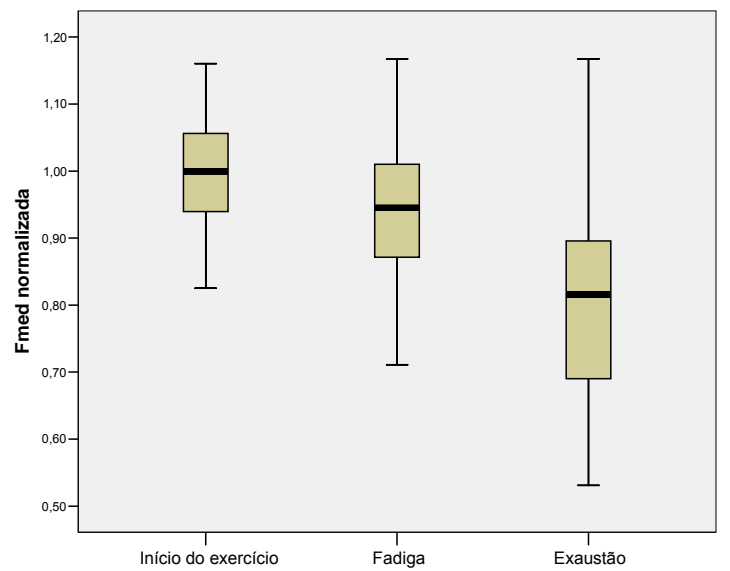

RF

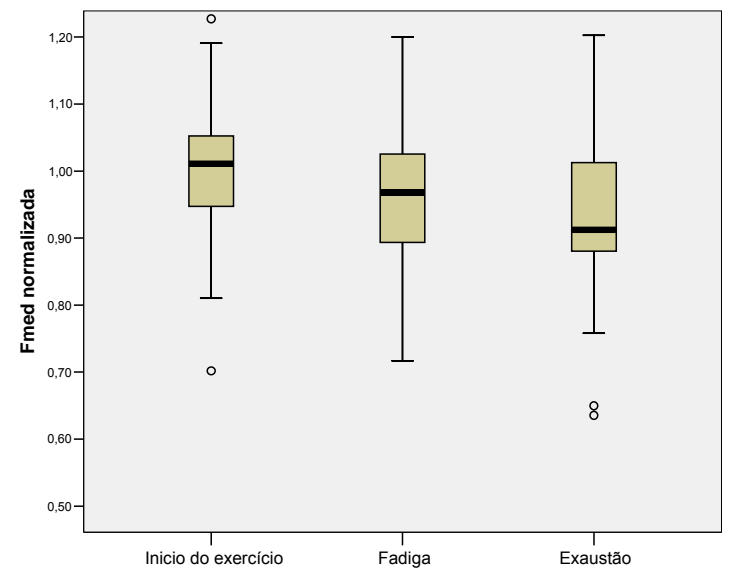

VM

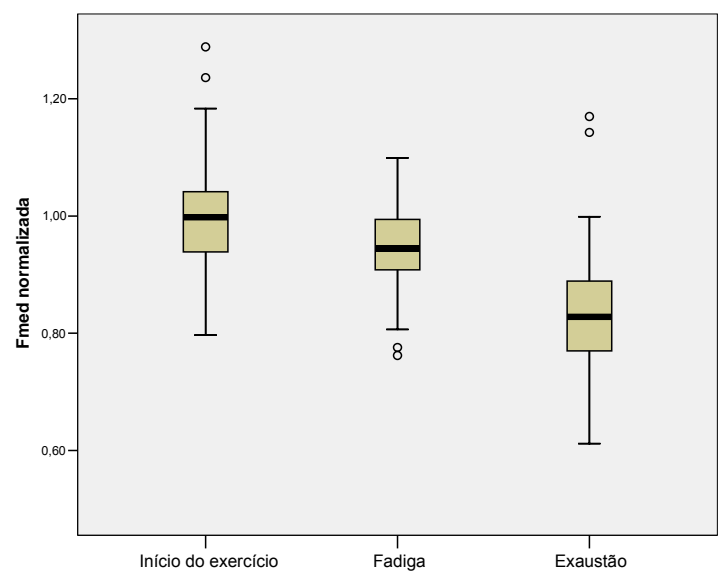

VL

FIGURA 31- Gráficos representativos da distribuição dos valores da Fmed durante os três momentos selecionados, no pós-teste isotônico, para as três porções musculares: RF, VM e VL. 
TABELA 14 - Valores médios ( \pm SD), dos tempos, em segundos, para as porções do VL, VM e RF nos momentos de fadiga e exaustão durante o pós-teste e o tempo total de exercício na carga $15 \%$ do teste de fadiga isotônico com peso fixo $(n=15)$.

\begin{tabular}{cccc}
\hline \multirow{2}{*}{ Tempos (s) } & \multicolumn{3}{c}{ Músculos } \\
\cline { 2 - 4 } & RF & VM & VL \\
\hline \multirow{2}{*}{ Tempo total carga 15\% } & 131 & 131 & 131 \\
\cline { 2 - 4 } & \pm 34 & \pm 34 & \pm 34 \\
Tempo da fadiga & $117^{\mathrm{a}}$ & $121^{\mathrm{a}}$ & $110^{\mathrm{a}}$ \\
pós-teste & \pm 41 & \pm 32 & $\mathbf{4}$ \\
\cline { 2 - 4 } Tempo da exaustão & 157 & 157 & 157 \\
pós-teste & \pm 32 & \pm 32 & \pm 32 \\
\cline { 2 - 4 } $\mathbf{p}$ & $<0.05$ & $<0.05$ & $<0.05$ \\
\hline
\end{tabular}

${ }^{a}$ Diferença significativa em relação ao tempo da exaustão no pós-teste.

\subsection{Resultados do teste descontínuo no ergômetro.}

5.5.1. Coeficiente de inclinação e limiar de fadiga eletromiográfico.

A figura 32 apresenta a distribuição dos coeficientes de inclinação obtidos do ajuste entre as Fmed e o tempo de exercício nos testes de fadiga. A análise descritiva do comportamento dos coeficientes, diferentemente das outras modalidades de exercício, indica um aumento linear, em módulo, na inclinação da reta em relação a carga, apenas para a porção do VL e VM. 


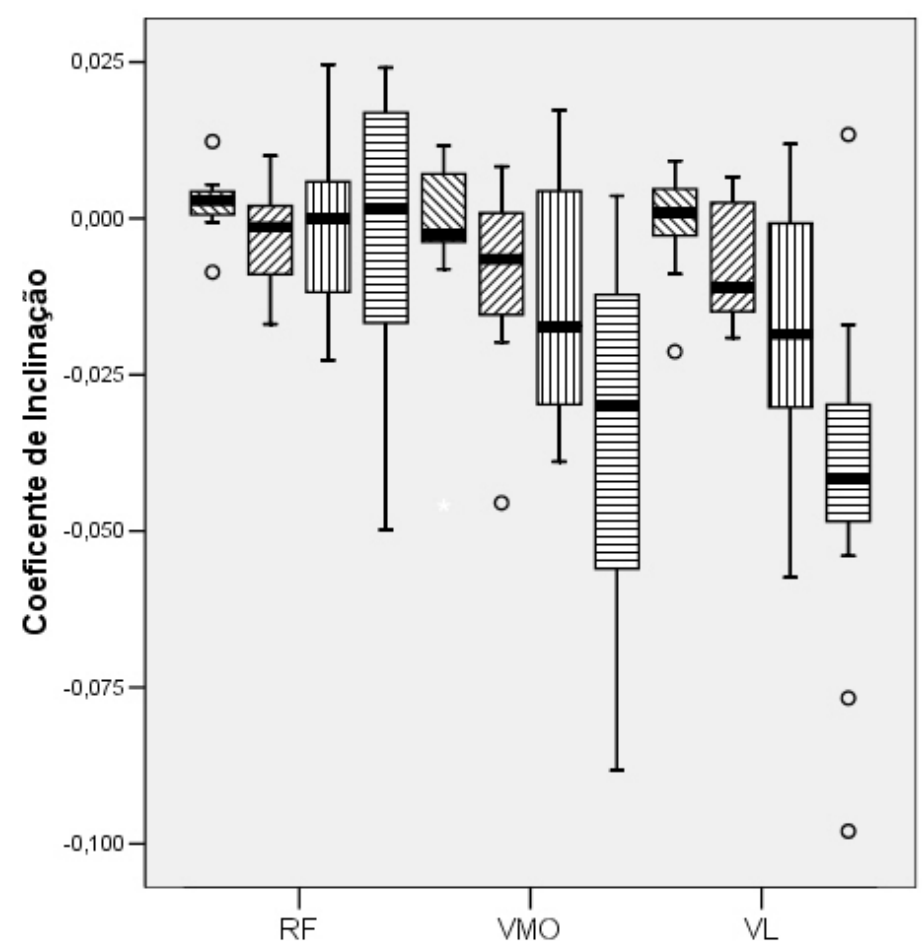

(N $70 \%$

口 $80 \%$

口 $90 \%$

日 $100 \%$

FIGURA 32- Coeficientes de inclinação obtidos nas três porções do músculo quadríceps .

Comparando os valores médios dos coeficientes para um mesmo músculo nas diferentes cargas e para uma mesma carga nos diferentes músculos, obteve-se os resultados compilados na tabela 15. Na comparação entre os músculos, constatou-se diferença significativa para o reto femoral em relação ao vasto lateral e ao vasto medial, somente para a carga de $100 \%$. Comparando-se as cargas para um mesmo

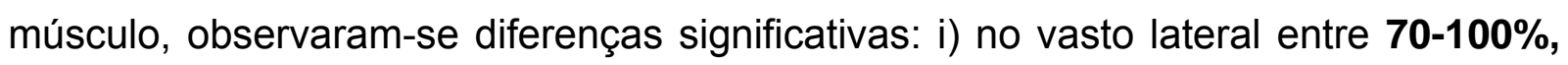

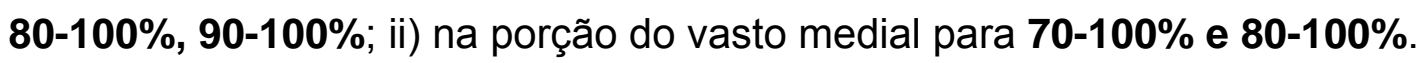


TABELA 15- Valores médios $( \pm S D)$ dos coeficientes de inclinação entre a freqüência mediana em função do tempo de exercício, para as porções do VL, VM e RF durante o teste de fadiga no ergômetro a $70 \%, 80 \%, 90 \%$ e $100 \%$ correspondente ao $\mathrm{VO}_{2}$ máximo $(\mathrm{n}=15)$.

\begin{tabular}{|c|c|c|c|c|c|}
\hline & b 70\% & b 80\% & b 90\% & b 100\% & p \\
\hline RF & $\begin{array}{c}0 \\
\pm 0.005\end{array}$ & $\begin{array}{l}-0.002 \\
\pm 0.007\end{array}$ & $\begin{array}{l}-0.001 \\
\pm 0.015\end{array}$ & $\begin{array}{l}-0.003 \\
\pm 0.023\end{array}$ & NS \\
\hline VM & $\begin{array}{c}-0.002^{b} \\
\pm 0.01\end{array}$ & $\begin{array}{l}-0.009^{b} \\
\pm 0.015\end{array}$ & $\begin{array}{l}-0.013 \\
\pm 0.019\end{array}$ & $\begin{array}{l}-0.036^{a} \\
\pm 0.031\end{array}$ & $<0.05$ \\
\hline VL & $\begin{array}{l}-0.002^{b} \\
\pm 0,008\end{array}$ & $\begin{array}{l}-0.006^{\mathrm{b}} \\
\pm 0.009\end{array}$ & $\begin{array}{c}-0.018^{b} \\
\pm 0.02\end{array}$ & $\begin{array}{l}-0.041^{a} \\
\pm 0.029\end{array}$ & $<0.05$ \\
\hline$p$ & NS & NS & NS & $<0.05$ & 7 \\
\hline
\end{tabular}

Assim como nos testes anteriores, para estabelecer a qualidade dos ajustes das Femd nos testes de fadiga, analisou-se o coeficiente de correlação ( $r$ ) e o $\mathbf{p}$ valor para o teste $\mathbf{t}$ do coeficiente de inclinação da reta.

A tabela 16 apresenta os resultados de uma análise descritiva dos valores destes parâmetros. Com relação ao comportamento do coeficiente $r$, observa-se que existe a tendência na melhora da associação entre a Fmed e o tempo de exercício, à medida que a carga aumenta. Entretanto esta melhora é observada somente entre as cargas 70 e $80 \%$, além de que os valores médios de $r$ são extremamente baixos, principalmente se comparados aos valores dos testes anteriores. Neste teste a porção do RF foi a que apresentou os piores ajustes. Já a quantidade de ajustes cuja inclinação não se diferenciou significativamente de zero $(p<0.05)$, foi em média de $34 \%$. Este valor é $21 \%$ maior que no teste isométrico e $14 \%$ maior que no teste isotônico com peso fixo. 
TABELA 16 - Parâmetros relacionados a qualidade dos ajustes lineares das Fmed em função do tempo de exercício, durante os testes de fadiga na modalidade de exercício no ergômetro.

\begin{tabular}{|c|c|c|c|c|c|c|c|c|c|c|c|c|c|c|c|c|}
\hline & \multicolumn{4}{|c|}{ Carga 70\% } & \multicolumn{4}{|c|}{ Carga 80\% } & \multicolumn{4}{|c|}{ Carga 90\% } & \multicolumn{4}{|c|}{ Carga 100\% } \\
\hline & \multicolumn{2}{|c|}{ Correlação (r) } & \multicolumn{2}{|c|}{ Inclinação (Cl) } & \multicolumn{2}{|c|}{ Correlação (r) } & \multicolumn{2}{|c|}{ Inclinação (Cl) } & \multicolumn{2}{|c|}{ Correlação (r) } & \multicolumn{2}{|c|}{ Inclinação (Cl) } & \multicolumn{2}{|c|}{ Correlação (r) } & \multicolumn{2}{|c|}{ Inclinação (Cl) } \\
\hline & $\mathrm{m}(\mathrm{sd})$ & $\begin{array}{l}\text { Max.I } \\
\text { min. }\end{array}$ & $m(s d)$ & $P<0.05$ & $\mathrm{~m}(\mathrm{sd})$ & $\begin{array}{l}\text { Max.I } \\
\text { min. }\end{array}$ & $\mathrm{m}(\mathrm{sd})$ & $P<0.05$ & $\mathrm{~m}(\mathrm{sd})$ & $\begin{array}{l}\text { Max.I } \\
\text { min. }\end{array}$ & $\mathrm{m}(\mathrm{sd})$ & $P<0.05$ & $\mathrm{~m}(\mathrm{sd})$ & $\begin{array}{l}\text { Max.I } \\
\text { min. }\end{array}$ & $\mathrm{m}(\mathrm{sd})$ & $P<0.05$ \\
\hline RF & $\begin{array}{c}0.08 \\
\pm 0.07\end{array}$ & $\begin{array}{c}0.271 \\
0\end{array}$ & $\begin{array}{c}0 \\
\pm 0.005\end{array}$ & $53 \%$ & $\begin{array}{c}0.12 \\
\pm 0.08\end{array}$ & $\begin{array}{c}0.26 / \\
0\end{array}$ & $\begin{array}{l}-0.002 \\
\pm 0.007\end{array}$ & $53 \%$ & $\begin{array}{c}0.16 \\
\pm 0.12\end{array}$ & $\begin{array}{c}0.34 / \\
0\end{array}$ & $\begin{array}{l}-0.001 \\
\pm 0.015\end{array}$ & $66 \%$ & $\begin{array}{c}0.16 \\
\pm 0.12\end{array}$ & $\begin{array}{c}0.44 / \\
0\end{array}$ & $\begin{array}{l}-0.003 \\
\pm 0.023\end{array}$ & $60 \%$ \\
\hline VMO & $\begin{array}{c}0.13 \\
\pm 0.10\end{array}$ & $\begin{array}{c}0.35 / \\
0\end{array}$ & $\begin{array}{l}-0.002 \\
\pm 0.01\end{array}$ & $70 \%$ & $\begin{array}{c}0.18 \\
\pm 0.13\end{array}$ & $\begin{array}{l}0.471 \\
0.03\end{array}$ & $\begin{array}{l}-0.009 \\
\pm 0.015\end{array}$ & $73 \%$ & $\begin{array}{c}0.21 \\
\pm 0.13\end{array}$ & $\begin{array}{l}0.55 / \\
0.05\end{array}$ & $\begin{array}{l}-0.013 \\
\pm 0.019\end{array}$ & $73 \%$ & $\begin{array}{c}0.21 \\
\pm 0.16\end{array}$ & $\begin{array}{c}0.52 / \\
0\end{array}$ & $\begin{array}{l}-0.036 \\
\pm 0.031\end{array}$ & $60 \%$ \\
\hline VL & $\begin{array}{c}0.11 \\
\pm 0.08\end{array}$ & $\begin{array}{l}0.26 / \\
0.02\end{array}$ & $\begin{array}{l}-0.002 \\
\pm 0,008\end{array}$ & $60 \%$ & $\begin{array}{c}0.17 \\
\pm 0.12\end{array}$ & $\begin{array}{c}0.33 / \\
0\end{array}$ & $\begin{array}{l}-0.006 \\
\pm 0.009\end{array}$ & $74 \%$ & $\begin{array}{c}0.23 \\
\pm 0.17\end{array}$ & $\begin{array}{l}0.541 \\
0.02\end{array}$ & $\begin{array}{l}-0.018 \\
\pm 0.02\end{array}$ & $66 \%$ & $\begin{array}{c}0.29 \\
\pm 0.11\end{array}$ & $\begin{array}{l}0.421 \\
0.09\end{array}$ & $\begin{array}{l}-0.041 \\
\pm 0.029\end{array}$ & $80 \%$ \\
\hline
\end{tabular}

A distribuição dos limiares de fadiga muscular localizada obtidos durante 0 teste de fadiga no ergômetro $(n=15)$, é apresentada na figura 33. Os valores médios $( \pm S D)$ obtidos para as porções do RF, VM e VL foram respectivamente $\mathbf{7 4 . 8} \mathbf{\pm 5 . 5 \%}$, $\mathbf{7 6 . 0} \pm \mathbf{8 . 8 \%}$ e $\mathbf{8 9 . 0} \pm \mathbf{6 . 0 \%}$, em porcentagem do $\mathrm{VO}_{2}$ máximo. Comparando-se estes valores não se observou diferenças significativas entre as porções ( $p>0.05)$.

Nota-se que os valores médios do LFE são superiores aos determinados nas outras duas modalidades de exercício. Também se verifica uma menor variação nos valores do LFE, se comprados aos testes anteriores, para as três porções musculares.

5.5.2. Resultados da análise do comportamento da freqüência mediana inicial e final durante os testes de fadiga no ergômetro.

Os resultados referentes às análises das freqüências medianas no início do exercício e quando o sujeito atinge o estado de exaustão, são apresentados nas tabelas 17 e 18, respectivamente.

Comparando os valores médios, normalizados, da Fmed no início do exercício para as quatro cargas, observou-se diferença significativa para a porção do VM entre a carga $70 \%-90 \%, 80 \%-90 \%$ e $90 \%-100 \%$. 


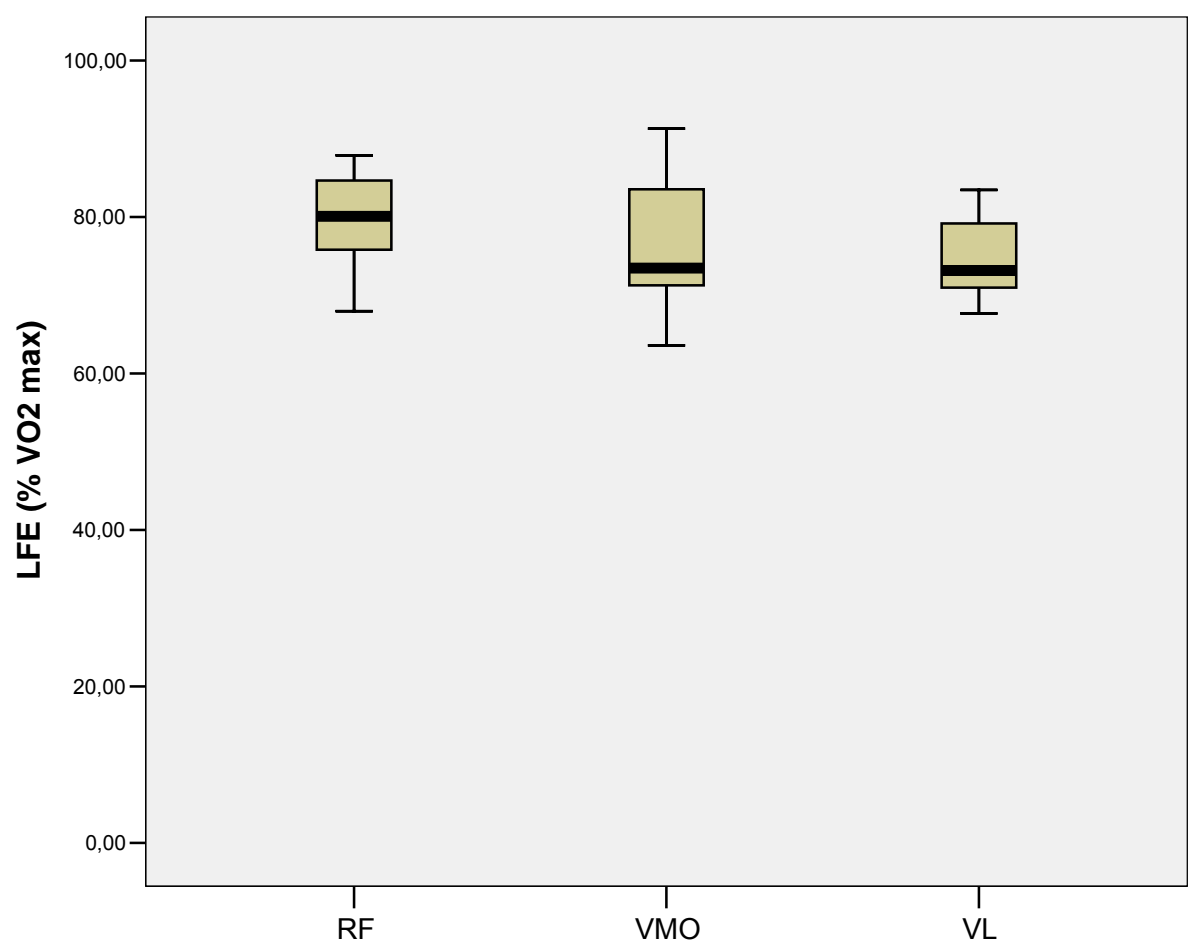

FIGURA 33- Limiares de fadiga muscular localizada obtidos durante o teste de fadiga isométrico.

TABELA 17 - Valores médios $\left( \pm S D\right.$ ), normalizados ${ }^{1}$, da Fmed no início do exercício para as porções do VL, VM e RF durante o teste de fadiga no ergômetro a $70 \%, 80 \%$, $90 \%$ e $100 \%$ correspondente ao $\mathrm{VO}_{2}$ máximo $(n=15)$.

\begin{tabular}{cccc}
\hline \multirow{2}{*}{ Cargas } & \multicolumn{3}{c}{ Músculos } \\
\cline { 2 - 4 } & RF & VM & VL \\
\cline { 2 - 4 } $70 \%$ & 11.08 & $8.52^{\mathrm{a}}$ & 12.45 \\
& \pm 4.7 & \pm 2.50 & \pm 7.1 \\
\cline { 2 - 4 } $80 \%$ & 9.81 & $7.87^{\mathrm{a}}$ & 11.35 \\
& \pm 2.9 & \pm 1.56 & \pm 3.94 \\
\cline { 2 - 4 } $90 \%$ & 13.40 & $12.54^{\mathrm{b}}$ & 12.29 \\
& \pm 6.2 & \pm 5.43 & \pm 4.17 \\
\cline { 2 - 4 } $100 \%$ & 12.93 & 7.44 & 13.50 \\
& \pm 4.5 & \pm 2.06 & \pm 7.15 \\
\hline $\mathbf{p}$ & $\mathrm{NS}$ & $\mathrm{NS}$ & $\mathrm{NS}$ \\
\hline
\end{tabular}

\footnotetext{
${ }^{a}$ Diferença significativa em relação a $90 \%$.

${ }^{\mathrm{b}}$ Diferença significativa em relação a $100 \%$.
} 
Quando comparado os valores médios, normalizados, da Fmed no final do exercício (exaustão), para as quatro cargas, observou-se diferença significativa apenas para a porção do VL entre $70 \%$ - 80\% (tabela 18). A queda média do valor da Fmed do início para a exaustão, nas quatro cargas, foram de $4 \%$ para as porções VL e VM.

TABELA 18 - Valores médios ( \pm SD), normalizados ${ }^{1}$, da Fmed no final do exercício (exaustão) para as porcõos do VL, VM e RF durante o teste de fadiga no ergômetro a

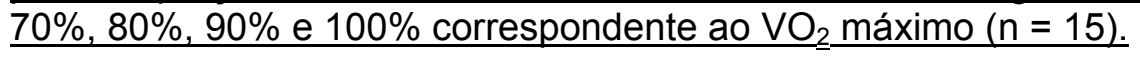

\begin{tabular}{|c|c|c|c|}
\hline \multirow{2}{*}{ Cargas } & \multicolumn{3}{|c|}{ Músculos } \\
\hline & RF & VM & VL \\
\hline $70 \%$ & $\begin{array}{c}1.02 \\
\pm 0.06\end{array}$ & $\begin{array}{c}1.01 \\
\pm 0.08\end{array}$ & $\begin{array}{l}1.04^{\mathrm{a}} \\
\pm 0.06\end{array}$ \\
\hline $80 \%$ & $\begin{array}{l}0.98 \\
\pm 0.1\end{array}$ & $\begin{array}{l}0.98 \\
\pm 0.1\end{array}$ & $\begin{array}{r}0.93 \\
\pm 0.1\end{array}$ \\
\hline $90 \%$ & $\begin{array}{c}0.99 \\
\pm 0.11\end{array}$ & $\begin{array}{l}0.95 \\
\pm 0.1\end{array}$ & $\begin{array}{r}0.94 \\
\pm 0.1\end{array}$ \\
\hline $100 \%$ & $\begin{array}{c}1.01 \\
\pm 0.08\end{array}$ & $\begin{array}{c}0.93 \\
\pm 0.07\end{array}$ & $\begin{array}{c}0.95 \\
\pm 0.07\end{array}$ \\
\hline$p$ & NS & NS & $<0.05$ \\
\hline
\end{tabular}

${ }^{\mathrm{a}}$ Diferença significativa em relação à $80 \%$.

5.5.3. Resultados do pós-teste no ergômetro.

Como descrito no item 4.6.1 do capítulo anterior, os sujeitos retornaram ao laboratório para realizar o exercício na intensidade do seu respectivo LFE. Nestes testes analisou-se o tempo de fadiga e exaustão com referência ao tempo total de exercício na carga mais leve (neste caso $70 \%$ ), tabela 20. Também se analisou os valores da Fmed em três momentos distintos: início do exercício fadiga e exaustão, tabela 19.

Nesta tabela, observa-se que a queda no valor da Fmed entre o início do exercício e o momento de fadiga foi, em média, de $1 \%$ para as três porções 
musculares. Essa queda em relação ao momento de exaustão foi de 5\%, em média, também para as três porções. Comparando os valores médios da Fmed (tabela 19), não é observada diferença significativa ( $p>0.05)$ apenas entre os momentos de início do exercício e fadiga, para o RF. Em todos os outros momentos, em suas respectivas porções musculares, observam-se diferenças significativas $(p<0.05)$ entre os valores médios da Fmed.

Quando comparado os valores médios da Fmed no momento de exaustão do pós-teste em relação à exaustão no teste com carga de $70 \%$, observou-se diferença significativa $(p<0.05)$ somente para a porção do VI. Sendo os valores da Fmed, no teste com carga de $70 \%$, em média $4 \%$ menores que no momento de exaustão do pós-teste, quando considerado todas as porções musculares.

A análise dos tempos mostra que o momento de fadiga durante o pós-teste foi inferior ao tempo total de exercício na carga $70 \%$, para as três porções musculares. Outro fato é que, em média, o tempo de fadiga no pós-teste, para as três porções, foi de $30 \%$ em relação ao tempo de exaustão. Este por sua vez foi $10 \%$ menor que o tempo total de exercício no teste com carga de $70 \%$. Também não se observou diferenças significativas ( $p>0.05$ ) na comparação entre os tempos médios de fadiga no pós-teste, para as três porções musculares.

TABELA 19 - Valores médios ( $\pm S D$ ), da Fmed normalizada ${ }^{2}$ para as porções do VL, VM e RF nos momentos de início do exercício, fadiga e exaustão no pós-teste $(n=15)$.

\begin{tabular}{cccc}
\hline \multirow{2}{*}{ Momentos } & \multicolumn{3}{c}{ Músculos } \\
\cline { 2 - 4 } & $\mathrm{RF}$ & $\mathrm{VL}$ & $\mathrm{VM}$ \\
\hline \multirow{2}{*}{ Início do exercício } & 1.0 & $1.0^{\mathrm{a}}$ & $1.0^{\mathrm{a}}$ \\
& \pm 0.02 & \pm 0.03 & \pm 0.02 \\
\cline { 2 - 4 } Fadiga & 0.99 & $0.99^{\mathrm{a}}$ & 0.99 \\
& \pm 0.03 & \pm 0.05 & \pm 0.05 \\
\cline { 2 - 4 } Exaustão & 0.97 & 0.93 & 0.93 \\
& \pm 0.06 & \pm 0.06 & \pm 0.08 \\
\cline { 2 - 4 } $\mathbf{p}$ & $\mathrm{NS}$ & $<0.05$ & $<0.05$ \\
\hline
\end{tabular}

${ }^{a}$ Diferença significativa em relação ao momento de exaustão. 
TABELA 20 - Valores médios ( \pm SD), dos tempos, em segundos, para as porcões do VL, VM e RF nos momentos de fadiga e exaustão durante o pós-teste e o tempo total de exercício na carga $70 \%$ do teste de fadiga no ergômetro $(n=15)$.

\begin{tabular}{cccc}
\hline \multirow{2}{*}{ Tempos (s) } & \multicolumn{3}{c}{ Músculos } \\
\cline { 2 - 4 } & RF & VL & VM \\
\hline \multirow{2}{*}{ Tempo total carga $70 \%$} & $502^{\mathrm{a}}$ & $502^{\mathrm{a}}$ & $502^{\mathrm{a}}$ \\
& \pm 122 & \pm 122 & \pm 122 \\
\cline { 2 - 4 } Tempo da fadiga & $126^{\mathrm{a}}$ & $135.96^{\mathrm{a}}$ & $148^{\mathrm{a}}$ \\
pós-teste & \pm 82 & \pm 67.89 & \pm 72 \\
\cline { 2 - 4 } Tempo da exaustão & 450 & 450 & 450 \\
pós-teste & \pm 60 & \pm 60 & \pm 60 \\
\cline { 2 - 4 } $\mathbf{p}$ & $<0.05$ & $<0.05$ & $<0.05$ \\
\hline
\end{tabular}

${ }^{a}$ Diferença significativa em relação ao tempo da exaustão no pós-teste.

\subsection{Resultados da análise das bandas de freqüência através do método da componente principal.}

Conforme descrito no item 4.6.3 do capítulo anterior, as bandas de freqüência, entre $0-400 \mathrm{~Hz}$, que compõe o espectro do sinal EMG foram isoladas e analisadas utilizando-se o método das componentes principais (PCA). Neste estudo, o objetivo desta análise foi verificar quais bandas de freqüência do sinal EMG que determinam uma efetiva diferenciação entre uma situação no início do exercício comparado com o fim (condição de exaustão).

Os resultados apresentados neste item se referem a um exemplo intencional, da análise realizada na porção do reto femoral (RF) durante um teste de fadiga na carga mais leve, para as três modalidades de exercício. Justifica-se a escolha do RF para este exemplo, pois esta porção apresentou um comportamento fora do padrão esperado no teste de fadiga no ergômetro. Fato que nos fornece elementos interessantes que serão melhor explorados em uma posterior discussão.

Como já descrito anteriormente no item 4.7.1 os resultados apresentados a seguir se baseiam na análise de componentes principais, realizada de duas formas: i) separadamente servindo para interpretar o peso das variáveis originais na 
combinação das componentes principais mais importantes; ii) visualizando o conjunto da amostra apenas pelo gráfico das duas primeiras componentes principais (Component Scores), sabendo-se que essas detêm maior parte da informação estatística.

\subsubsection{Teste de fadiga isométrico.}

A figura 34 apresenta o comportamento das bandas isoladas em um momento no início e no final do exercício. Através do cálculo do PCA, observa-se para as seis bandas selecionadas, $0-20 \mathrm{~Hz}, 20-40 \mathrm{~Hz}, 40-60 \mathrm{~Hz}, 60-80 \mathrm{~Hz}, 80-100 \mathrm{~Hz}$ e $100-120 \mathrm{~Hz}$, uma diferença mais acentuada entre o início do exercício e o momento de exaustão. Também, pode-se determinar através da análise do peso das variáveis originais na combinação da primeira componente principal, que as bandas selecionadas são responsáveis por aproximadamente $98 \%$ da variação total do espectro entre 0 $400 \mathrm{~Hz}$, entre o início e a condição de exaustão. Estas bandas, nesta situação, representam apenas $30 \%$ das bandas que compõe o espectro de $0-400 \mathrm{~Hz}$.

Quando o comportamento da porção muscular é comparado entre o inicio e o final do exercício, levando-se em conta os $70 \%$ das bandas responsáveis por $2 \%$ da variação total do espectro $(0-400 \mathrm{~Hz})$, observa-se o padrão apresentado na figura 35 . A análise do gráfico, figura 35 , indica que não existem diferenças efetivas entre as duas situações avaliadas.

Se a mesma análise realizada acima for repetida utilizando-se as seis bandas responsáveis pelos $98 \%$ da variação total do espectro, observa-se o padrão apresentado na figura 36. Nesta situação a análise do gráfico indica uma efetiva diferenciação no comportamento da porção do RF entre o momento no início e fim do exercício. 


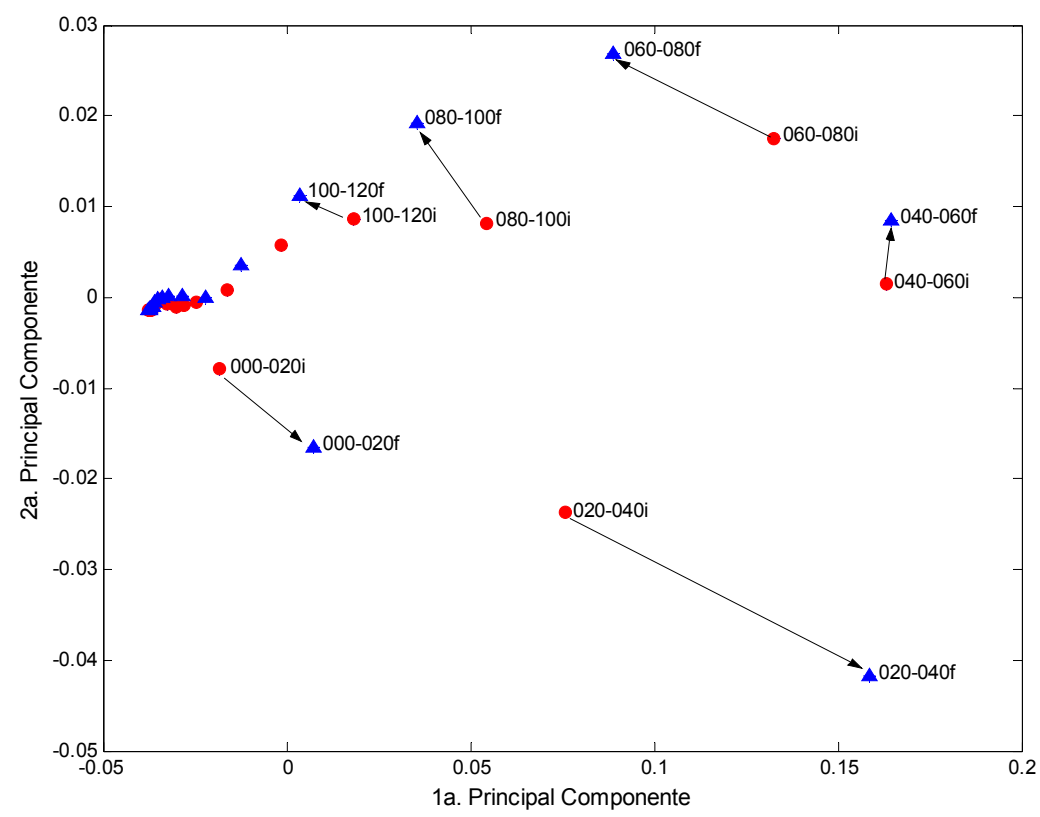

FIGURA 34 - "Component scores" das bandas isoladas. Quanto maior a distância entre os pares de bandas (seta) maior a contribuição desta componente para a variação total do espectro na faixa analisada de $0-400 \mathrm{~Hz}$, para o teste isométrico. Os índices i e f correspondem as bandas selecionadas no início e no final do exercício, respectivamente.

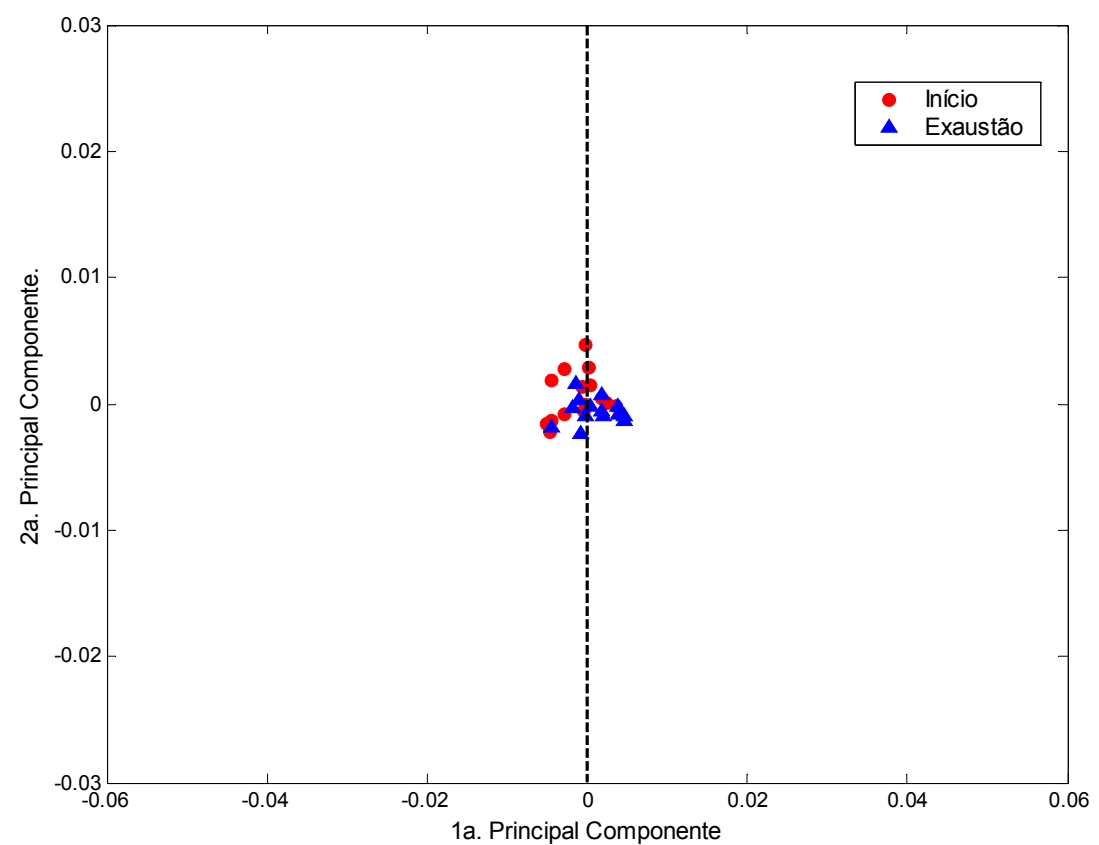

FIGURA 35 - "Component scores" dos sujeitos nas duas situações de exercício ( $n=15)$ utilizando-se as bandas que representam $2 \%$ da variação total do espectro, para o teste de fadiga isométrico. 


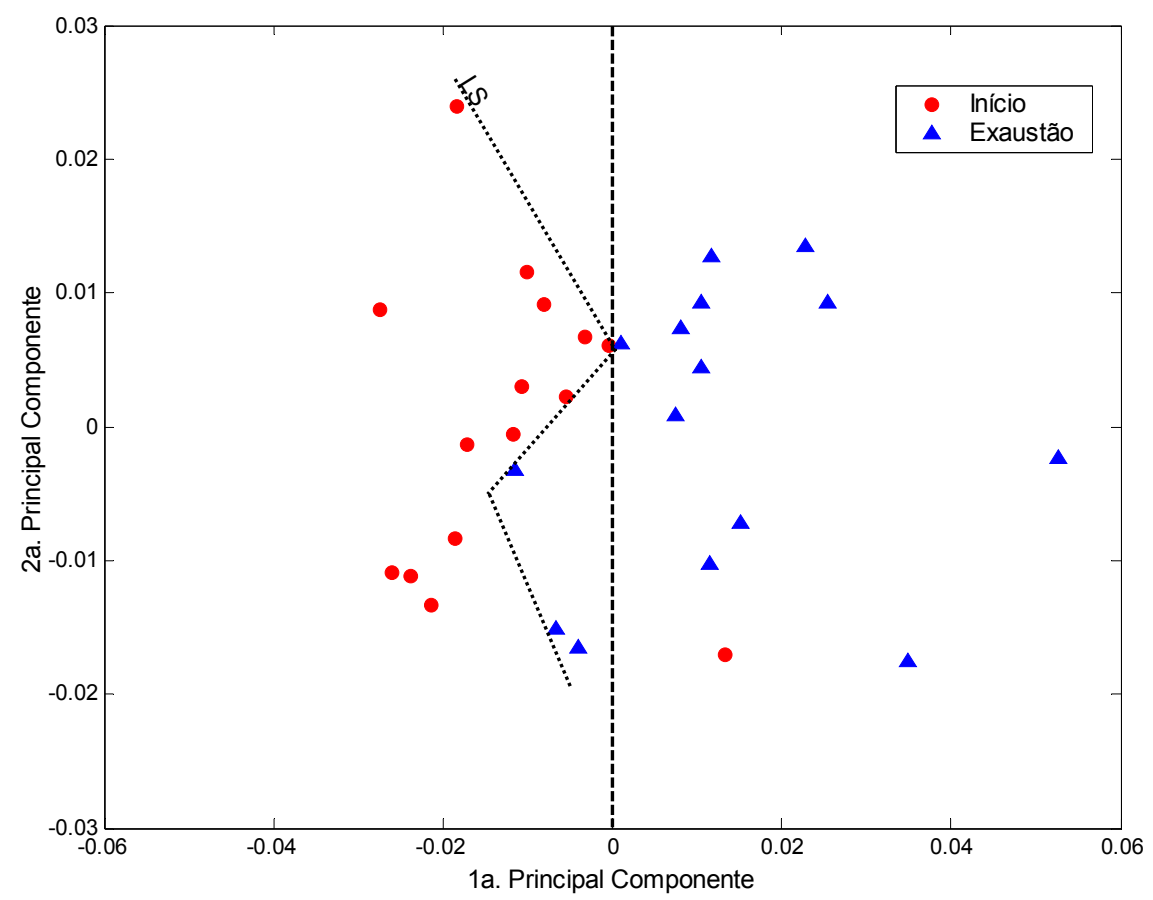

FIGURA 36 - "Component scores" dos sujeitos nas duas situações de exercício $(n=15)$ utilizando-se as bandas que representam $98 \%$ da variação total do espectro, para o teste de fadiga isométrico. A linha pontilhada (LS) separa as duas situaccões.

5.6.2. Teste de fadiga isotônico com peso fixo.

A figura 37 apresenta o comportamento das bandas isoladas em um momento no início e no final do exercício. Observa-se que as quatro bandas selecionadas, 20$40 \mathrm{~Hz}, 40-60 \mathrm{~Hz}, 60-80 \mathrm{~Hz}$ e $80-100 \mathrm{~Hz}$, são responsáveis por $96 \%$ da variação total do espectro entre $0-400 \mathrm{~Hz}$ comparando-se uma situação no início e fim do exercício. Estas bandas, nesta situação, representam $20 \%$ das bandas isoladas e analisadas.

Quando se verifica o comportamento da porção muscular em uma situação no início e no final do exercício, levando-se em consideração os $80 \%$ das bandas que representam apenas $4 \%$ da variação total do espectro, observa-se o padrão apresentado na figura 38. A análise do gráfico indica que não existem diferenças efetivas entre as duas situações. 


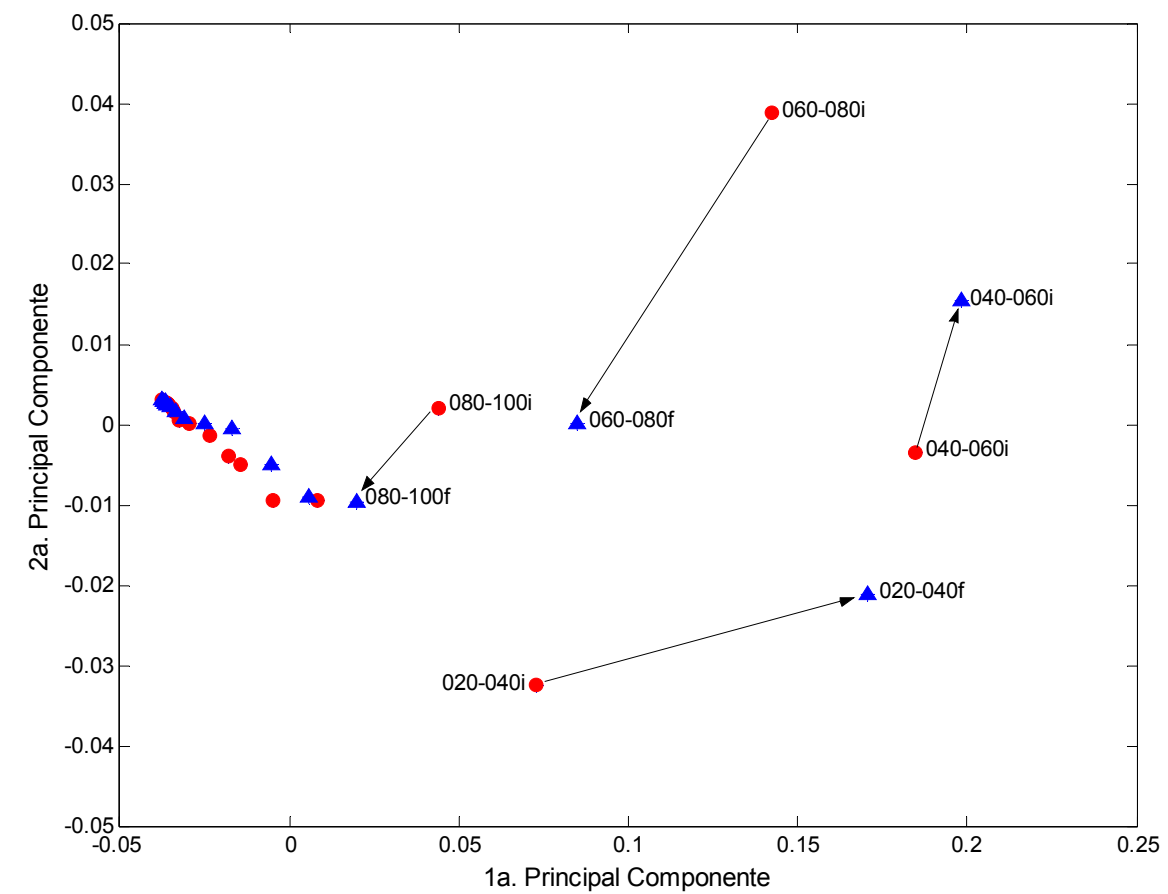

FIGURA 37 - "Component scores" das bandas isoladas. Quanto maior a distância entre os pares de bandas (seta) maior a contribuição desta componente para a variação total do espectro na faixa analisada $0-400 \mathrm{~Hz}$, para o teste de fadiga isotônico.

Se a mesma análise realizada acima for repetida utilizando-se as quatro bandas que representam $98 \%$ da variação total do espectro, observa-se o padrão apresentado na figura 39. Nesta situação a análise do gráfico indica uma efetiva diferenciação no comportamento da porção do RF entre o momento no início e fim do exercício.

Comparando-se esta modalidade de exercício com a anterior, percebe-se que a diferenciação entre as duas situações é bem definida, apesar das bandas de 0$20 \mathrm{~Hz}$ e $100-120 \mathrm{~Hz}$ não comporem o conjunto das bandas que são efetivamente responsáveis pela variação global do espectro. 


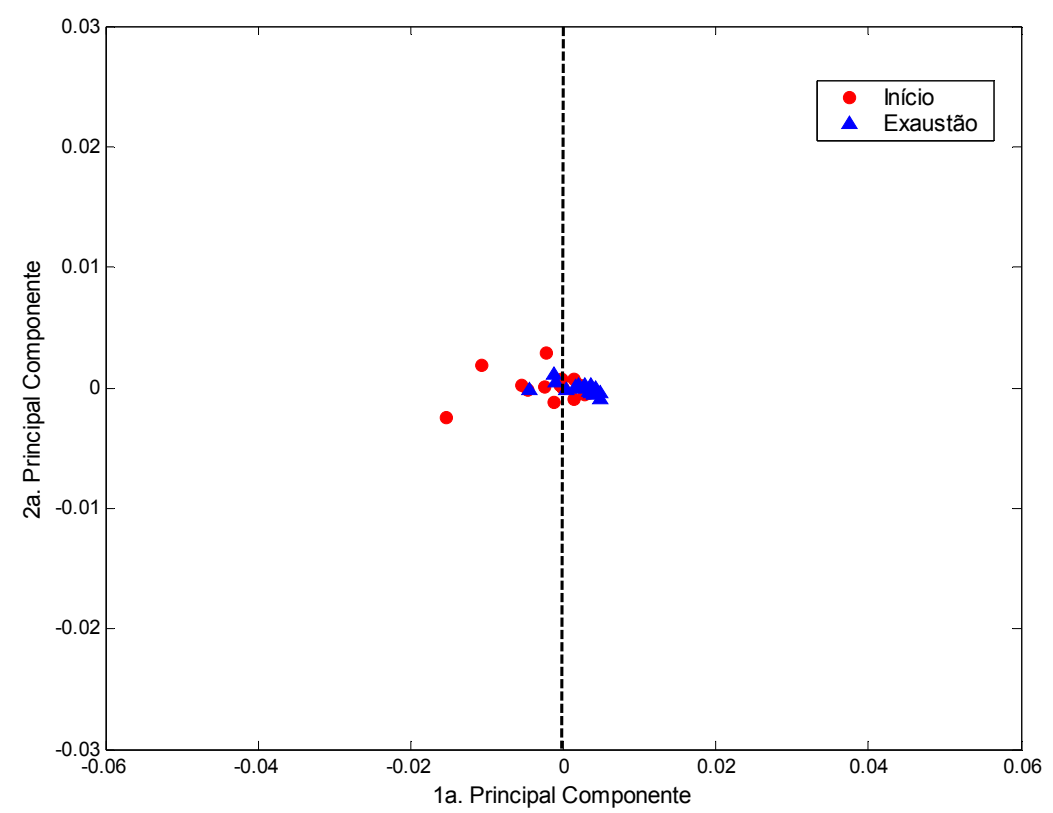

FIGURA 38 - "Component scores" dos sujeitos nas duas situações de exercício ( $n=15)$ utilizando-se $70 \%$ das bandas que representam $2 \%$ da variação total do espectro, para o teste de fadiga isotônico.

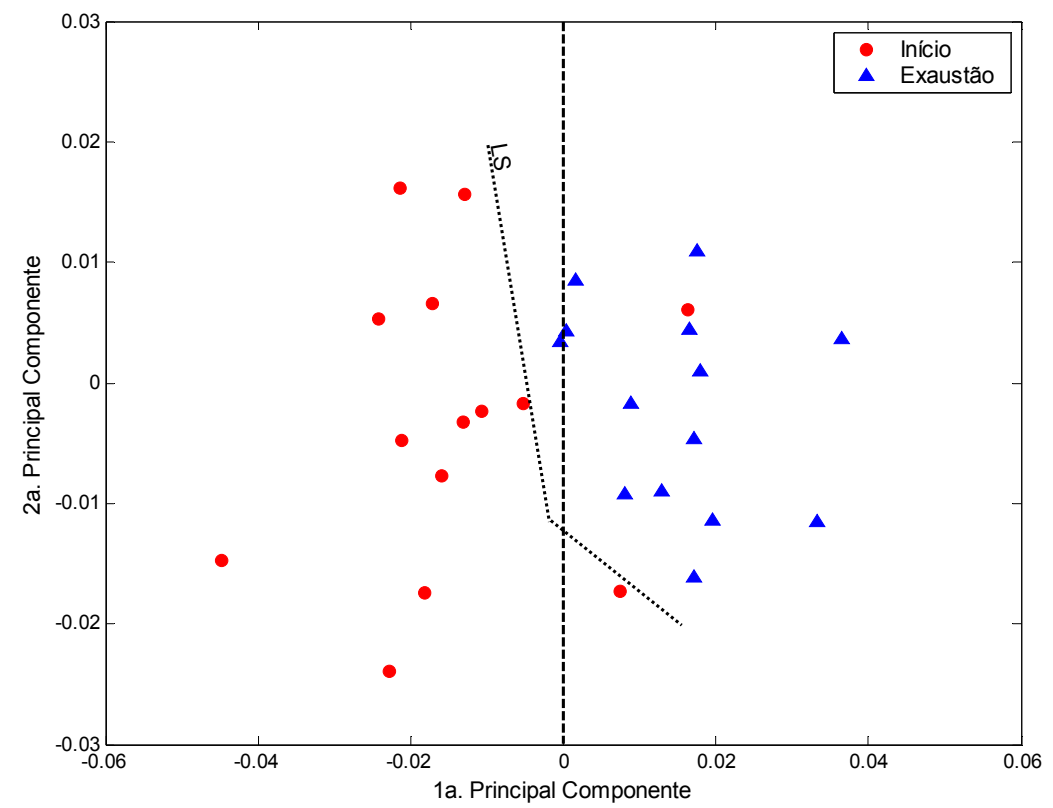

FIGURA 39 - "Component scores" dos sujeitos nas duas situações de exercício $(n=15)$ utilizando-se $30 \%$ das bandas que representam $98 \%$ da variação total do espectro, para o teste de fadiga isométrico. A linha pontilhada representa o limite de separação (LS) entre as duas situações, para o teste de fadiga isotônico. 
5.6.3. Teste de fadiga no ergômetro.

A figura 40 apresenta o comportamento das bandas isoladas em um momento no início e no final do exercício. Observa-se que as cinco bandas selecionadas, 40$60 \mathrm{~Hz}, 60-80 \mathrm{~Hz}, 80-100 \mathrm{~Hz}$ são responsáveis por $87 \%$ da variação total do espectro entre $0-400 \mathrm{~Hz}$ comparando-se uma situação no início e fim do exercício. Estas bandas, nesta situação, representam apenas $15 \%$ das bandas isoladas e analisadas. Observa-se que as distâncias (setas), entre os pares de bandas, são menores se comparados as modalidades de exercício anteriores.

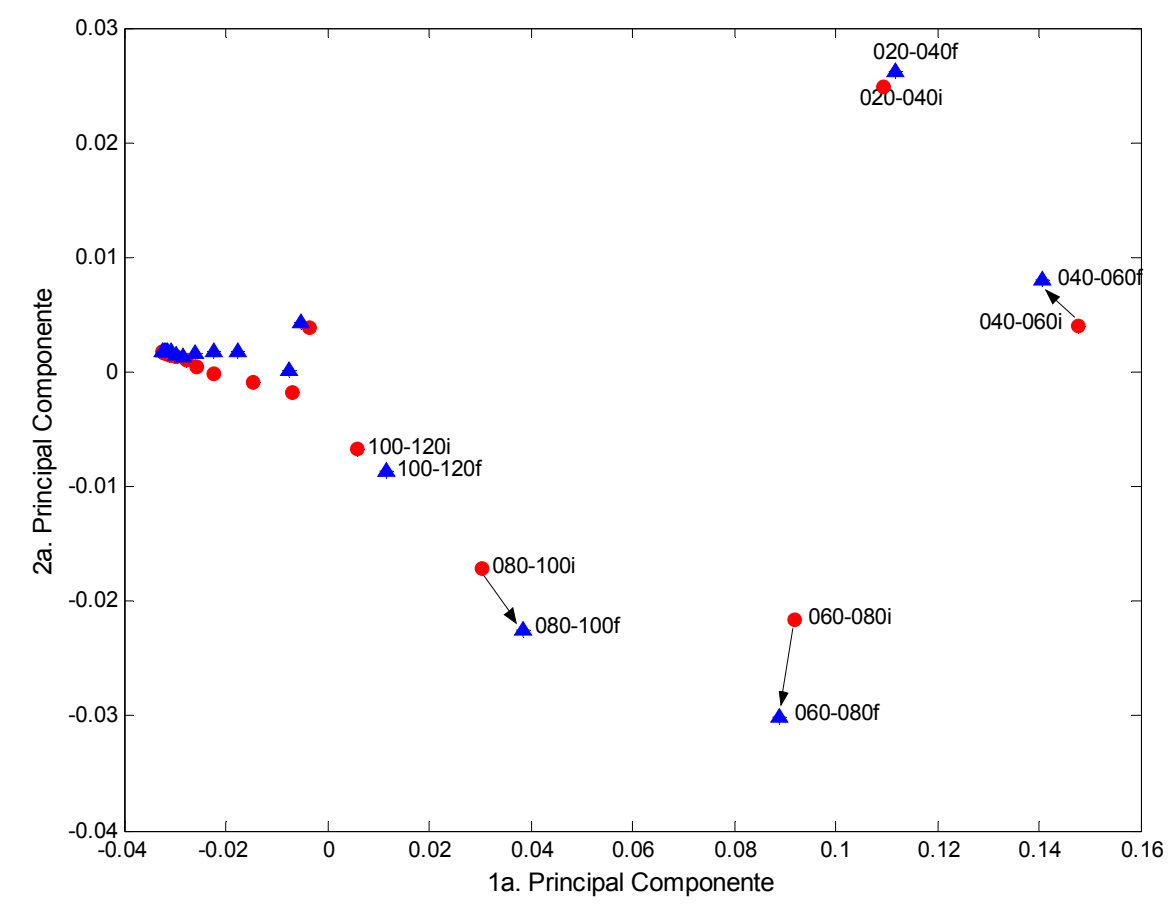

FIGURA 40 - "Component scores" das bandas isoladas. Quanto maior a distância entre os pares de bandas (seta) maior a contribuição desta componente para a variação total do espectro na faixa analisada $0-400 \mathrm{~Hz}$, para o teste de fadiga no ergômetro. 
Quando se verifica o comportamento da porção muscular em uma situação no início e no final do exercício, levando-se em conta os $85 \%$ das bandas que representam $13 \%$ da variação total do espectro, observa-se um padrão semelhante ao apresentado na figura 38. Entretanto, se a mesma análise é realizada utilizandose as 3 bandas que representam $87 \%$ da variação total do espectro, observa-se o padrão apresentado na figura 41. Comparando-se esta modalidade de exercício com a anterior, percebe-se que a diferenciação entre as duas situações não é bem definida, impossibilitando o traçado de um limite de separação. Tal fato pode estar relacionado a diminuição nas distâncias entre os pares das bandas.

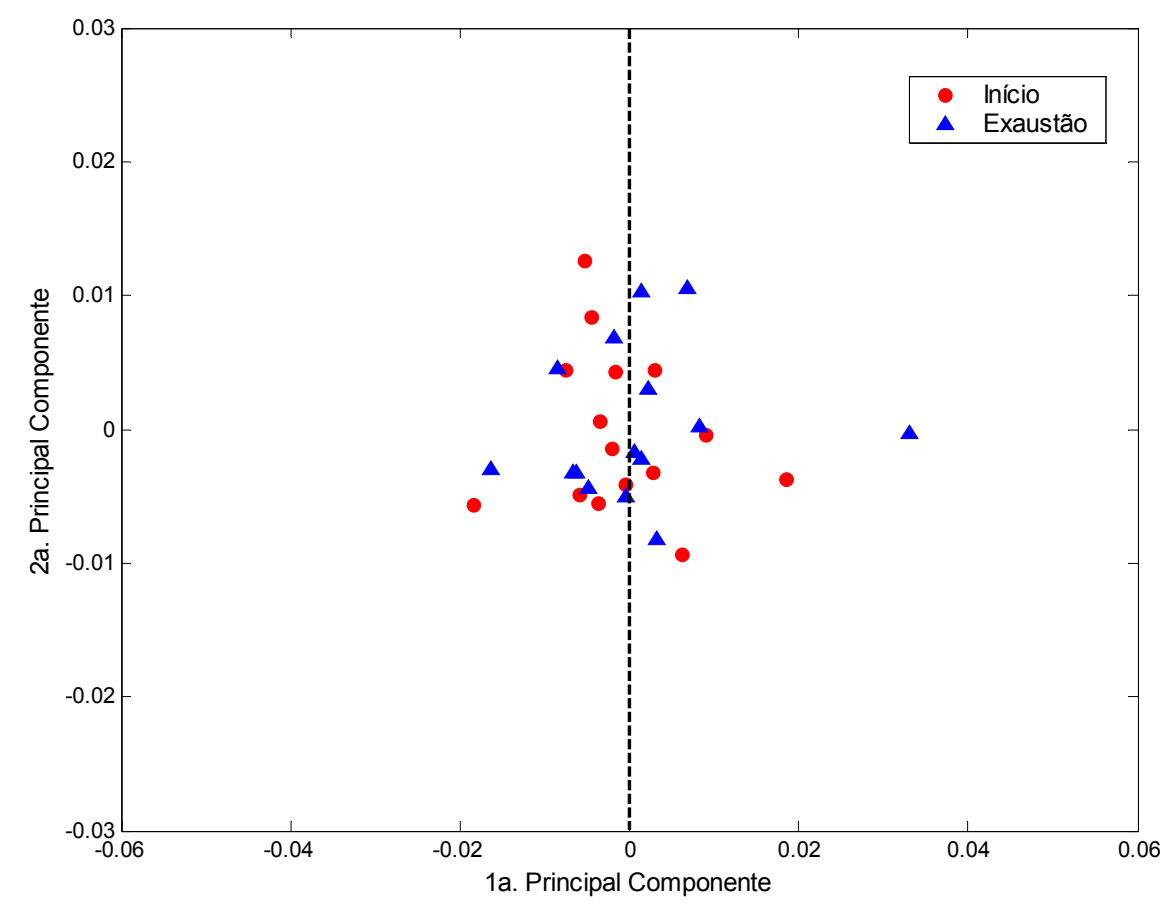

FIGURA 41 - "Component scores" dos sujeitos nas duas situacões de exercício ( $n=15)$ utilizando-se as bandas que representam $98 \%$ da variação total do espectro, para o teste de fadiga isométrico. 


\section{DISCUSSÃO.}

\subsection{Considerações sobre o delineamento experimental.}

Antes de analisar efetivamente os resultados relacionados ao comportamento da LFE nas três modalidades de exercício, discute-se a cerca das principais variáveis experimentais. Acredita-se que esta discussão seja de igual importância as estabelecidas adiante, neste capítulo, especificamente sobre o comportamento do limiar de fadiga eletromiográfico.

\subsubsection{Caracterização dos sujeitos.}

Inicialmente observa-se o comportamento dos sujeitos quanto a sua condição física, caracterizado através do $\mathrm{VO}_{2}$ máximo e pela pontuação no questionário IPAQ. Entende-se que uma variação muito grande na condição física entre os sujeitos pode resultar também em um aumento na variação dos indicadores da fadiga muscular localizada.

Tomando-se o valor de $\mathrm{VO}_{2}$ máximo como referência, estudos clássicos na área apresentam um grupo amostral com um CV em média de 16\%. (PRINGLE e JONES, 2002; HOUSH, et al. 2000; PAVLAT et al, 1995, 1993. MORITANI et al., 1993). No presente trabalho a variação do $\mathrm{VO}_{2}$ máximo, entre os sujeitos da amostra, foi em média de 13\%, valor que se apresenta em consonância com os estudos citados. Assim, pode-se inferir que os sujeitos submetidos aos testes apresentaram uma condição aeróbica homogênea. Entretanto é importante reforçar que esta variável é influenciada por questões fisiológicas sistêmicas e pode não representar efetivamente a máxima carga que o sujeito tem capacidade de desenvolver. 
6.1.2. Velocidade angular dos movimentos no teste de fadiga isotônico com peso fixo.

Especificamente no teste descontínuo isotônico com peso fixo, tem-se a velocidade do movimento como um fator que pode afetar os indicadores de fadiga derivados do sinal EMG (MERLETTI, 2004). Entende-se que a variação na aceleração do movimento, determina o aumento ou a diminuição na intensidade da força muscular durante a execução do gesto. Neste contexto a velocidade do movimento constitui uma variável cujo controle pode melhorar o delineamento experimental.

Esta preocupação não é explicitada em alguns dos estudos sobre a determinação de indicadores da fadiga muscular através de exercícios dinâmicos (DIAS da SILVA e GONÇALVES, 2006; PINCIVERO, et al., 2006; LINNAMO, et al. 2000a). Em outros, o uso do dinamômetro isocinético como dispositivo limitador de velocidade, acaba excluindo esta preocupação do delineamento experimental (EBERSOLE, et al., 2005; KOMI e TESCH, 1979). Também, a simples marcação no ritmo em que o sujeito executa o gesto, não garante que a velocidade ao longo do arco de movimento, entre os ciclos e testes de fadiga seja constante. Por este motivo, no presente estudo, a velocidade angular, durante os testes de fadiga, foi monitorada. Nos testes de fadiga a velocidade do movimento apresentou uma variação (CV) média de 13\%, apesar de seus valores médios entre as cargas não apresentarem diferença significativa.

A determinação da influência da variação nos valores de LFE obtidos não pôde ser realizada neste estudo. Embora constitua uma importante fonte de informação a respeito do controle experimental nos testes dinâmicos. Entende-se que a velocidade, a posição do membro e a quantidade de força gerada pelo músculo caracterizem um conjunto de variáveis, cujo controle é determinante para a diminuição de um possível erro global nos resultados dos indicadores da fadiga neuromuscular (CLANCY et al. 2007). Por exemplo, o uso de um dinamômetro isocinético, permitiria assegurar uma situação na qual a variação na velocidade do exercício não exerceria influência sobre o comportamento dos indicadores utilizados 
para determinação do LFE. Isto porque neste dispositivo a variação da velocidade ao longo do arco de movimento é nula (EBERSOLE, et al., 2005, 1999; KOMI e TESCH, 1979). Embora não haja um controle rigoroso da velocidade como em um equipamento isocinético, a técnica usada neste trabalho permite avaliar o LFE dentro de uma razoável margem de erro.

\subsection{O Tempo total de exercício como indicador global do processo de fadiga muscular.}

Alguns autores sugerem que o processo de fadiga muscular é tempodependente (DEDERING et al., 2002,1999). Entende-se nesta situação que a simples observação da queda do tempo total de um exercício em função do aumento da carga, poderia em caráter global indicar a manifestação do processo de fadiga muscular.

No presente estudo o tempo total dos testes de fadiga (figura 23 e 24), considerado como exaustão, apresentou tendência de queda do tempo total do teste quando a porcentagem de carga era aumentada. Uma explicação para este fenômeno diz que uma maior demanda muscular está relacionada ao aumento na ativação sucessiva de uma quantidade maior de unidades motoras rápidas. Fato que leva a precoce instalação da fadiga e conseqüentemente uma queda no tempo total de exercício (BERNARDI, et al., 1999, 1996; BILODEAU, et al., 1991). A partir desta argumentação pode-se concluir que a manifestação da fadiga muscular é tempodependente.

Entretanto outros estudos se referem a fatores, além do tempo de exercício, que também tem relação com a manifestação da fadiga muscular, como por exemplo: i) o ritmo circadiano (NICOLAS, et al., 2006); ii) aspectos psicológicos (WEIR et. al., 2006; BORG, 1990), que por sua natureza constitui uma variável subjetiva e, por conseqüência, de difícil controle; iii) estratégias de controle do sistema nervoso central (MERLETTI, 2004). 
Contrariando todos os autores anteriormente citados, MAÏSETTI et al. (2002) conclui em seu estudo que a manifestação da fadiga muscular independe totalmente do tempo de exercício.

Poder-se-ia este momento ser apropriado para revisar a seguinte reflexão: o processo de fadiga muscular é tempo-dependente? Tomando-se por base a análise conjunta, e preliminar, dos tempos de exaustão em cada teste de fadiga e de seus respectivos coeficientes de inclinação tem-se os seguintes exemplos:

i) no teste de fadiga isométrico e isotônico os tempos de exaustão para as cargas 45 e 60\% não apresentam diferença significativa. Os seus respectivos coeficientes de inclinação também não apresentam diferença significativa, com exceção da porção do VL em isometria.

ii) no teste de fadiga no ergômetro os tempos de exaustão para as cargas 90 e $100 \%$ não apresentam diferença significativa. Os seus respectivos coeficientes de inclinação também não apresentam diferença significativa, com exceção da porção do VL.

Estes exemplos demonstram que o comportamento da fadiga muscular não apresenta relação dependente do tempo em todas as intensidades de carga nos testes de fadiga. Também se observa que entre as cargas onde o tempo total de exercício apresentou diferença significativa, seus respectivos coeficientes de inclinação não acompanharam, necessariamente, esta tendência estatística.

Neste contexto entende-se que o tempo total de exercício nos testes de fadiga, representa uma importante variável de referência experimental. Entretanto, os resultados obtidos neste estudo não evidenciam seu papel de indicador global do processo de fadiga muscular. MAÏSETTI et al. (2002) estudou o processo de fadiga muscular em duas situações de exercício, com carga máxima e com $50 \%$ desta intensidade. Sendo que o autor não observou relação significante entre o tempo total nas duas situações de exercício.

Assim, constata-se que o sucesso de um teste de fadiga pode depender de outros fatores, alguns possíveis de serem quantificados e, por conseqüência, controlados como já discutido anteriormente. Outras variáveis como, por exemplo, as 
relacionadas às sensações não podem ser diretamente quantificadas sem a influência subjetiva do sujeito. Alguns estudos se ocupam do equacionamento deste problema que, como sugerido, exerce influência sobre os resultados obtidos neste trabalho. Entretanto, de uma forma geral, observa-se que na sua maioria estes estudos se apresentam de forma ainda bastante controversa, como será demonstrado nos itens a seguir (WEIR et. al., 2006; DEDERING et al., 2002; 1999; BORG, 1990).

\subsection{Comportamento da freqüência mediana durante o exercício, monitorado através do coeficiente de inclinação.}

6.3.1. Considerações sobre o coeficiente de inclinação como indicador do processo de fadiga muscular.

Como já descrito anteriormente (item 4.5), o método para determinação do LFE envolve o cálculo dos coeficientes angulares de retas ajustadas às funções estabelecidas entre o indicador EMG monitorado e o tempo de exercício. Entende-se que o resultado destes ajustes pode ser considerado como ponto chave dentro do método para determinação do LFE. Ou seja, a caracterização do LFE experimental com LFE teórico depende de uma série de fatores relacionados à qualidade destes ajustes.

O coeficiente de inclinação obtido através de um ajuste nos valores de Fmed em função do tempo é considerado por vários autores como um indicador do processo de fadiga (DIAS DA SILVA e GONÇALVES, 2006; MERLETTI, 2004, 1991; DeLUCA, 1997). Segundo DeLUCA (1997) existe uma tendência à diminuição nos valores de Fmed ao longo do tempo de exercício. Entende-se que para efeito de análise a relação da queda da Fmed em função do tempo de exercício é considerada linear. Assim, um ajuste linear destes dados representaria bem o fenômeno monitorado, sendo o seu coeficiente angular o indicador global do comportamento da Fmed, em função do tempo. 
MERLETTI (2004, 1991); também demonstra que a velocidade de queda nos valores da Fmed aumenta à medida que o nível de carga do exercício é incrementado. Neste contexto, espera-se uma relação diretamente proporcional entre estas variáveis, onde o aumento da intensidade da carga determina um aumento no coeficiente de inclinação da reta ajustada. Outros estudos clássicos na área demonstram esta mesma relação quando monitorado o comportamento da intensidade do sinal EMG. (DIAS DA SILVA e GONÇALVES, 2006; HOUSH et al., 2000, 1995; PAVLAT et al., 1995, 1993; MORITTANI et al., 1993; deVRIES et al, 1990).

Portanto espera-se um comportamento distinto entre os coeficientes de inclinação calculados em testes de fadiga executados com diferentes níveis de carga. No presente estudo, verifica-se a tendência no aumento, em módulo, do valor médio do coeficiente angular em função do nível de carga nos testes de fadiga. Entretanto não se observa, de forma geral, uma distinção significativa entre os valores dos coeficientes, as cargas e os músculos. O comportamento dos coeficientes de inclinação, neste caso, não sugere uma relação dependente da carga ou do musculo.

Uma possível explicação para este comportamento está relacionada à grande variação nos valores do coeficiente de inclinação entre os sujeitos. No presente estudo observa-se um CV médio na ordem de $70 \%$ para os valores do coeficiente de inclinação no exercício isométrico. Enquanto que no exercício isotônico o CV médio é de $90 \%$, em ambos os casos considerando as três porções musculares. Entretanto percebe-se uma tendência a diminuição desta variação em função do aumento da intensidade da carga do teste. Comportamento semelhante também é demonstrado por CIFREK et al., (2000) em seu estudo.

DIAS DA SILVA e GONÇALVES (2006) monitoraram o comportamento do RMS do sinal EMG durante testes de fadiga com quatro cargas distintas. É interessante observar que a comparação entre as médias dos coeficientes angulares apresentou resultados semelhantes aos descritos anteriormente. Ou seja, não se observou diferença significativa entre todas as intensidades de carga. Outro fato que chama a atenção é que os CV para os coeficientes são igualmente altos, porém observa-se uma tendência na sua queda à medida que o nível de carga diminui. Este 
último comportamento também foi observado por PRINGLE e JONES (2002) em seu estudo.

O fato de o $\mathrm{CV}$, para os coeficientes angulares, apresentar um comportamento inverso comparando os dois estudos, reforça o entendimento de que a intensidade e o espectro do sinal são sensíveis a mecanismos fisiológicos distintos que são responsáveis pela instalação de um mesmo processo denominado de fadiga (BILODEAU et al., 2003).

A variação do coeficiente de inclinação, obtido através da monitoração da Fmed, pode estar relacionada às estratégias que o sistema nervoso central utiliza para realizar a manutenção da força muscular desejada. Em estudo recente MELLO (2006) demonstra uma menor variação da Fmed, entre sujeitos, em níveis máximos de carga se comparado a níveis submáximos (15\%). Neste caso sugere-se que a menor variação da Fmed está relacionada com a influência de um número menor de fatores ligados às estratégias de controle motor presentes na execução do gesto.

Diante do exposto entende-se que o coeficiente de inclinação, obtido através da monitoração da Fmed durante o exercício, pode ser utilizado como indicador do processo de fadiga. Entretanto percebe-se, também, que sua efetiva aplicação dentro de futuras ferramentas de avaliação, depende de uma série de condições ainda pouco exploradas na literatura, principalmente as que se referem à padronização dos testes de fadiga e processamento do sinal EMG. Tal fato reforça o argumento de MERLETTI (2004) a cerca do comportamento da Fmed como um indicador sensível não só ao fenômeno fisiológico da fadiga, mas a vários outros fatores presentes durante a contração muscular como, por exemplo, o tipo de fibra predominante, tipo de contração, estratégias de controle, de-recruitment ${ }^{4}$ de unidades motoras, entre outros.

\footnotetext{
${ }^{4}$ Termo técnico em inglês que se refere a liberação de unidades motoras devido a estratégias de controle específicas que ocorrem durante o exercício (MERLETTI, 2004).
} 


\subsubsection{Considerações sobre a qualidade dos ajustes.}

Como complemento ao item anterior, entende-se que o nível de associação entre as variáveis ajustadas é fator determinante na sua relação com o fenômeno da fadiga muscular. Para compor a determinação do LFE um ajuste deve contemplar duas situações: i) apresentar uma inclinação significantemente $(p<0.05)$ menor que zero; ii) o coeficiente de correlação deve indicar uma razoável associação entre as variáveis ajustadas (MORITTANI et al., 1993; PAVLAT et a., 1995, 1993).

No que se refere à primeira situação, os resultados deste estudo demonstram que o exercício isométrico e isotônico foram as modalidades que apresentaram a maior quantidade de ajustes com inclinação negativa diferente de zero, em média $88 \%$ e $78 \%$ respectivamente. É importante ressaltar que nestas duas situações de exercício os ajustes não diferentes de zero $(p>0.05)$ concentraram-se na carga mais baixa $(15 \%)$.

Ainda nestas duas modalidades de exercício, quando o comportamento dos coeficientes de correlação é analisado, observa-se que a associação entre as variáveis ajustadas melhora à medida que o nível de carga aumenta. Este comportamento pode ser justificado considerando que, para alguns sujeitos da amostra, o nível de carga 15\% corresponde a um valor próximo ao LFE. Já que nesta intensidade de carga espera-se pouca associação entre a Fmed e o tempo de exercício.

$\mathrm{Na}$ modalidade de exercício no ergômetro a quantidade de ajustes com inclinação diferente de zero foi em média de $65 \%$. Quanto ao coeficiente de correlação, observam-se baixos níveis de associação entre a Fmed e o tempo de exercício, mesmo nas cargas mais altas $(0.14<r<0.22)$. Ainda nesta modalidade de exercício PAVLAT et al. (1995), monitorando o RMS do sinal EMG, apresenta $100 \%$ de ajustes diferentes de zero $(p<0.05)$ em seus resultados. Enquanto que PRINGLE e JONES (2002), monitorando a IEMG, não conseguiram determinar o LFE para $50 \%$ de seus sujeitos devido a problemas com a qualidade dos ajustes nos testes de fadiga.

Os resultados apresentados neste estudo e os acima relatados, permitem inferir que as alterações no espectro de freqüência do sinal EMG são menos 
sensíveis aos processos que levam a fadiga muscular na modalidade de exercício no ergômetro. PERRY et al. (2001) reforça este entendimento demonstrando em seu estudo a dissociação entre os indicadores no domínio do tempo e da freqüência, para a porção do VL em um teste de fadiga no ergômetro. Neste caso os coeficientes de correlação do ajuste para a Fmed e para o RMS monitorado foram, respectivamente, de 0.02 e 0.72 .

PERRY et al. (2001) também sugere que a diminuição na velocidade de condução do potencial de ação ocorre de forma mais expressiva na segunda metade do teste de fadiga. Assim, não é esperado uma associação significativa entre a Fmed e o tempo de exercício na primeira metade do teste, podendo estas amostras ser descartadas da análise. Também, como será mostrado mais adiante neste capítulo, somente algumas faixas de freqüência podem ser sensíveis as estas mudanças, mais sutis, na primeira fase do teste, em comparação com a análise do espectro todo (0-500Hz) através da Fmed.

É fato que a monitoração da Fmed nesta modalidade de exercício necessita ser melhor explorada sendo, predominante na literatura, o uso de indicadores no domínio do tempo para a indicação do processo de fadiga e determinação do LFE, (MORITANI et al., 1978, 1984; HOUSH et al., 1996; SABAPATHY et al., 2003; HUG et al., 2003; JAMMES et al. 1998; DAVIS et al., 1976, 1979).

Como citado anteriormente, observa-se uma melhor qualidade dos ajustes nas modalidades de exercício isométrico e isotônico, principalmente quando considerada as maiores intensidades de carga. Entretanto deve-se lembrar que existe espaço para aprimorar a qualidade destes indicadores. Este processo pode se basear nos argumentos expostos no item anterior, e em um outro fator complementar relacionado ao grau da equação utilizada nos ajustes.

Alguns autores consideram a relação de decréscimo da Fmed em função do tempo de exercício, como sendo linear (DeLUCA e BASMAJIAN, 1985; DeLUCA 1997; BILODEAU, et al., 1991; MERLETTI, 2004). No entanto, a prática demonstra que este comportamento é verdadeiro para alguns sujeitos e para outros não. PERRY et al. (2001) apresenta uma situação na qual o ajuste que melhor representa o comportamento das Fmed, durante um teste de fadiga, é descrito por uma equação de segundo grau. 
Casos como o demonstrado acima, acontecem com grande freqüência e na sua maioria são resultados da grande variação nos valores da Fmed ao longo do tempo de exercício. Esta variação, por sua vez, ocorre sob a influência de vários fatores durante o processo de contração muscular, como já citado anteriormente (MERLETTI, 2004). Neste sentido, o desenvolvimento de métodos para a determinação de indicadores menos sensíveis as variações não relacionadas com o processo de fadiga, representa um amplo campo de trabalho ainda pouco explorado na literatura.

\subsection{Considerações sobre o Limiar de Fadiga Eletromiográfico e sua caracterização.}

MORITANI e YOSHITAKE (1998) no congresso da sociedade internacional de eletromiografia e cinesiologia, apresentaram uma conferência com tema central ligado ao uso da eletromiografia na fisiologia aplicada. Nesta conferência um dos pontos abordados foi o método para determinação do chamado Limiar de Fadiga Eletromiográfico. Neste texto a interpretação atribuída pelos autores para o LFE foi: "a máxima carga em que o sujeito realiza um exercício sem a evidência da fadiga neuromuscular". Entende-se, de uma forma global, que a fadiga neuromuscular é aquela que se identifica através de indicadores derivados do sinal EMG (DeLuca, 1997). Talvez a importância deste estudo esteja no fato de representar um marco referente à ampla divulgação de uma proposta de método para determinação do LFE.

Baseando-se na interpretação citada acima, observa-se que são poucos e controversos os estudos realizados em relação à padronização de métodos e caracterização do LFE experimental (MORITANI et. al., 1993; PAVLAT et al.,1993, 1995). Um bom exemplo desta controvérsia pode ser observado na confrontação dos resultados de MORITANI et al. (1993), com os de PAVLAT et al. (1995). Basicamente ambos os estudos se ocupam em caracterizar o LFE experimental em relação ao LFE teórico, sendo que os resultados de MORITANI et. al. (1993) reforçam o 
conceito teórico do LFE, enquanto que PAVLAT et. al. (1995) sustenta uma conclusão oposta.

Observa-se que os resultados obtidos no presente estudo, para a modalidade de exercício no ergômetro, estão mais próximos dos apresentados por PAVLAT et al. (1995). No entanto, entende-se que estes resultados não representam um reforço às conclusões deste autor, pois os métodos para determinação do LFE, no presente estudo, foram diferentes. Principalmente em relação ao uso de um indicador no domínio da freqüência. Neste sentido, verifica-se que os estudos relacionados à determinação do LFE, nesta modalidade de exercício, utilizam indicadores no domínio do tempo como, por exemplo, o RMS e a IEMG (MORITANI et al., 1982, 1993; HOUSH et al., 1996).

Em relação à modalidade de exercício isométrico e isotônico os resultados obtidos no presente estudo, foram semelhantes aos obtidos por DIAS DA SILVA e GONÇALVES (2006). Um fato interessante é que apesar dos valores médios do LFE serem próximos, sua variação em torno da média é menor no estudo de DIAS DA SILVA e GONÇALVES (2006). Pode-se especular que a menor variação está relacionada a algumas diferenças metodológicas verificadas no estudo citado, como por exemplo: i) os sujeitos eram do sexo feminino (BILODEAU et al., 2003); ii) o indicador utilizado para monitorar o processo de fadiga foi o RMS (MELLO, 2006; MERLETTI, 2004); iii) o posicionamento dos sujeitos para execução dos testes de fadiga, na modalidade de exercício isométrico, foi diferente (OTA, 2006, 2005; PINCIVERO, 2003, 2000); iv) as intensidades de carga para os testes de fadiga foram diferentes (PRINGLE e JONES, 2002).

Entende-se que as controvérsias metodológicas verificadas nos textos citados caracterizam uma temática relativamente recente e que apresenta um amplo espaço para estudos com o objetivo de se melhorar os processos de determinação do LFE. No entanto, de uma forma geral, observa-se que os resultados obtidos no presente estudo, não apresentam discrepância com os observados na literatura, para as três modalidades de exercício. Mesmo com impossibilidade de confrontar diretamente os resultados apresentados com os da literatura, os fatos expostos evidenciam que os métodos empregados foram coerentes com o objetivo de se determinar o LFE em três modalidades diferentes de exercício. 
Como complemento a proposta central deste estudo, tem-se a caracterização dos LFE determinados nos testes descontínuos, para as três modalidades de exercício. Os resultados apresentados dentro deste contexto foram obtidos através dos procedimentos descritos no item 4.6.1 do capítulo 4.

A análise do momento de início da fadiga nos pós-testes evidencia que a carga utilizada na execução do exercício, só pode ser caracterizada como LFE durante um período de $54 \%, 73 \%$ e $30 \%$ do tempo total de exercício, respectivamente, para as modalidades de exercício isométrico, isotônico e no ergômetro. Lembrando que no período de tempo compreendido entre o início do exercício e o momento de início da fadiga a Fmed se apresentou estável, fator fundamental na caracterização do LFE (MORITANI et al., 1993; MORITANI e YOSHITAKE, 1998). Esta análise evidencia que no estado de exaustão o processo de fadiga neuromuscular já está efetivamente instalado (MERLETTI, 2004; BILODEAU et al., 2003; KARLSSON et al., 2003; DeLUCA; 1997).

Observa-se também que os valores médios da Fmed entre o início do exercício e o momento de início da fadiga, se apresentam bastante próximos. Já quando comparado aos valores médios do momento de início da fadiga com o momento de exaustão, verifica-se uma queda acentuada. Sugere-se que a partir do momento do início da fadiga, a queda acentuada da Fmed seja resultado de uma efetiva influência dos fatores fisiológicos que caracterizam o estado de fadiga neuromuscular (MERLETTI, 2004; DeLuca, 1997).

No entanto, a análise dos resultados na modalidade de exercício no ergômetro mostra que a queda no valor médio da Fmed, para as três porções musculares, entre o início do exercício e o momento de exaustão é de $4 \%$, enquanto que nas outras modalidades este valor é de $8 \%$. Este fato pode reforçar o entendimento de que, na modalidade de exercício no ergômetro, o uso de um indicador no domínio da freqüência, do sinal EMG, necessita ser melhor estudado. Com o objetivo de aprimorar sua sensibilidade em relação aos fatores fisiológicos que caracterizam a fadiga neuromuscular. 


\subsection{Considerações sobre as análises complementares.}

6.5.1. Freqüências medianas obtidas durante o início e o momento de exaustão nos testes de fadiga.

Observa-se, de forma geral, para as três modalidades de exercício que não existem diferenças significativas $(p>0.05)$ quando são comparadas as Fmed finais entre as cargas dos testes de fadiga. Ou seja, independentemente da intensidade da carga ou do tempo total de exercício, verifica-se uma tendência de igualdade entre os valores médios da Fmed no momento de exaustão dos testes de fadiga. (MAÏSETTI, et al., 2002). Uma análise preliminar deste comportamento sugere a possibilidade de se desenvolver um indicador "mestre" do processo de fadiga muscular.

O desenvolvimento deste indicador baseia-se no entendimento de que a Fmed normalizada apresenta uma relação linear com o tempo de exercício e, também, que o seu valor normalizado será sempre o mesmo no momento de exaustão, independentemente da intensidade da carga do exercício (MAÏSETTI et al., 2002). Este contexto permite uma descrição linear, aproximada, do comportamento da Fmed para um conjunto de sujeitos, dentro de uma determinada banda de confiança, (figura 42). Estabelecendo os parâmetros de ajuste do comportamento da Fmed para um determinado músculo, tem-se a possibilidade em predizer o seu estado ou seu LFE, através de simulações, sem a necessidade do sujeito realizar uma série de testes de fadiga. Lembrando que um teste de fadiga implica na execução do exercício até a condição de exaustão. Momento cuja determinação é subjetiva e que apresenta elevada variação dos indicadores derivados do sinal EMG: RMS, IEMG, Fmed (PRINGLES e JONES, 2002; CIFREK et al, 2000).

É importante ressaltar que apesar da proposta deste indicador "mestre" estar fundamentada em uma análise preliminar, ela pode representar um grande potencial na composição de uma futura ferramenta de avaliação da fadiga muscular localizada baseada na monitoração do sinal EMG. Neste sentido, o seu desenvolvimento passa pelas mesmas discussões realizadas ao longo deste capítulo, e também por 
trabalhos complementares focados especificamente nas análises complementares apresentadas neste estudo.

Em relação as Fmed no início do exercício, de forma global, também não apresentam diferença significativa $(p>0.05)$ quando os seus valores médios, entre as cargas dos testes de fadiga, são comparados. Em um primeiro momento, este comportamento evidência que o descanso de vinte minutos entre as cargas foi suficiente para o sujeito sofrer uma recuperação em relação ao seu estado inicial (VERBURG et al., 1999). Entretanto, é importante ressaltar que este fato não descarta um possível efeito acumulativo relacionado à condição de fadiga muscular no decorrer do teste descontínuo.

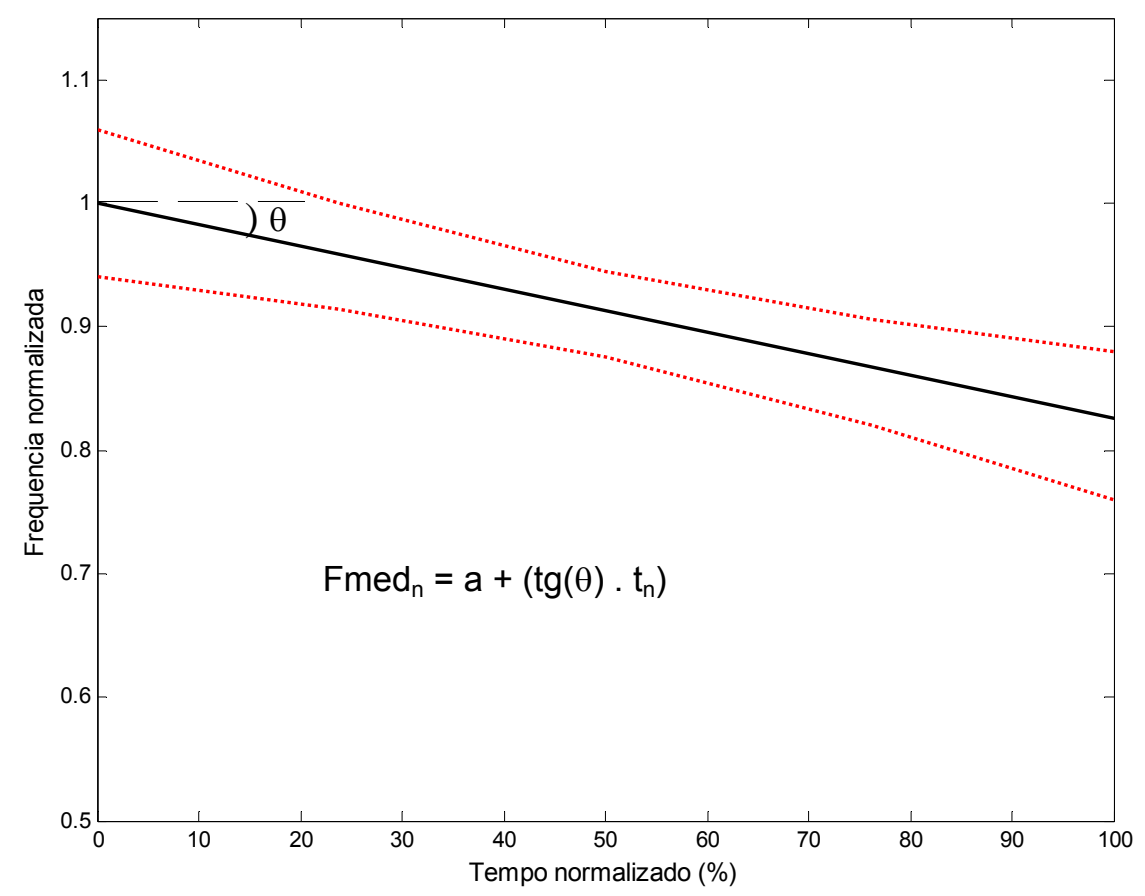

FIGURA 42- Gráfico exemplificando um ajuste "mestre" (linha) e sua banda de confiança (linha pontilhada) para um conjunto de sujeitos. Este ajuste é descrito pela equação onde: Fmed $_{n}$ representa o valor da Fmed normalizada; "a" representa o intercepto da reta; $\underline{\operatorname{tg}(\theta)}$ representa o coeficiente linear da reta; $t_{n}$ representa o tempo normalizado de exercício. 
Neste contexto, a análise conjunta do comportamento acima verificado e dos resultados do pós-teste, pode evidenciar a presença de um efeito acumulativo entre os testes de fadiga. Considerando que no pós-teste o sujeito realizou o exercício até a exaustão, esperava-se que neste momento o valor médio da Fmed fosse igual aos verificados nos teste de fadiga para as diferentes cargas. Comparando-se os valores da Fmed no momento de exaustão do pós-teste e do teste de fadiga verifica-se uma diferença, em média, de 7\%. Uma possível explicação para esta diferença pode estar relacionada à presença de fatores musculares derivados de uma situação onde testes de fadiga são realizados de forma consecutiva, independentemente do intervalo entre as séries e da condição inicial do sujeito. Ou seja, ao executar o pósteste o sujeito não estava sob a influência destes fatores, pois não havia executado exercícios prévios. Nesta condição não se caracterizou um possível efeito acumulativo e, por conseqüência, os valores médios da Fmed no momento de exaustão diferenciaram-se dos observados nos testes de fadiga. De uma forma geral, esta análise demonstra a importância e a necessidade em se considerar a influência deste efeito acumulativo em procedimentos futuros que tenham como objetivo o desenvolvimento e a validação de um indicador "mestre" do processo de fadiga muscular localizada (WEIR et al., 2006).

6.5.2. Considerações sobre a análise isolada das bandas de freqüência através do método de componentes principais.

Foi amplamente discutido neste capítulo que é possível se monitorar o processo de fadiga muscular, bem como determinar o LFE, através de indicadores EMG no domínio da freqüência. No entanto, as discussões estabelecidas anteriormente apontam, também, para algumas possíveis desvantagens relacionadas a estes indicadores. Talvez a mais importante esteja relacionada ao grau de sensibilidade da Fmed como indicador do processo de fadiga.

Neste ponto deve-se lembrar que a Freqüência Mediana é um indicador relativo do comportamento da densidade do espectro de freqüência de uma série temporal selecionada de um sinal EMG (DeLUCA, 1997). Ou seja, entende-se que 
em alguns casos uma alteração em uma determinada banda do espectro, pode ser compensada pela alteração em outras bandas, não resultando em uma mudança efetiva no valor da Fmed (MELLO, 2006).

Dentro deste contexto, tem-se como fundamento para análise proposta neste estudo, o entendimento de alguns autores que sugerem que determinadas característica ligadas os mecanismos de controle motor podem ser avaliadas através da monitoração do comportamento de específicas bandas que compõe o espectro de freqüência do sinal EMG (MELLO, 2006; MERLETTI, 2004; MORITTANI et al., 1998). Neste sentido, pode-se inferir que determinadas bandas de freqüência podem apresentar uma sensibilidade maior aos fatores fisiológicos que determinam a instalação do processo de fadiga muscular. E, consequentemente, sua análise isolada pode representar uma forma mais precisa de monitoração deste processo.

A avaliação do comportamento de bandas isoladas do espectro não é uma tarefa trivial, principalmente quando se estrutura esta análise através de ferramentas estatísticas usuais (MELLO, 2006). Alguns poucos estudos apresentam formas alternativas de se operacionalizar este procedimento através de análise multivariada, especificamente pelo método de componentes principais (HU e NENOV, 2004; KIRYU et al., 1997).

Como já descrito anteriormente, a análise de componentes principais é uma técnica estatística poderosa que pode ser utilizada para se obter uma visão estatisticamente privilegiada do conjunto de dados. Neste contexto, em caráter preliminar propôs-se, no presente estudo, um método para se analisar o comportamento de bandas isoladas do espectro, em uma situação no início do exercício e no momento de exaustão.

Resumidamente, os resultados obtidos no presente estudo demonstram que na modalidade de exercício isométrico ocorre uma maior diferenciação, entre o início do exercício e o momento de exaustão, para as bandas de freqüência entre 20 e $120 \mathrm{~Hz}$. Já para a modalidade de exercício isotônico esta diferenciação ocorre de forma mais acentuada para as bandas entre 20 e $100 \mathrm{~Hz}$. Quando se observa os resultados para o exercício no ergômetro aparece uma maior diferenciação entre os momentos do exercício na faixa de 40 e $100 \mathrm{~Hz}$. Porém esta diferença é mais discreta em relação às outras duas modalidades de exercício. 
Estes resultados sugerem, por exemplo, que uma forma mais precisa no cálculo do LFE estaria associada à monitoração da Fmed do espectro determinado pelas bandas que apresentam maior diferenciação. Acredita-se que mesmo na modalidade de exercício no ergômetro, onde as análises tradicionais mostraram que a Fmed não se apresentou como um bom indicador, poderia haver uma melhora dos resultados partindo-se do pressuposto apresentado.

Ainda neste contexto, os resultados apresentados suportam a idéia do desenvolvimento de uma ferramenta de avaliação capaz de classificar, baseando-se em dados populacionais, os vários estágios relacionados à condição de fadiga de um músculo, durante o período de execução de um exercício, conforme exemplo ilustrativo apresentado na figura 43. Entretanto é importante ressaltar que esta é uma análise preliminar dentro de um escopo metodológico bastante especifico, pouco explorado e de procedimentos ainda inseguros, evidenciando a necessidade pela validação do procedimento.

A demanda por estudos que objetivem a validação deste método, representa um grande potencial relacionado à melhora dos procedimentos de processamento do sinal EMG para determinação do LFE (HU e NENOV, 2004; TSCHARNER, 2002; KIRYU et al., 1997). Entretanto, deve-se lembrar que os resultados obtidos reforçam a indicação de uso da Fmed como instrumento de monitoração do processo de fadiga. Embora, sugere-se a existência de um espaço para estudos que tenham como objetivo desenvolver métodos para melhora do comportamento desta variável. 


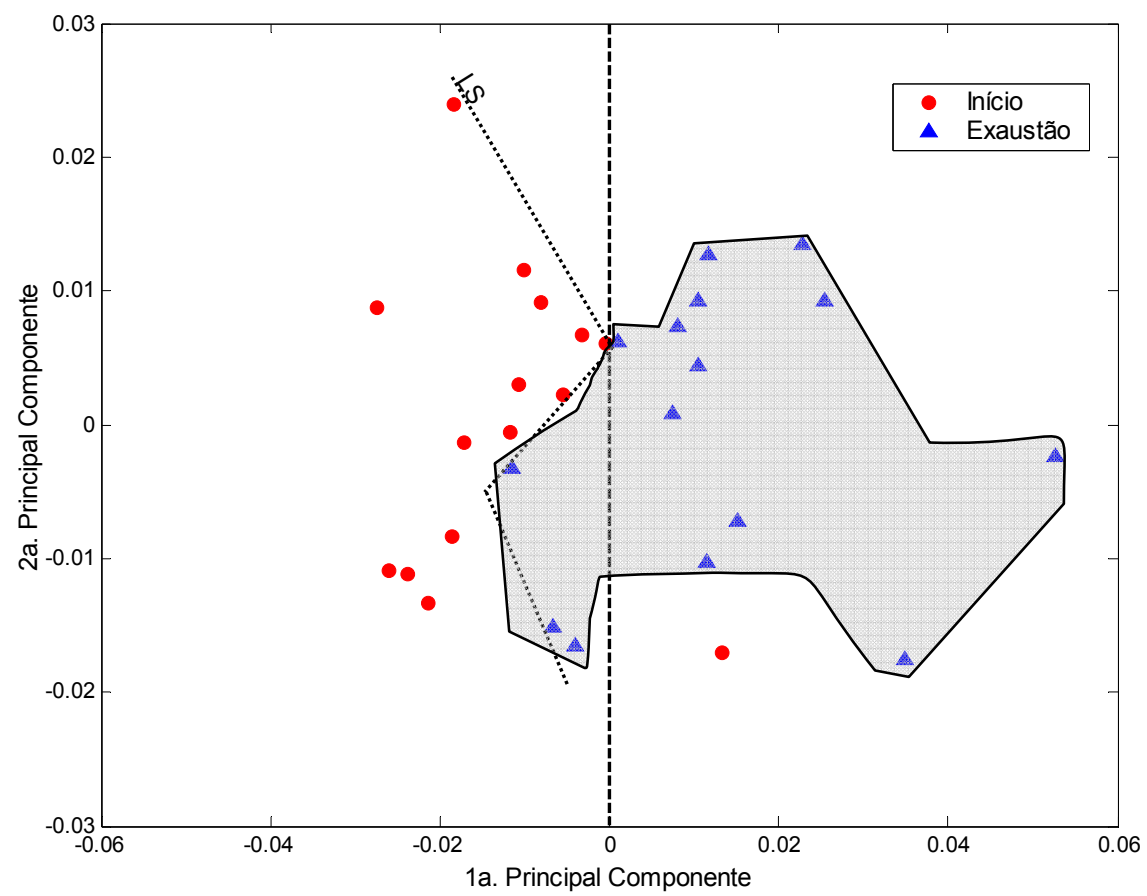

FIGURA 43- Exemplo da caracterização de uma condição de exaustão, baseado na análise de bandas isoladas através da PCA, para um grupo de 15 sujeitos. Observa-se que a área cinza delimita a condição de exaustão.

O objetivo geral deste capítulo foi discutir amplamente o uso da Fmed como parâmetro eletromiográfico para a determinação do LFE em diferentes situações de exercício. Esta ampla discussão foi dirigida não somente ao comportamento da variável Fmed, mas também aos fatores ligados a sua monitoração e indução dos processos fisiológicos que ela reflete. Neste contexto, pode-se verificar alguns pontos que, se melhorados, certamente vão representar um salto de qualidade e representatividade do LFE determinado a partir da Fmed. Outras análises serviram como fundamento na proposição de procedimentos alternativos para monitoração do processo de fadiga através de parâmetros no domínio da freqüência do sinal EMG, que não necessariamente a Fmed. No entanto, ao finalizar este capítulo, verifica-se que apesar de todos os fatores que influenciam no comportamento da Fmed, foi possível determinar e caracterizar o LFE nas três modalidades de exercício. 


\section{CONCLUSÃO.}

Baseando-se nos resultados apresentados e nas discussões estabelecidas anteriormente, pode-se concluir que a Freqüência Mediana do sinal EMG contemplou o propósito de servir como um parâmetro para monitoração do processo de fadiga muscular. Entretanto, os resultados também apontam para a necessidade de se buscar meios que proporcionem uma redução na sua variação. Neste sentido, sugerem-se como principais pontos críticos:

i) a determinação da melhor faixa de intensidade de carga para execução dos testes de fadiga;

ii) o aprimoramento das condições que caracterizam o momento de exaustão dentro dos testes de fadiga;

iii) o aprimoramento dos métodos de processamento do sinal EMG, em relação a condição de exercício isométrico e dinâmico.

Conclui-se também que a partir da monitoração da Freqüência Mediana foi possível determinar e caracterizar o Limiar de Fadiga Eletromiográfico, para as três modalidades de exercícios. No entanto a caracterização do Limiar para o exercício no cicloergômetro sugere que os valores determinados não contemplam seu entendimento teórico que se refere, "a máxima carga em que o sujeito realiza um exercício sem a evidência da fadiga neuromuscular" (MORITANI e YOSHITAKE, 1998). Já para o exercício isométrico e isotônico com peso fixo, a caracterização dos valores do Limiar de Fadiga Eletromiográfico aponta para uma concordância em relação ao seu entendimento teórico. Admitindo-se que o LFE foi determinado dentro de uma razoável margem de erro, verifica-se a possibilidade de melhorar sua precisão.

Neste sentido além dos pontos sugeridos anteriormente, as análises complementares apresentadas neste estudo representaram uma importante fonte de informação a cerca desta condição. Por exemplo, as análises isoladas das bandas de freqüência sugerem a possibilidade da extração de um parâmetro mais sensível ao fenômeno fisiológico que se pretende monitorar. Além disso, estas informações 
fundamentam a proposição preliminar de métodos alternativos para monitoração da fadiga muscular localizada e para determinação do LFE.

Ao final deste estudo pode-se simplesmente considerar que sua contribuição esta diretamente ligada as constatações e sugestões de melhorias que poderiam ser aplicadas imediatamente dentro do método usual para determinação do LFE. Entretanto, entende-se que este estudo apresenta, também, uma frente bastante promissora no desenvolvimento de métodos mais eficientes no processo de monitoração da fadiga muscular localizada. Sabe-se que a operacionalização das propostas apresentadas ainda são preliminares e dependem de estudos futuros, porém acredita-se que esta seja a principal contribuição deste estudo. 


\section{REFERÊNCIAS BIBLIOGRÁFICAS.}

ALMEIDA, M. A. F. Filtragem Digital de Sinais Biomédicos. 116 p. Tese de Mestrado, PGEEL, UFSC, Florianópolis, Brasil. 1997.

AMADIO, A. C. Fundamentos biomecânicos para a análise do movimento humano. São Paulo, Laboratório de Biomecânica / EEFUSP, 1996. 162p.

AZEVEDO F. M. Avaliação da força e da atividade elétrica do músculo quadriceps femoris submetido a exercícios com resistência elástica. DISSERTAÇÃO DE MESTRADO. Universide de São Paulo, Programa de pós-graduação em bioengenharia EESC/FMRP/IQSC-. 110p. 2003.

BENOIT, G.; COZZONE, P., J.; BENDAHAN, D. Non-invasive investigations of muscular fatigue: metabolic and electromyographic components. Biochimie, Article in press, 2003.

BENDAT, J. S.; PIERSOL, A. G. Random Data: analysis and measurement procedures. Wiley, New York, 2ed.,1986.

BERNARDI, M; FELICI, F; MARCHETTI, M; MONTTELANICO, F; PIACENTINI, M. F; SOLOMONOW, M. Force generation performance and motor unit recruitment strategy in muscles of contralateral limbs. Journal of Electromyography and Kinesiology. v. 9, p. 121 - 130, 1999.

BERNARDI, M; SOLOMONOW, G; NGUYEN, G; SMITH, A; BARATTA, R. Motor unit recruitment strategies changes with skill acquisition. Eur. J. Appl. Physiol. v. 74: p. 52- 59, 1996.

BIGLAND-RITCHIE, B. et al. Conduction velocity EMG power spectrum changes in fatigue of sustained maximal efforts. Journal Applied Physiology, v.51, p. 13001305, 1981.

BILODEAU, M.; IVENS, S., S.; WILLIAMS, D., M.; CHANDRAN, R.; SHARMA, S., S. EMG frequency content changes with increasing force and during fatigue in the quadriceps femoris muscle of men and women. Journal of Electromyography and Kinesiology. v. 13, p. 83-92, 2003.

BILODEAU M.; CINCERA, M.; ARSENAULT B. A.; GRAVEL D. Normality and stationarity of EMG signals of elbow flexor Muscles during ramp and step isometric contractions. Journal of Electromyography and Kinesiology. v. 7, p. 87 - 96, 1997.

BILODEAU, M., et al. Changes in the electromyographic spectrum power distribution caused by a progressive increase in the force level. European Journal of Applied Physiology. v. 71 (3), p. 113 - 123, 1995. 
BILODEAU, M; ARSENAULT, A. B; GRAVEL, D; BOURBONNAIS, D. EMG power spectra of elbow extensor during ramp and step isometric contractions. Eur J Appl Physiol. v. 63: p. $24-28,1991$.

BLECKMAN, R. B.; TUKEY, J.W. The Measurement of Power Spectra. Dover Publications, New York, 1958.

BORG, G; Psycophysical scaling with applications in physical work and the perception of exertion. Scand j Work Environ Health. v. 16: p. 55 - 8, 1990.

BROWN, M.S.H.; STEIN, B.R. The relation between the surface electromyogram and muscular force. Journal of Physiology. _, 549-569. 1974.

CIFREK, M.; TONKOVIÉ, S.; MEDVED, V. Measurement and analysis of surface myoelectric signals during fatigued cyclic dynamic contractions. Measurement. v. 27, p. 85-92, 2000.

CLANCY, E. A; BERTOLINA, M. V; MERLETTI, R; FARINA, D. Time and frequency domain monitoring of the myoelectric signal during a long-duration, cyclic, forcevarying, fatiguing hand-grip task. Journal of Electromyography and Kinesiology. doi: 10.1016/j. jelekin. 2007.02.007, 2007.

CRAIG et al. International physical activity questionnaire: 12-country reliability and validity. Medicine e Science in Sports e Exercise. 2003.

DAVIS, J., A., et al. Anaerobic threshold and maximal aerobic power for thee modes of exercise. Journal Applied Physiology. v. 41, p. 544-550, 1976.

DAVIS, J., A., et al. Anaerobic threshold alterations caused by endurance training in midle-aged men. Journal Applied Physiology. v. 46, p. 1039-1046, 1979.

DEDERING, A; ODDSSON, L; HARMS, K; NÉMETH, G. Electromiography and ratings of lumbar muscle fatigue using a four-level staircase protocol. Clinical Biomechanics. v. 17: p. $171-176,2002$.

DEDERING, A; HARMS, K; NÉMETH, G. Correlation between electromiographic spectral changes and subjective assesment of lumbar muscle fatigue in subjects without pain from the lower back. Clinical Biomechanics. v. 14: p. $103-111,1999$.

DE LUCA, C.J.; BASMAJIAN, J. Muscles alive: Their functions revealed by eletromyography. 5.ed. USA, 1985. 561p.

DE LUCA, C. The use of surface electromyography in biomechanics. Journal of Applied Biomechanics. v.2, n.13, p.135-163, 1997.

deVIRES et al. Factors affecting the estimation of physical working capacity at the fatigue threshold. Ergonomics. v. 33(1): p. 25-33, 1990. 
deVIRES, H., A., et al. The relation between critical power and neuromuscular fatigue as estimated from electromyographic data. Ergonomics. v. 25, p. 783-791, 1982.

Di FABIO, R. P. "Reliability of computadorized surface electromyograph for determining the onset of muscle activity". Physical Therapy. V.67: p.43 - 48, 1987.

DIAS DA SILAVA, S; GONÇALVES, M. Dynamic and isometric protocols of knee extension: effect of fatigue on the EMG signal. Electromyogr. Clin. Neurophysiol. V. 46: p. 35-42, 2006.

EBERSOLE, K. T; O'CONNOR, K. M; WIER, A P. Mechanographic and electromyographic responses to repeated concentric muscle actions of quadriceps femoris. Journal of Electromyography and Kinesiology. v. 16: p. 149 - 157, 2005.

EBERSOLE, K. T; HOUSH, T. J; JOHNSON, G. O; EVETOVICH, T. K; SMITH, D. B; PERY, S. R. MMG and EMG responses of de superficial quadriceps femoris muscles. Journal of Electromyography and Kinesiology. v. 7(3), p. 219 - 227, 1999.

EDWARDS, R., H.; HILL, D., K.; JONES, D., A.; MERTON, P., A. Fatigue of long duration In human skeletal muscle after exercise. Journal Physiology. v. 272, p. 769-778, 1997.

ENOKA, R. M; STUART, D. G. Neurobiology of muscle fatigue. Ameriacn Physiological Society. 1992.

ESPOSITO, F. et al. Electromyogram and mechanomyogram changes in fresh and fatigued muscle during sustained contraction in men. European Journal Applied Physiology, v.78, p. 492-501, 1998.

GEDES, L. A. Electrodes and the Measurement of Bioelectric Events. New York: Wiley, 1972.

GIANNESINI et al. Non-invasive investigations of muscular fatigue: metabolic and electromyographic components. Biochime. v. 85: p. 873-883, 2003.

GONÇALVES, M. Análise da fadiga muscular por indicadores biomecânicos. TESE DE LIVRE DOCÊNCIA. Universidade Estadual Paulista - Rio Claro, 2003.

GUEDES, D. P; LOPES, C. C; GUEDES, J. E. R. P. Reprodutibilidade e validade do Questionário Internacional de Atividade Física em adolescentes. Rev Bras Med Esporte. v.1,1 n.2, p.151-158, 2005

GREEN, H. J. Neuromuscular aspects of fatigue. Can. J. Spt. Sci.. 12(suppl.1), 1987. HARY, D. et al. A statical analysis of the spectral moments used in EMG test of endurance. Journal Applied Physiology, v.53, p. 779-783, 1982. 
HERMENS, J. H.; FRERIKS, B., DISSELHORST-KLUG, C.; RAU, G. Development of recommendations for SEMG sensors and sensor placement procedures. Journal of Electromyography and Kinesiology. v. 10, p. 361-374, 2000.

HOSTENS, I.; SEGHERS, J.; SPAEPEN, A.; RAMON, H. Validation of the wavelet spectral estimation technique in biceps brachii and brachioradialis fatigue assessment during prolonged low-level static and dynamic contractions. Journal of Electromyography and Kinesiology. Article in press, 2003.

HOUSH, T. J; PERRY, S. R; BULL, A. J; JOHSON, G., O; EBERSOLE, K., T; HOUSH, D., J; deVRIES, H., A. Mechanographic and electromyographic responses during submaximal cycle ergometry. European Journal of Applied Physiology. v. 4-5, p. 381-387, 2000.

HOUSH T. J., et al. Neuromuscular fatigue thresholds of the vastus lateralis, vastus medialis and rectus femoris mucles. Electromyography Clinical Neurophysiology. v. 36(4): p. 247-255, 1996.

HOUSH T. J., et al. Electromyographic fatigue thresholds on the superficial muscles of the quadriceps femoris. European Journal Applied Physiology. v. 71(3): p. 131136, 1995.

HU, X; NENOV, V. Multivariate AR modeling of electromyography for the classification of upper arm movements. Clinical Neurophysiology. v. 115: p. 12761287, 2004.

HUG, F.; DECHERCHI, P.; MARQUESTE, T.; JAMMES, Y. EMG versus oxygen uptake cycling exercise in trained and untrained subjects. Journal of Electromyography and Kinesiology. Article in press, 2003.

JACKSON, L. B. Digital Filters and Signal Processing. Kluwer Academic, Boston, 2ed, 1989.

JAMMES, Y.; CAQUELARD, F.; BADIER, M. Correlation between surface electromyogram, oxygen uptake and blood lactate concentration during dynamic leg exercises. Respiration Physiology, v. 112, p. 167-174, 1998.

KARLSSON, J. S; OSTLUND, O; LARSSON, B; GERDLE, B. An estimation of influence of force decrease on the mean power spectral frequency shift of the EMG during repetitive maximum dynamic knee extensions. Journal of Electromyography and Kinesiology. v. 13, p. 461-468, 2003.

KOMI, P. V; TESCH, P. EMG frequency espectrum, muscle structure, and fatigue during dynamic contractions in man. European Journal of Applied Physiology. v. 42, p. 41-50, 1979. 
KRNJEVIC, K., MILEDI, R. Failure of Neuromuscular Propagation in Rats, Journal of. Physiology. London, 140, 440-461. 1958.

KIRYU, T; TAKAHASHI, K; OGAWA, K. Multivariate Analysis of Muscular Fatigue During Bicycle Ergometer Exercise. IEEE transactions on biomedical engineering. v. 44(8): p. 665-672, 1997.

LIPPOLD,O.C.J. The relation between integrated action potentials in a human muscle and its isometric tension. Journal of Physiology. v.7, p. 492-499, 1952.

LINDSTRÖN, L.; KADEFORS, R.; PETERSEN, I. Muscular fatigue and action potential conduction velocity changes studies with frequency analysis of EMG signals. Electromyography. v.10, p.341-356, 1970.

LINNAMO, V., NEWTON, R., U.; HAKKINEN, K.; KOMI, P., V.; DAVIE, A.; McGUIGAN, M.; McBRIDE, T., T. Neuromuscular responses to explosive and heavy resistance loading. Journal of Electromyography and Kinesiology. v. 10, p. 417424, 2000a.

LINNAMO, V.; BOTTAS, R.; KOMI, P. V. Force and EMG power spectrum during and after eccentric and concentric fatigue. Journal of Electromiography and Kinesiology. v. 10: p. 293 - 300, 2000b.

LIU-ROMAN et al. Quantitative assessment of upper limb muscle fatigue depending on the conditions of repetitive task load. Journal of Electromiography and Kinesiology. v. 14: p. 671-682, 2004.

LOWERY, M.; NOLAN, P.; O'MALEY, M.; Electromyogram median frequency, spectral compression and muscle fibre conduction velocity during sustained submaximal contraction of the brachioradialis muscle. Journal of Eletromyography and Kinesiology. v. 12, p. 111-118, 2002.

MAISETTI, O; GUÉVEL, A; LEGROS, P; HOGREL, J. SEMG power spectrum changes during a sustained $50 \%$ maximum voluntary isometric torque do not depend upon the prior knowledge of the exercise duration. Journal of Electromyography and Kinesiology. v. 12, p. 103 - 109, 2002.

MELLO, E, M. Avaliação de parâmetros eletromiográficos em diferentes ações musculares durante contrações isométricas submáximas. 120 p. Dissertação (Mestrado em Bioengenharia) - Programa Interunidades EESC/FMRP/IQSC, Universidade de São Paulo, São Carlos, 2006.

MERLETTI, R. (org.). Electromyography: physiology, engineering, and noninvasive applications. Italy, Philip Paker, 2004.

MERLETTI, R. Introduction to the special issue on the SENIAM European Concerted Action. Journal of Electromyography and Kinesiology. v.10, p. 283-286, 2000. 
MERLETTI, R. e LO CONTE, R., L. Surface EMG Signal Processing During Isometric Contractions. Journal of Electromyography and Kinesiology. v. 7, p. 241-250, 1997.

MERLETTI, R.; KNAFLITZ, M.; De LUCA, C., J. Electrically evoked myoelectric signals. Crit. Rev. Biomed. Eng. v. 19, p. 293-340, 1992.

MERLETTI, R.; Lo CONTE, R. L.; ORIZIO, C. Indices of Muscle Fatigue. Journal of Electromyography and Kinesiology. v. 1, p. 20 -33, 1991.

MOHAMED, O.; PERRY, J.; HISLOP, H. Relationship between wire EMG activity, muscle length and torque of the hamstrings. Clinical Biomechanics. 17, 569-579. 2002.

MORITANI T.. et al. Electrophysiology and kinesiology for health and disease. Journal of Electromiography and Kinesiology. v. 15: p. 240-255, 2005.

MORITANI, T; YOSHITAKE, Y. 1998 ISEK Congress keynote lecture: the use of electromyography in applied physiology. Journal of Electromiography and Kinesiology. v. 8: p. 363-381, 1998.

MORITANI T; TAKAISHI T; MATSUMOTO T. Determination of maximal power output at neuromuscular fatigue threshold. Journal Applied Physiology. v. 74(4): p. 1729 1734, 1993.

MORITANI, T. et al. Oxygen availability and motor activity in humans. European Journal Applied Physiology. v. 64, p. 522-556, 1992.

MORITANI, T; MURAMATSU, S; MURO, M. Activity of motor units during concentric and eccentric contractions. Am. J. Phys. Med. v. 66(6): p. 338-50, 1987.

MORITANI et al. Relationship between myoelectric signals and blood lactate during incremental forearm exercise. Am. J. Phys. Med. v. 63(3): p. 122-132, 1984.

MORITANI, T; NAGATA; MURO, M. Electromyographyc manifestation of muscular fatigue. Med Phys Fitness. v. 14(3): p. 198 - 202, 1982.

MORITANI, T.; HERBERT, A. Reexamination of the relationship between the sufarce integrated electromyogram (IEMG) and forçe of isometric contraction. American Journal of Physical Medicine. 57:6, 263-277. 1978.

NICOLAS, A; GAUTHIER, A; TROUILLET, J; DAVENNE, D. The influence of circadian rhythm during a sustained submaximal exercise and on recovery process. Journal of Electromiography and Kinesiology. doi: 10.1016/ j. jelekin.2006.10.003, 2006. 
ONISHI, H.; YAGI, R.; MOMOSE, K.; IHASHI, K.; HANDA, Y. Relationship between EMG signals and force in human vastus lateralis muscle using multiple bipolar wire electrodes. Journal of Electromyography and Kinesiology. 10, 59-67. 1999.

OTA, L. Análise da relação entre eletromiografia e força do músculo quadríceps em exercícios resistidos. 171 p. Dissertação (Mestrado em Bioengenharia) Programa Interunidades EESC/FMRP/IQSC, Universidade de São Paulo, São Carlos, 2006.

OTA, L.; ALVES, N.; MELLO, E.; AZEVEDO, F. M.; NEGRÃO R. F. Relação entre eletromigrafia e força voluntária isométrica máxima do músculo quadríceps. Revista de Fisioterapia da Universidade de São Paulo, São Paulo, v. 12, p. 622-622, 2005.

PAPOULIS, A. Probability, Ramdom Variables, and Stocastic Process. Mc-Graw Hill, Singapore, 2ed. (international), 1984.

PARDINI, R; MATSUDO, S; ARAÚJO, T; MATSUDO, V; ANDRADE, E; BRAGGION, G; ANDRADE, D; OLIVEIRA, L; FIGUEIRA JR, A; RASO, W. Validação do questionário internacional de nível de atividade física (IPAQ - versão 6): estudo piloto em adultos jovens brasileiros. Revista. Brasileira de Ciências e Movimento, Brasília, v. 9, n. 3 p. 45-51, 2001.

PATON, W. D. M.; WAUD, D. R. The Margin of Safety of Neuromuscular Transmition, Journal of Physiology., London, 191, 59-60. 1967.

PAVLAT, D. T; HOUSH, T. J; JOHNSON, G.O; ECKERSON, J.M. Electromyographic reponses at the neuromuscular fatigue threshold. Journal Sports Medicine Physical Fitness. v. 35, p. 31-37, 1995.

PAVLAT, D. T; HOUSH, T. J; JOHNSON, G.O; SCHMIDT, R. J; ECKERSON, J.M. An examination of the electromyographic fatigue threshold test. Eur $\mathbf{J}$ Appl Physiol Occup Physiol. v. 4, p. 305-308, 1993.

PEREIRA, M.C.V.; AZEVEDO, F.M. Análise para um ajanelamento adequado para sinais bioelétricos. In: XVIII CONGRESSO BRASILEIRO DE ENGENHARIA BIOMÉDICA, São José dos Campos, 2002. Cd-rom.

PICIVERO, D. M.; GANDHI, V.; TIMMONS, M. K.; COELHO, A. J. Quadriceps femoris eletromyogram during concentric, isometric and eccentric phases of fatiguing dynamic knee extensions. Journal of Biomechanics. v. 39, p. $246-254,2006$

PINCIVERO, D.M. Knee extensor torque and quadriceps femoris EMG during perceptually-guided isometric contractions. Journal of Electromyography and Kinesiology. v.13, n.2, p.159-167, 2003. 
PINCIVERO, D. M. Gender and muscle differences in EMG amplitude and median frequency, and variability during maximal voluntary contractions of the qudriceps femoris. Journal of Electromyography and Kinesiology. v. 10, p. 189 - 196, 2000.

PERRY, R. S; HOUSH, T. J; WEIR, P. J; JOHNSON, O G; BULL A. J; EBERSOLE, K. T. Mean power frequency and amplitude of the mechanomyographic and electromyographic signals during incremental cycle ergometry. Journal of Electromyography and Kinesiology. v.11: p.299 - 305, 2001.

PETROFSKY, J; LIND, A. R. Metabolic, cardiovascular, and respiratory factors in the development of fatigue in lifting tasks. Ameriacn Physiological Society. v. 66(6): p. 338-50, 1978.

POMPEU, F. A. M. S. Guia para estudos em biodinâmica do movimento humano. $1^{a}$ ed. São Paulo: Ph editora, 2006. 141p.

POTVIN, J., R.; BENT, R., L. A validation of technicques using surface EMG signals from dynamic contractions to quantify muscle fatigue during repetitive task. Journal of Electromyography and Kinesiology. v. 7 (2), p. 131-139, 1997.

POWERS, S. K., HOWLEY, E. T. Fisiologia do exercício. 3.ed. São Paulo: Manole, 2000. 527p.

PRINGLE, S. M; JONES, A M. Maximal lactate steady state, critical power and EMG during cycling. Eur. J. Appl. Phusiol. v. 88: p. 214 - 226, 2002.

SABAPATHY, S.; SCHNEIDER, A.; COMADIRA, G.; JOHNSTON, I.; MORRIS, N., R. Oxygen uptake kinetics during severe exercise: a comparison between young and older men. Respiratory Physiology e Neurobiology. Article in press, 2003.

SADOYAMA, T. e MIYANO, H. Frequency analysis of surface EMG to evaluation of muscle fatigue. European Journal Applied Physiology, v.47, p. 239-246, 1981.

TESCH, P., A. et al. Influence of lactate accumulation of EMG frequency-spectrum during repeated concentric contractions. Acta Physiologica Scandinavica. v. 119, p. 61-67, 1983.

TSCHARNER, V. Time-frequency and principal-component methods for the analysis of EMGs recorded during a midly fatiguing exercise on a cycle ergometer. Journal of Electromyography and Kinesiology. v. 12, p. 479-492, 2002.

WASERMAN et al. Principles of exercise testing e interpretation: includings pathophysiology and clinical applications. 3ed. Philadelphia: Lippincott Williams e Wilkins, 1999. 556p.

WEBSTER, J. G., Medical Instrumentation: Application and Design. Editor: Jonh G. Webster, 3.ed., New York, 1998. 
WEIR, J. P; BECK T. W; CRAMER, J. T; HOUSH, T. J. Is fatigue all in your head? A critical review of the central governor model. Br J Sports Med. v. 40(7): p. $573-586$, 2006.

VERBURG, E; HALLEN, J; SEJERSTED, O. M; VOLLESTAD, K, M. Loss of potassium from muscle during moderate exercises in humans: a result of insufficient activation of the $\mathrm{Na}^{+}-\mathrm{K}^{+}$pump? Acta Physiol Scand. v. 165: p. $357-367,1999$.

VIEIRA, S. Bioestatística: tópicos avançados. Ed. Elsevier, 216p., São Paulo 2003. 


\section{ANEXO I}

Neste anexo serão apresentadas as principais linhas de comando contidas no programa desenvolvido para realização das etapas descritas no item 4.5. Por ser bastante extenso, foram selecionados do código fonte ${ }^{5}$ alguns dos principais trechos que contém as funções utilizadas nas etapas para determinação do LFE.

\section{- Etapa 1 - Entrada dos dados.}

[files path]=uigetfiles('*.txt', 'Selecione arquivo EMG') pause

$\% \% \% \% \% \% \% \% \% \% \%$ Primeiro arquivo

file=files $\{1\}$;

arq $=[$ path, file];

[tempo emg] = textread(arq, '\%f \%f','headerlines',2);

\section{- Etapa 2 - Filtragem dos sinais EMG.}

[b a]=butter(4,([20 500]/(Fa./2)),'bandpass');

emg = filtfilt(b,a,emg);

- Etapa 3 e 4 - Classificação automática dos sinais EMG. Seleção automática das séries temporais

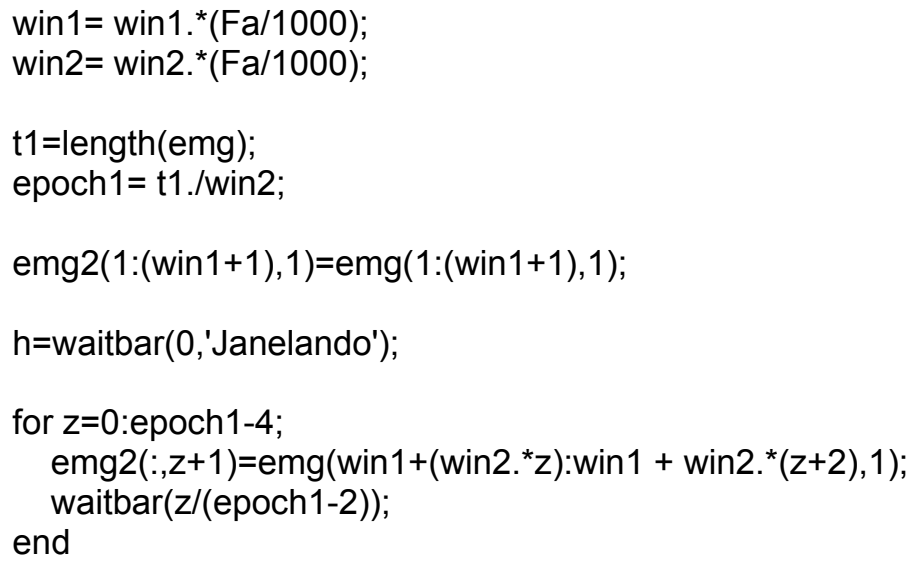

${ }^{5} \mathrm{O}$ arquivo executável pode ser disponibilizado através do contato via e-mail com o autor: micolis@uol.com.br ; ou pelo Laboratório de Fisioterapia Aplicada ao Movimento Humano da FCT - UNESP - tel. (18)3229-5388 r. 5416 
close (h)

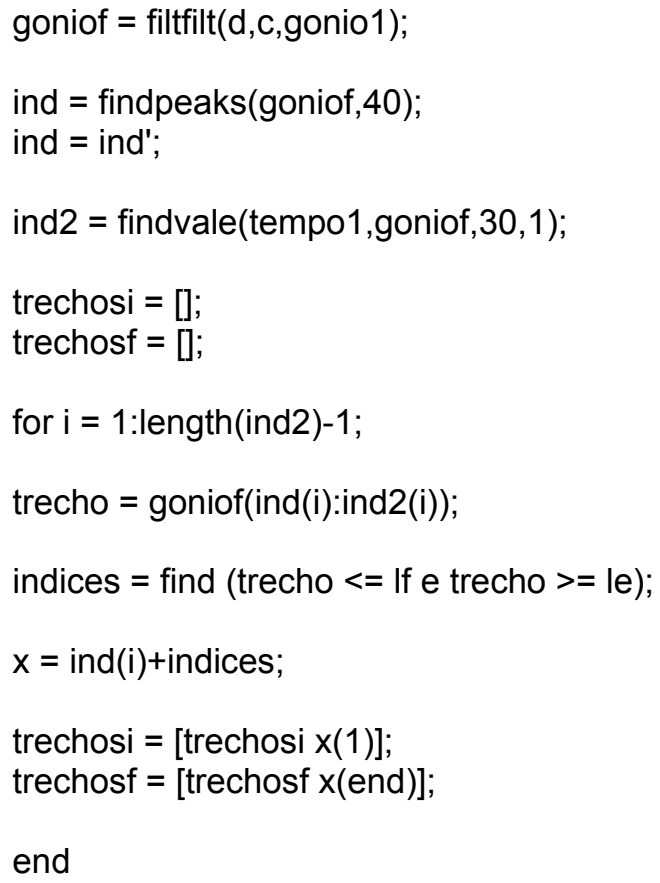

- Etapa 5 e 6 - Cálculo do espectro de potencia do sinal EMG e das Fmed. $[1, \mathrm{c} 2]=\operatorname{size}(\mathrm{emg} 22)$; h=waitbar(0,'Calculando FFT para 55\%'); 
for $i=1: c 2$

[mpf(:,i),peak(:,i),F51(:,i),f95(:,i),F(:,i),p(:,i)]=psd2(emg(:,i),Fa);

$\operatorname{rms} 55(\mathrm{i}, 1)=\operatorname{rms}(\mathrm{emg} 22(:, \mathrm{i}))$;

waitbar(i/c2);

end

close(h)

- Etapa 7 - Ajuste das Fmed e determinação dos coeficientes de inclinação.

$\mathrm{t} 3=$ linspace $(0$, length (emg3)/Fa,c3)';

p3=polyfit(t3,Fmed32,1);

F32fit=polyval $(p 3, t 3)$;

- Etapa 8 - Ajuste dos coeficientes de inclinação em função das cargas de exercício para determinação do LFE.

$x=[p 1(:, 1)$ p2(:,1) p3(:,1) p4(:,1)]';

$y=$ sobrecargas';

p5=polyfit $(x, y, 1)$;

LFEfit=polyval(p5,x); 


\section{ANEXO II}

Neste anexo serão apresentadas as principais linhas de comando contidas no programa desenvolvido para realização das etapas descritas no item 4.5.2. Por ser bastante extenso, foram selecionados do código fonte alguns dos principais trechos que contém as funções utilizadas nas etapas para processamento no pós-teste.

\section{- Exemplo para tratamento de um sinal isométrico.}

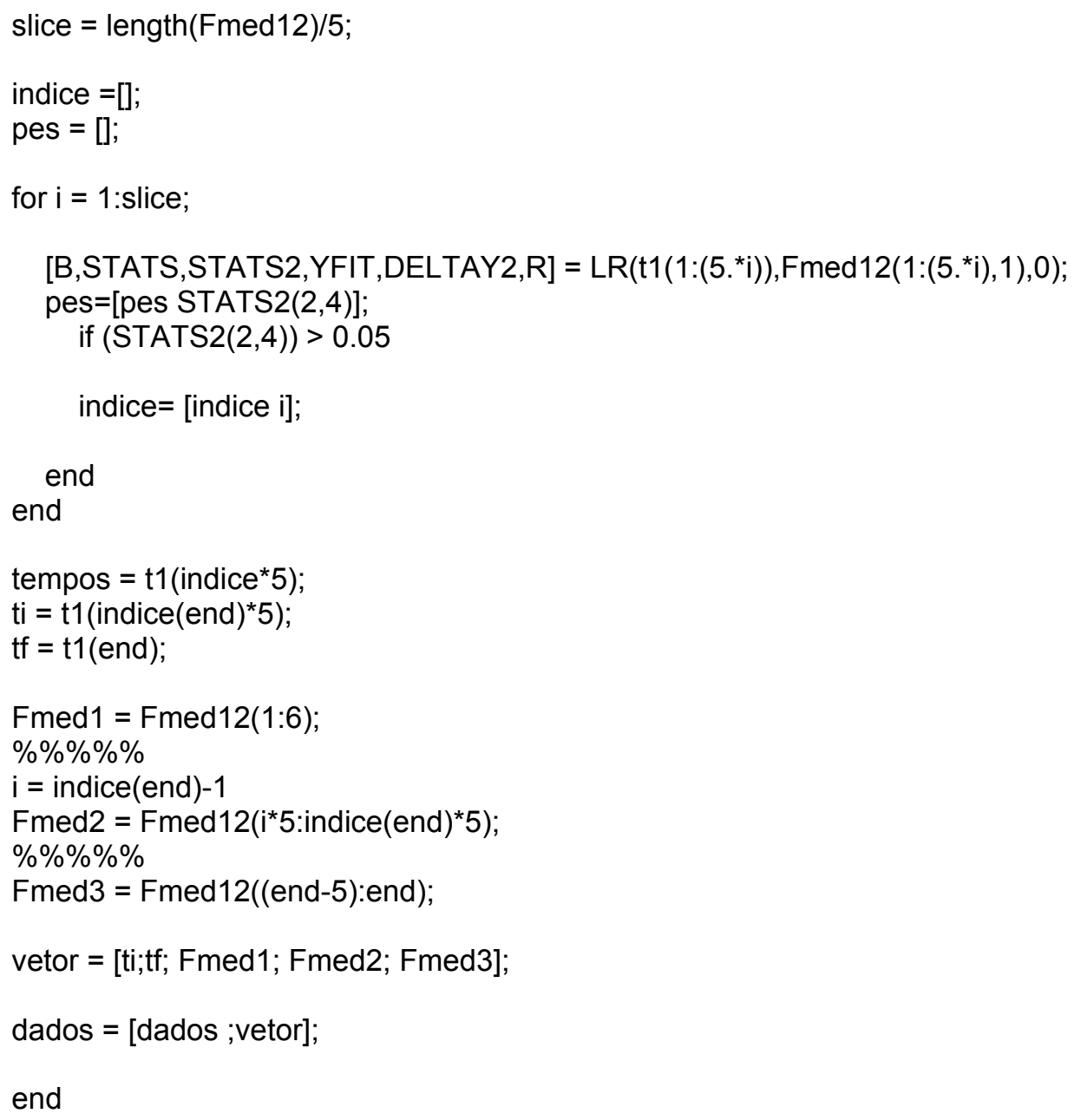




\section{ANEXO III}

Neste anexo serão apresentadas as principais linhas de comando contidas no programa desenvolvido para realização das etapas descritas no item 4.6.2. Por ser bastante extenso, foram selecionados do código fonte alguns dos principais trechos que contém as funções utilizadas nas etapas para a análise descritiva dos parâmetros das regressões dos testes de fadiga.

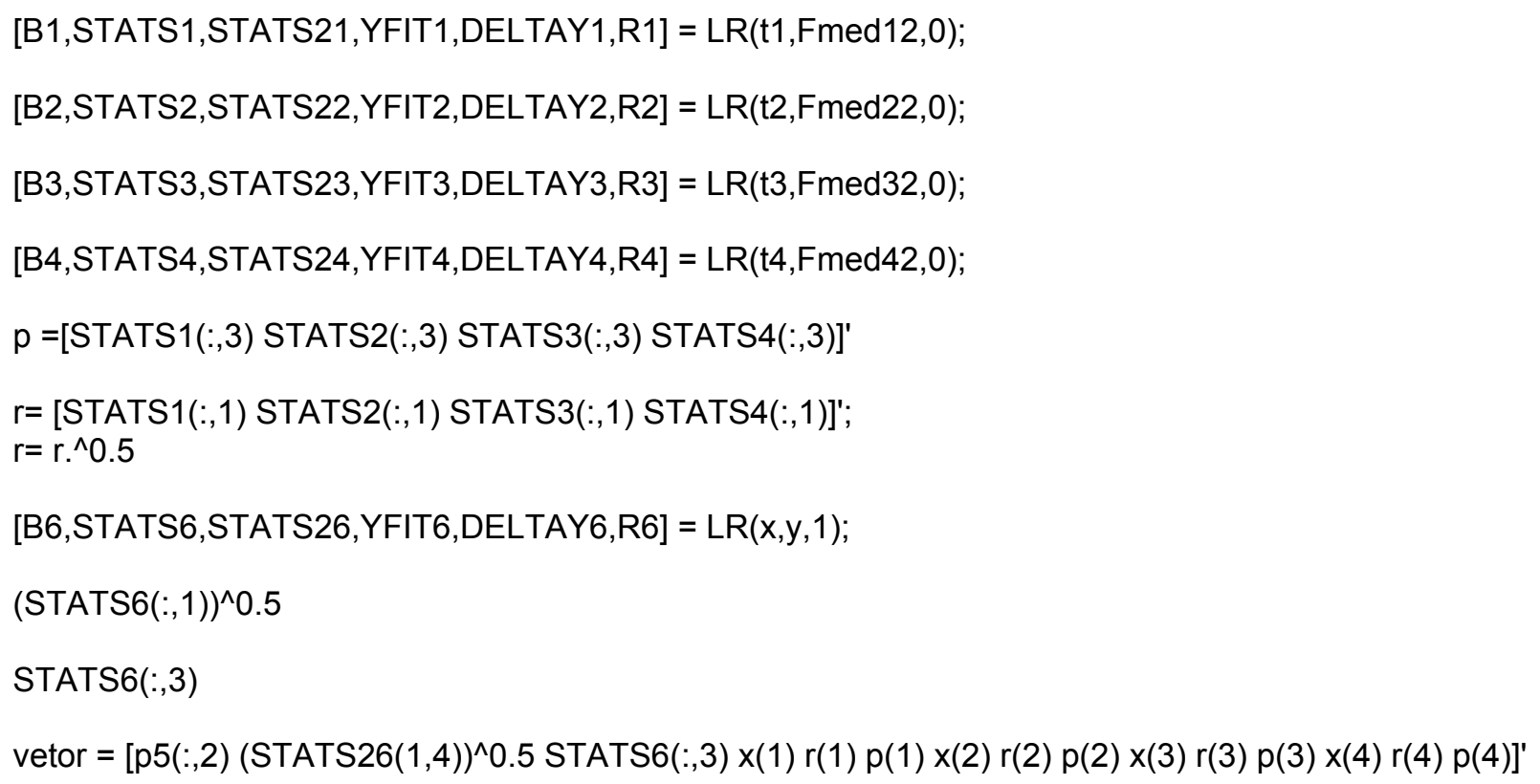




\section{ANEXO IV}

Neste anexo serão apresentadas as principais linhas de comando contidas no programa desenvolvido para realização das etapas descritas no item 4.6.3. Por ser bastante extenso, foram selecionados do código fonte alguns dos principais trechos que contém as funções utilizadas nas etapas para a análise isolada das bandas de freqüência e PCA.

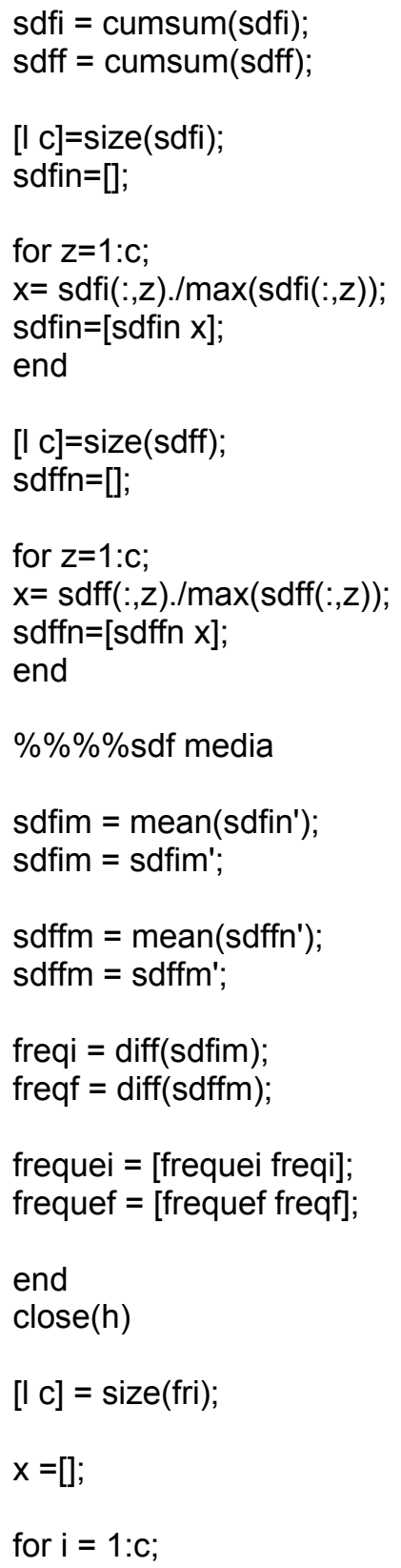


freqsi=[];

for $z=1: 20$;

ind $=$ find(fri(:,i) $>=\left(20 .{ }^{*}(z-1)\right)$ e fri (:,i) $\left.<=\left(20 .{ }^{*} z\right)\right)$;

$\mathrm{k}=$ mean(frequei(ind, $\mathrm{i})$ );

freqsi $=[$ freqsi;k];

$[$ pcs, newdata, variances, $\mathrm{t} 2]=$ princomp $($ fator $)$;

end 


\section{ANEXO V}

Nome:

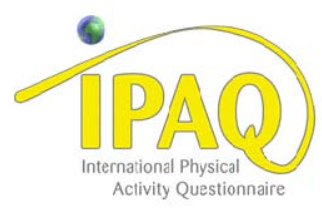

QUESTIONÁRIO INTERNACIONAL DE ATIVIDADE FÍSICA VERSÃO CURTA.

Data: Idade : Sexo: F ( ) M ( )

Nós estamos interessados em saber que tipos de atividade física as pessoas fazem como parte do seu dia a dia. Este projeto faz parte de um grande estudo que está sendo feito em diferentes países ao redor do mundo. Suas respostas nos ajudarão a entender que tão ativos nós somos em relação à pessoas de outros países. As perguntas estão relacionadas ao tempo que você gasta fazendo atividade física na ÚLTIMA semana. As perguntas incluem as atividades que você faz no trabalho, para ir de um lugar a outro, por lazer, por esporte, por exercício ou como parte das suas atividades em casa ou no jardim. Suas respostas são MUITO importantes. Por favor responda cada questão mesmo que considere que não seja ativo. Obrigado pela sua participação!

Para responder as questões lembre que:

atividades físicas VIGOROSAS são aquelas que precisam de um grande esforço físico e que fazem respirar MUITO mais forte que o normal atividades físicas MODERADAS são aquelas que precisam de algum esforço físico e que fazem respirar UM POUCO mais forte que o normal

Para responder as perguntas pense somente nas atividades que você realiza porpelo menos 10 minutos contínuos de cada vez.

1a Em quantos dias da última semana você CAMINHOU por pelo menos 10 minutos contínuos em casa ou no trabalho, como forma de transporte para ir de um lugar para outro, por lazer, por prazer ou como forma de exercício?

dias por SEMANA ( ) Nenhum

1b. Nos dias em que você caminhou por pelo menos 10 minutos contínuos quanto tempo no total você gastou caminhando por dia?

horas: Minutos: 
2a. Em quantos dias da última semana, você realizou atividades MODERADAS por pelo menos 10 minutos contínuos, como por exemplo pedalar leve na bicicleta, nadar, dançar, fazer ginástica aeróbica leve, jogar vôlei recreativo, carregar pesos leves, fazer serviços domésticos na casa, no quintal ou no jardim como varrer, aspirar, cuidar do jardim, ou qualquer atividade que fez aumentar moderadamente sua respiração ou batimentos do coração (POR FAVOR NÃOINCLUA CAMINHADA) dias por SEMANA ( ) Nenhum

2b. Nos dias em que você fez essas atividades moderadas por pelo menos 10 minutos contínuos, quanto tempo no total você gastou fazendo essas atividades por dia?

horas: Minutos:

3a. Em quantos dias da última semana, você realizou atividades VIGOROSAS por pelo menos 10 minutos contínuos, como por exemplo correr, fazer ginástica aeróbica, jogar futebol, pedalar rápido na bicicleta, jogar basquete, fazer serviços domésticos pesados em casa, no quintal ou cavoucar no jardim, carregar pesos elevados ou qualquer atividade que fez aumentar MUITO sua respiração ou batimentos do coração.

dias por SEMANA ( ) Nenhum

3b Nos dias em que você fez essas atividades vigorosas por pelo menos 10 minutos contínuos quanto tempo no total você gastou fazendo essas atividades por dia?

horas: Minutos:

Estas últimas questões são sobre o tempo que você permanece sentado todo dia, no trabalho, na escola ou faculdade, em casa e durante seu tempo livre. Isto inclui o tempo sentado estudando, sentado enquanto descansa, fazendo lição de casa visitando um amigo, lendo, sentado ou deitado assistindo TV. Não inclua o tempo gasto sentando durante o transporte em ônibus, trem, metrô ou carro.

4a. Quanto tempo no total você gasta sentado durante um dia de semana? horas __ minutos 4b. Quanto tempo no total você gasta sentado durante em um dia de final de semana? horas minutos 